\title{
Documentation of the Streamflow-Routing (SFR2) Package to Include Unsaturated Flow Beneath Streams-A Modification to SFR1
}

Chapter 13 of

Section A, Ground Water, of

Book 6, Modeling Techniques

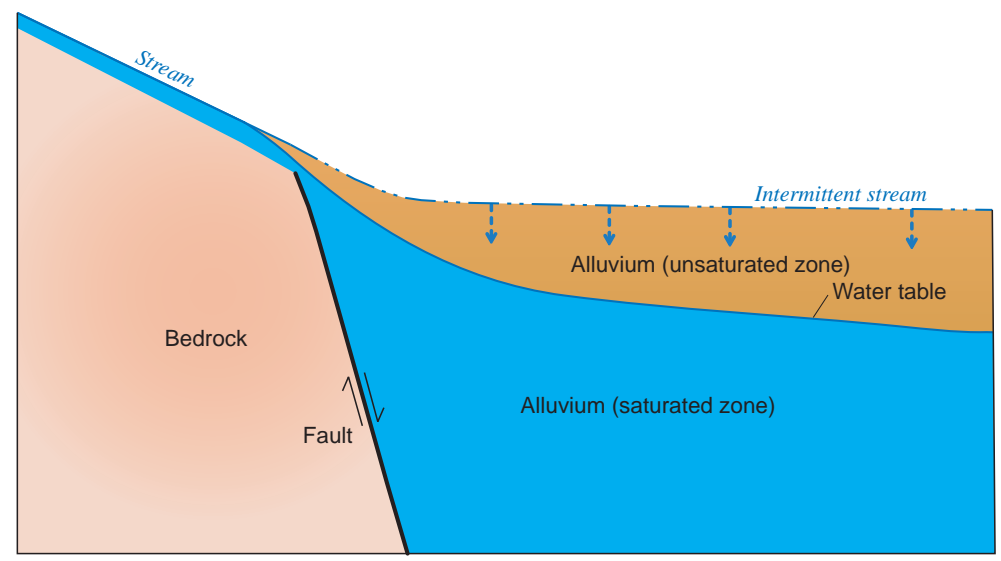

A. Profile of an intermittent stream leaving the mountain front.

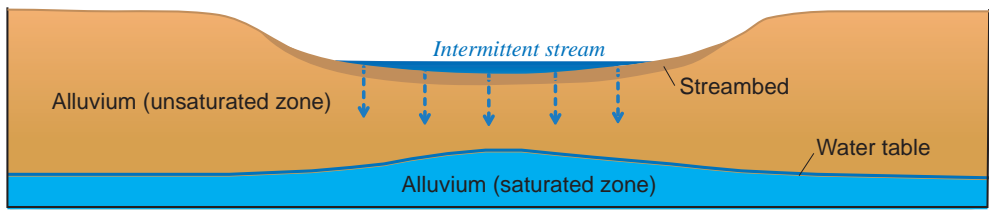

B. Cross section of stream separated from the water table by an unsaturated zone.

Techniques and Methods 6-A13

Version 1.30, April 2010

\section{U.S. Department of the Interior}

U.S. Geological Survey 


\section{Documentation of the Streamflow-Routing (SFR2) Package to Include Unsaturated Flow Beneath Streams-A Modification to SFR1}

By Richard G. Niswonger and David E. Prudic

Chapter 13 of

Section A, Ground Water, of

Book 6, Modeling Techniques

Techniques and Methods 6-A13

Version 1.[D, APRL20ए

U.S. Department of the Interior

U.S. Geological Survey 


\title{
U.S. Department of the Interior \\ Gale A. Norton, Secretary
}

\section{U.S. Geological Survey \\ P. Patrick Leahy, Acting Director}

U.S. Geological Survey, Reston, Virginia: 2005

Revised: April 2010

\author{
For sale by U.S. Geological Survey, Information Services \\ Box 25286, Denver Federal Center \\ Denver, CO 80225 \\ For more information about the USGS and its products: \\ Telephone: 1-888-ASK-USGS \\ World Wide Web: http://www.usgs.gov/
}

\footnotetext{
Any use of trade, product, or firm names in this publication is for descriptive purposes only and does not imply endorsement by the U.S. Government.

Although this report is in the public domain, permission must be secured from the individual copyright owners to reproduce any copyrighted materials contained within this report.
}

Suggested citation:

Niswonger, R.G., and Prudic, D.E., 2005, Documentation of the Streamflow-Routing (SFR2) Package to include unsaturated flow beneath streams-A modification to SFR1: U.S. Geological Survey Techniques and Methods 6-A13, $50 \mathrm{p}$. 


\section{Preface}

Performance of this computer program has been tested in models of hypothetical groundwater flow systems; however, future applications of the programs could reveal errors that were not detected in the test simulations. Users are requested to notify the U.S. Geological Survey (USGS) if errors are found in the documentation report or in the computer program. Correspondence regarding the report or program should be sent to:

U.S. Geological Survey, WRD

333 West Nye Lane, Room 203

Carson City, Nevada 89706

Attention: Richard G. Niswonger

Although the computer program has been used by the USGS, no warranty, expressed or implied, is made by the USGS or the United States Government as to the accuracy and functionality of the program and related program material. Nor shall the fact of distribution constitute any such warranty, and no responsibility is assumed by the USGS in connection therewith.

The revised Streamflow-Routing (SFR2) Package, MODFLOW-2000, and other ground-water programs are available for downloading from the USGS at the following World Wide Web (WWW) address: http://water.usgs.gov/software/ground_water.html. 


\section{Contents}

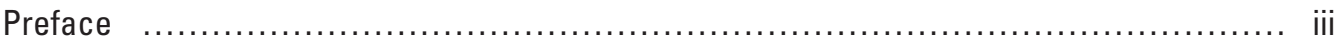

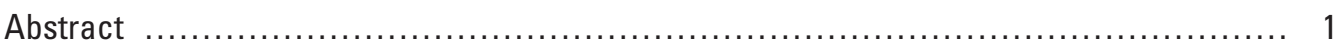

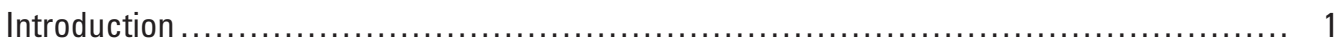

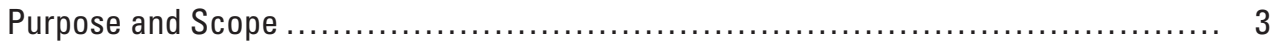

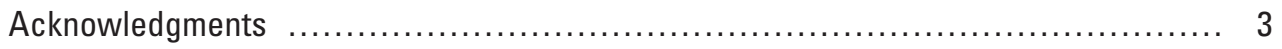

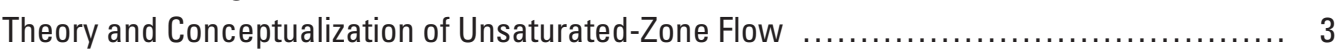

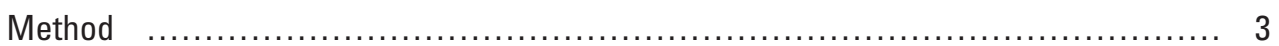

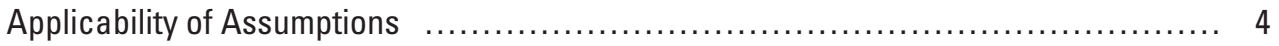

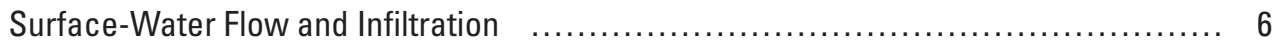

Coupling Unsaturated-Zone Flow in SFR2 to MODFLOW $\ldots \ldots \ldots \ldots \ldots \ldots \ldots \ldots \ldots \ldots \ldots \ldots$

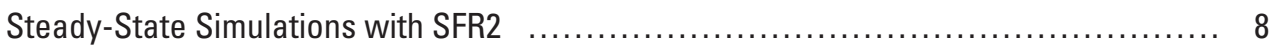

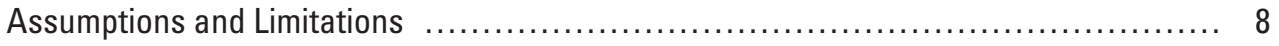

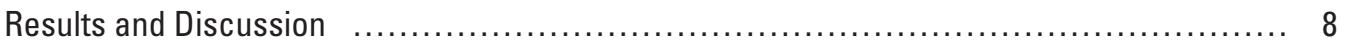

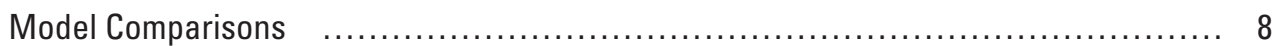

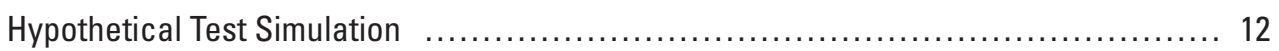

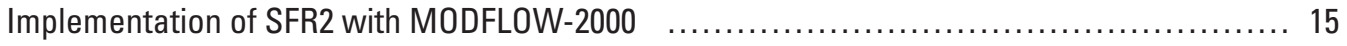

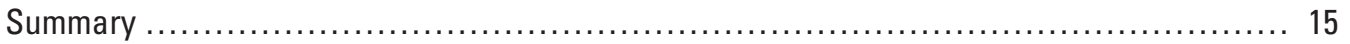

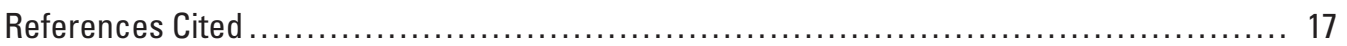

Appendix 1: Data Input Instructions for the Streamflow-Routing (SFR2) Package with

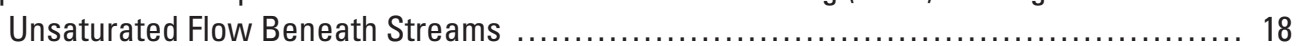

Appendix 2: Selected Input Data and Printed Results for the Hypothetical Test Simulation ... 34 


\section{Figures}

Figure 1. Conceptualization of a disconnected stream/aquifer system $\quad \ldots \ldots \ldots \ldots \ldots \ldots \ldots . \ldots 2$

Figure 2. Graph showing a wetting front through a uniform column of unsaturated material affected by a decrease in surface flux and results from a kinematic-wave approximation of the wetting front using leading and trailing waves

Figure 3. Diagram showing discretization of unsaturated zone beneath a stream in a single MODFLOW cell

Figure 4. Graphs showing comparison of results from the kinematic-wave approximation used in the Streamflow-Routing (SFR2) Package with the Variably Saturated Two-Dimensional Flow and Transport (VS2DT) Model

Figure 5. Graph showing comparison of results from the kinematic-wave approximation in the Streamflow-Routing (SFR2) Package with the Variably Saturated Two-Dimensional Flow and Transport (VS2DT; Healy, 1990) Model for seepage through a one-dimensional column filled with a silt loam ............ 11

Figure 6. Diagram showing conceptualization of hypothetical test simulation $\ldots \ldots \ldots \ldots \ldots 13$

Figure 7. Graphs showing effects of variations in thickness of a semipervious streambed... 14

\section{Tables}

Table 1. Hydraulic properties assigned in first test simulation assuming a column filled with sandy clay loam

Table 2. Input variables for second test simulation assuming vertical seepage through unsaturated zone that is restricted by a semipervious streambed

Table 3. Comparison of calculated fluxes through a semipervious streambed resulting from four different stream stages from kinematic-wave approximation in the Streamflow-Routing (SFR2) Package with those from the Variably-Saturated Two-Dimensional Flow and Transport (VS2DT) Model ..... 10

Table 4. Unsaturated zone input variables used in example problem .................... 12 


\section{Conversion Factors}

\begin{tabular}{lcl}
\hline Multiply & By & To obtain \\
\hline cubic meter $\left(\mathrm{m}^{3}\right)$ & 35.3147 & cubic foot \\
kilometer $(\mathrm{km})$ & 0.621371 & mile \\
meter $(\mathrm{m})$ & 3.28084 & foot \\
meter per second $(\mathrm{m} / \mathrm{s})$ & 3.281 & foot per second \\
\hline
\end{tabular}




\title{
Documentation of the Streamflow-Routing (SFR2) Package to Include Unsaturated Flow Beneath Streams-A Modification to SFR1
}

\author{
By Richard G. Niswonger and David E. Prudic
}

\author{
Abstract \\ Many streams in the United States, especially those \\ in semiarid regions, have reaches that are hydraulically \\ disconnected from underlying aquifers. Ground-water \\ withdrawals have decreased water levels in valley aquifers \\ beneath streams, increasing the occurrence of disconnected \\ streams and aquifers. The U.S. Geological Survey modular \\ ground-water model (MODFLOW-2000) can be used to model \\ these interactions using the Streamflow-Routing (SFR1) \\ Package. However, the approach does not consider unsaturated \\ flow between streams and aquifers and may not give realistic \\ results in areas with significantly deep unsaturated zones. \\ This documentation describes a method for extending the \\ capabilities of MODFLOW-2000 by incorporating the ability \\ to simulate unsaturated flow beneath streams. \\ A kinematic-wave approximation to Richards' equation \\ was solved by the method of characteristics to simulate \\ unsaturated flow beneath streams in SFR1. This new \\ package, called SFR2, includes all the capabilities of SFR1 \\ and is designed to be used with MODFLOW-2000. Unlike \\ SFR1, seepage loss from the stream may be restricted by the \\ hydraulic conductivity of the unsaturated zone. Unsaturated \\ flow is simulated independently of saturated flow within each \\ model cell corresponding to a stream reach whenever the \\ water table (head in MODFLOW) is below the elevation of \\ the streambed. The relation between unsaturated hydraulic \\ conductivity and water content is defined by the Brooks- \\ Corey function. Unsaturated flow variables specified in SFR2 \\ include saturated and initial water contents; saturated vertical \\ hydraulic conductivity; and the Brooks-Corey exponent. \\ These variables are defined independently for each stream \\ reach. Unsaturated flow in SFR2 was compared to the U.S.
}

Geological Survey's Variably Saturated Two-Dimensional Flow and Transport (VS2DT) Model for two test simulations. For both test simulations, results of the two models were in good agreement with respect to the magnitude and downward progression of a wetting front through an unsaturated column. A third hypothetical simulation is presented that includes interaction between a stream and aquifer separated by an unsaturated zone. This simulation is included to demonstrate the utility of unsaturated flow in SFR2 with MODFLOW-2000. This report includes a description of the data input requirements for simulating unsaturated flow in SFR2.

\section{Introduction}

For several decades, researchers have been modeling surface and subsurface flow as a continuum, for the purpose of considering all exchanges of water between the land surface and the underlying ground water. The U.S. Geological Survey (USGS) modular ground-water model, MODFLOW (McDonald and Harbaugh, 1988; and Harbaugh and others, 2000), has been used to model surface- and ground-water interaction over a wide range of spatial scales. The application of MODFLOW to simulate the interaction of surface water with ground water ignores the time delay for water to flow from surface-water bodies at land surface to the water table.

Where the depth to ground water is less than a few meters below the streambed, the time for water to flow through the unsaturated zone can be considered negligible. However, where the depth to ground water is tens to hundreds of meters below a streambed (fig. 1), the storage and flow of water 


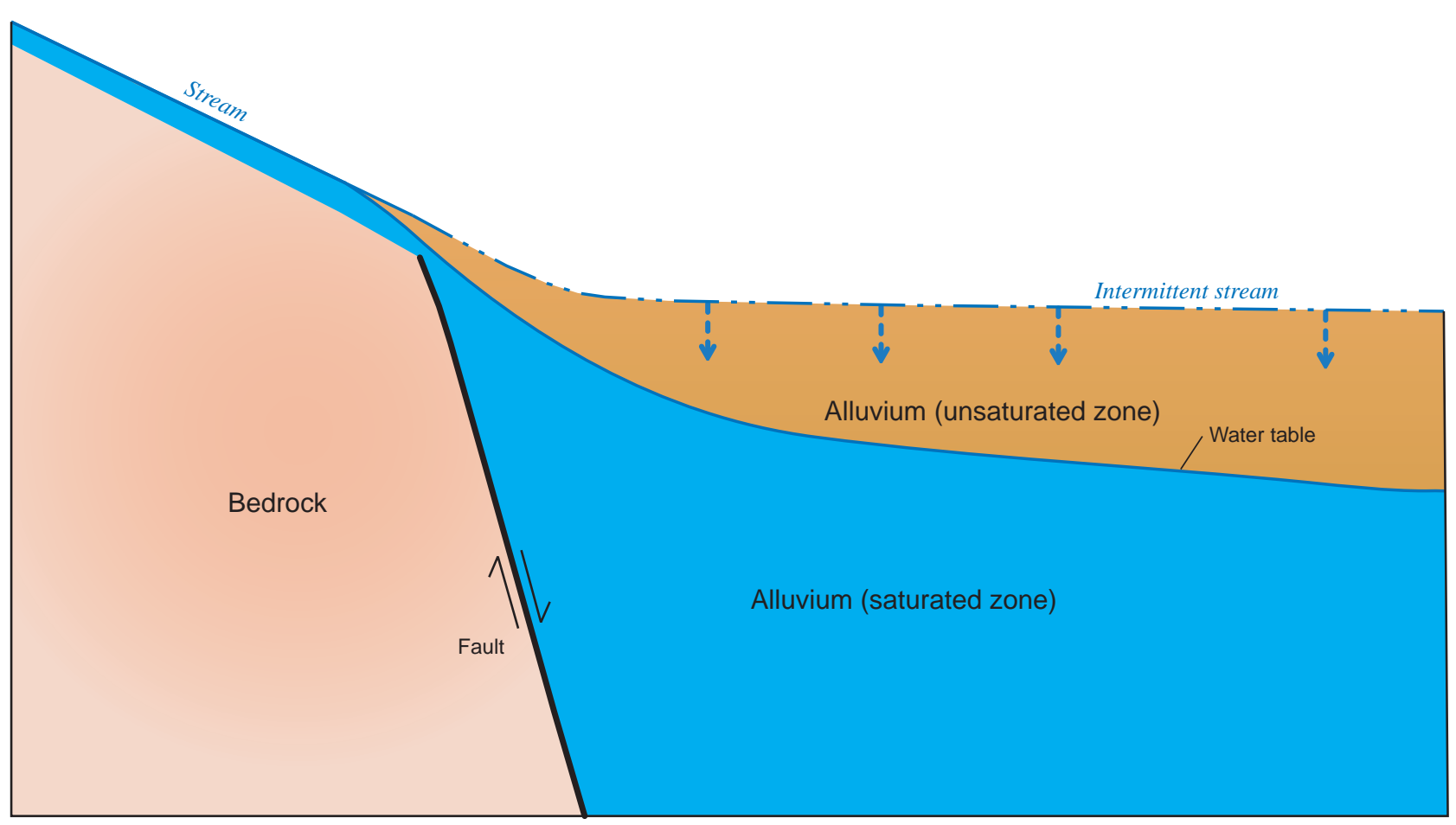

Not to Scale

A. Profile of an intermittent stream leaving the mountain front.

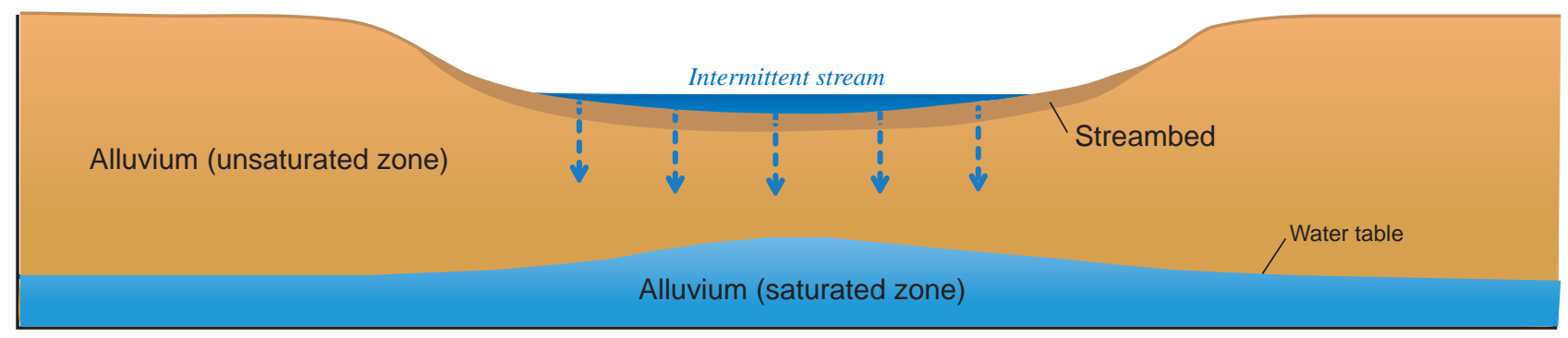

Not to Scale

B. Cross section of stream separated from the water table by an unsaturated zone.

Figure 1. Conceptualization of a disconnected stream/aquifer system.

within the unsaturated zone may be important when assessing changes in the water resources of those areas.

Because of the importance of water in arid regions, and, in particular, because of increased interest in the interaction of surface water and ground water, the capability of simulating unsaturated flow beneath streams has been added to the Streamflow-Routing (SFR1) Package (Prudic and others, 2004) of MODFLOW-2000. This new package is called

SFR2. Unsaturated flow beneath streams is simulated using a kinematic-wave approximation to Richards' equation that is solved by the method of characteristics (Smith, 1983; Smith and Hebbert, 1983). The kinematic-wave approximation to Richards' equation neglects diffusive forces and flow is assumed to occur in the vertical-downward direction through homogeneous and isotropic sediment. The method of characteristics is used to reduce the one-dimensional partial-differential equation resulting from the kinematicwave approximation to an ordinary differential equation that is solved by analytical integration. The solution tracks the movement of waves through the variably saturated zone and precludes the need to discretize the region between the water table and land surface. The Lagrangian formulation of the 
model allows seepage and unsaturated flow to occur over short time steps, while still maintaining suitably long time steps for ground-water flow in MODFLOW. This approach allows the simulation of flow and storage in the unsaturated zone, and for the simulation of a time delay for recharge while still maintaining the applicability of MODFLOW to basinscale problems. Assumptions made in this model may be an over-simplification for some natural systems where negative pressure gradients are important, such as in fine-grained or heterogeneous sediment.

There is another significant difference between simulating disconnected stream/aquifer interaction using SFR2 as compared to the instantaneous recharge approach using MODFLOW. The instantaneous approach simulates the saturation of the vadose zone after the onset of streamflow from the bottom up, where the water table must fill a volume of the pore space equal to the specific yield. SFR2 fills the pore space in the vadose zone from the top down, and because flow is assumed vertical in the vadose zone, the saturated region beneath the stream will be relatively narrow. This is in contrast to saturating the vadose zone from the bottom up where a significant proportion of ground-water flow will be horizontal and a much greater amount of pore space will need to be filled in order to saturate the vadose zone beneath the stream. Thus, intermittent streams that are hydraulically disconnected from the water table by several meters will be much more likely to reconnect to the water table using SFR2 as compared to the instantaneous approach in MODFLOW. Reconnection between a stream and the water table can reduce the vertical hydraulic gradient and decrease the amount of seepage loss from a stream.

\section{Purpose and Scope}

The purpose of this report is to describe a method for simulating gravity-induced unsaturated flow beneath streams using MODFLOW. A description of the equations used in the kinematic-wave approximation for simulation of unsaturated flow beneath streams using MODFLOW was presented by Niswonger and Prudic (2004). This report summarizes that description, describes the assumptions and limitations of the method, presents the results from three test simulations, describes how the kinematic-wave approximation was added to SFR1 and MODFLOW-2000 (Harbaugh and others, 2000), provides a description of the data input for SFR2, and presents an example of data input and selected model output for the third test simulation. Details associated with streamflow routing are the same as in SFR1 (Prudic and others, 2004).
Users of SFR2 should refer to the SFR1 documentation for information on these details.

\section{Acknowledgments}

The U.S. Geological Survey's Ground-Water Resources Program funded this work. The original idea was developed through many conversations with Jon P. Fenske and Arlen D. Feldman of the Army Corps of Engineers Hydrologic Research Center, Davis, California and with Stanly A. Leake and Richard W. Healy of the U.S. Geological Survey. We appreciate comments by Paul M. Barlow, Arlen W. Harbaugh, and Eric D. Swain (U.S. Geological Survey) and Gordon Thrupp (S.S. Papadopulos and Assoc. Inc.).

\section{Theory and Conceptualization of Unsaturated-Zone Flow}

\section{Method}

Vertical seepage through a homogeneous unsaturated zone can be approximated with kinematic waves (Smith, 1983; Smith and Hebbert, 1983). This approximation is made by simplifying Richards' equation. The one-dimensional Richards' equation for vertical flow is:

$$
\frac{\partial \theta}{\partial t}=\frac{\partial q}{\partial z}=\frac{\partial}{\partial z}\left[D(\theta) \frac{\partial \theta}{\partial z}-K(\theta)\right]
$$

where $\theta$ is the volumetric water content; $z$ is the elevation in the vertical direction $(\mathrm{m}) ; D(\theta)$ is the hydraulic diffusivity; $K(\theta)$ is the unsaturated hydraulic conductivity; and $t$ is time. Equation 1 is simplified such that vertical flux $(q)$ is only driven by gravitational forces. Vertical flux is

$$
q=-K(\theta)
$$

where $q$ is shown as positive upward. Substituting equation 2 into equation 1 and eliminating the diffusive term yields:

$$
\frac{\partial \theta}{\partial t}+\frac{\partial K(\theta)}{\partial z}=0
$$




\section{Applicability of Assumptions}

The method of characteristics solution to equation 3 is done by rewriting equation 3 so that $\theta$ is taken partially in terms of $t$ and $z$ :

$$
\frac{\partial \theta}{\partial t}=-\frac{\partial K(\theta)}{\partial \theta} \frac{\partial \theta}{\partial z}
$$

Dividing both sides of equation 4 by $\frac{\partial \theta}{\partial z}$ gives the characteristic solution for the kinematic-wave equation for unsaturated flow:

$$
\frac{d z}{d t}=\frac{\partial K(\theta)}{\partial \theta}=v(\theta), d \theta=0
$$

where $v(\theta)$ is the characteristic velocity, and $\theta$ is a constant along a characteristic path. The characteristic velocity, which has positive and negative characteristics in the case of open channel flow, is restricted to the downward direction for the movement of a wetting front because the force of gravity can only cause the wetting front to move downward.

The derivative $\frac{\partial K(\theta)}{\partial \theta}$ is discontinuous over a sharp wetting front that results from neglecting the diffusive term in equation 1 such that the spatial derivative in equation 3 is not defined in the absence of hydraulic diffusion. An analytic solution for the velocity may still be derived by considering the effects of diffusion and substituting an equivalent sharp wetting front of equal mass (Smith, 1983; Charbeneau, 1984). The solution to equation 1 for a wetting front that considers hydraulic diffusion can be found by integrating over a control volume containing a single wetting front (Charbeneau, 1984):

$$
\frac{d}{d t} \int_{z_{1}}^{z_{2}} \theta d z+\left.\left(K(\theta)-D(\theta) \frac{\partial \theta}{\partial z}\right)\right|_{z_{1}} ^{z_{2}}=0
$$

where $z_{1}$ and $z_{2}$ are points above and below the wetting front at distances far enough such that $\frac{\partial \theta}{\partial z} \approx 0$, respectively. $D(\theta)$ can be neglected because $\frac{\partial \theta}{\partial z} \approx 0$ at $z_{1}$ and $z_{2}$ such that:

$$
\frac{d}{d t} \int_{z_{1}}^{z_{2}} \theta d z+K\left(\theta_{2}\right)-K\left(\theta_{1}\right)=0
$$

where $K\left(\theta_{1}\right)$ and $K\left(\theta_{2}\right)$ are the values of $K(\theta)$ at depths $z_{1}$ and $z_{2}$. Integrating over a profile containing a sharp front with equivalent mass gives:

$$
\int_{z_{1}}^{z_{2}} \theta d z=\theta_{1}\left(z_{f}-z_{1}\right)+\theta_{2}\left(z_{2}-z_{f}\right),
$$

where $z_{f}$ is the depth of the sharp front. Combining equations 7 and 8 gives:

$$
\frac{d z_{f}}{d t}=u_{s}\left(\theta_{1}, \theta_{2}\right)=\frac{K\left(\theta_{1}\right)-K\left(\theta_{2}\right)}{\theta_{1}-\theta_{2}},
$$

where $u_{s}$ is the velocity of a sharp wetting front; $\theta_{1}$ is the volumetric water content above a wetting front; and $\theta_{2}$ is the volumetric water content below a wetting front.

Waves are generated by changes in infiltration resulting in waves with differing velocities. An increase in the surfaceinfiltration rate will cause a wetting front to form, which is represented by a lead wave. A decrease in the surface infiltration rate will cause internal drainage to occur, which is represented by a trailing wave. Attenuation of a lead wave occurs as a trailing wave of higher velocity overtakes it. When a trailing wave overtakes a lead wave, the lead wave water content becomes equal to the water content of the trailing wave. Consequently, this reduces the velocity, water content and flux of the lead wave. Conversely, when a lead wave overtakes a trailing wave or another lead wave of smaller magnitude, the overtaken wave(s) is (are) removed, and the water content and flux of the uppermost lead wave are maintained, resulting in rewetting.

In contrast to a wetting front that stays sharp due to gravity, trailing waves elongate with time due to gravity. Consequently, trailing waves must be either discretized into a series of incremental waves, or be represented by a function that describes internal drainage with time. In either case, internal drainage is determined based on the water content and relative location of points along a trailing wave. For example, points $A$ and $B$ shown in figure 2 represent two points along the trailing wave where the velocities may be determined. The velocity at points $A$ and $B$ is calculated from the characteristic solution (equation 5) and the ratio of their velocities is equal to the ratio of their depths:

$$
\frac{z_{B}}{z_{A}}=\frac{u\left(\theta_{B}\right)}{u\left(\theta_{A}\right)}=\frac{d K(\theta) /\left.d \theta\right|_{\theta=\theta_{B}}}{d K(\theta) /\left.d \theta\right|_{\theta=\theta_{A}}},
$$

where $\theta_{A}$ and $z_{A}$ are the water content and depth of the trailing wave increment below land surface represented by point $A$ in figure 2; and $\theta_{B}$ and $z_{B}$ are the water content and depth of trailing wave increment below land surface represented by point $B$ in figure 2 . 


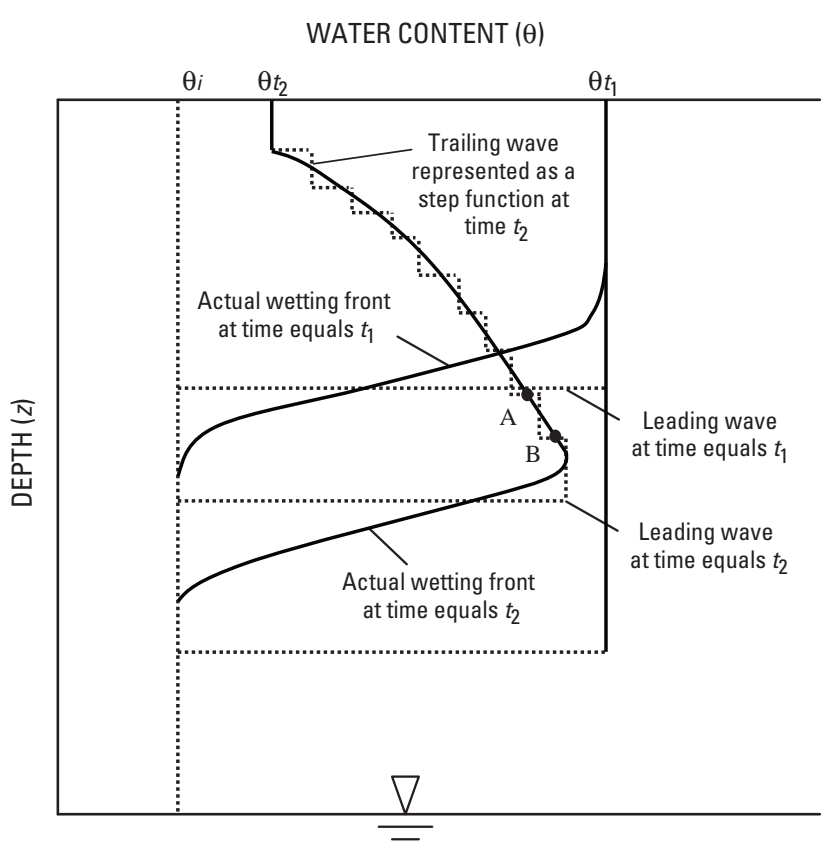

Figure 2. A wetting front through a uniform column of unsaturated material affected by a decrease in surface flux and results from a kinematic-wave approximation of the wetting front using leading and trailing waves.

(Modified from Smith and Hebbert, 1983.)

In contrast to a lead wave that forms a discontinuity in the water content profile, the derivative, $d K(\theta) / d \theta$, is continuous over a trailing front. Accordingly, the unsaturated hydraulic conductivity function described by Brooks and Corey (1966) can be used to evaluate $d K(\theta) / d \theta^{\prime}$. The Brooks-Corey function for unsaturated hydraulic conductivity can be expressed as:

$$
K(\theta)=K_{s}\left[\frac{\theta-\theta_{r}}{\theta_{s}-\theta_{r}}\right]^{\varepsilon},
$$

where $K_{s}$ is the saturated hydraulic conductivity; $\theta_{r}$ is the residual water content; $\theta_{s}$ is the saturated water content; and $\varepsilon$ is the Brooks-Corey exponent.

The drainable water from the unsaturated zone, referred to as the specific yield or $S_{y}$, is equal to the porosity minus the specific retention $\left(S_{r}\right)$, where $S_{r}$ is the volume of water per unit volume of rock that is retained when the rock is drained by gravity (Meinzer, 1923, p. 28). Specific yield also is used by MODFLOW to calculate the amount of storage within an unconfined aquifer. Thus, continuity between the unsaturated zone and unconfined aquifers in MODFLOW is maintained through the specific yield by approximating $S_{r}$ with $\theta_{r}$.
Residual water content generally is smaller than $S_{r}$, such that caution should be used when representing unsaturated flow variables in SFR2 with measured values. The value of $\theta_{\boldsymbol{S}} \theta_{r}$ is represented by $\mathrm{S}_{y}$ for the remaining sections of this report.

The velocity of the deepest point along a trailing wave is determined by taking the derivative of equation 11 :

$$
v=\frac{\varepsilon K_{s}}{S_{y}}\left[\frac{\theta-\theta_{r}}{S_{y}}\right]^{\varepsilon-1},
$$

where $v$ and $\theta$ are the velocity and water content at the deepest point along a trailing wave, respectively. A relation between the deepest point along a trailing wave and all other points along a trailing wave is determined by substituting the velocity defined by equation 12 into equation 10 :

$$
z(\theta)=z_{0}\left[\frac{\theta-\theta_{r}}{\theta_{0}-\theta_{r}}\right]^{\varepsilon-1},
$$

where $z(\theta)$ is the depth of a point on a trailing wave; $\theta$ is the water content of a point on a trailing wave; and $\theta_{0}$ and $z_{0}$ are the water content and depth of the deepest point along a trailing wave, respectively.

Complications arise when routing waves resulting from rapid fluctuations in the infiltration rate. For example, a lead wave generated by a pulse of infiltration will decay as trailing waves overcome the lead wave. Equations 12 and 13 define the spreading of a trailing wave; however, they are not applicable subsequent to the intersection with a leading wave. Analytic relations can be derived for routing trailing waves during intersection with a lead wave but these equations are difficult to solve. A simpler approach is to discretize the trailing wave into steps and calculate velocities of each step based on a finite-difference approximation (Smith, 1983):

$$
v=\frac{K(\theta)-K(\theta-\Delta \theta)}{\Delta \theta},
$$

where $\Delta \theta$ is the change in water content between two adjacent locations along a trailing wave.

As shown in figure 2, the finite-difference approximation of the true trailing wave does not conserve mass perfectly when a trailing wave intercepts a lead wave and vice versa. However, for problems involving rapidly varying infiltration rates, mass is conserved within an error of less than 0.05 percent when a trailing wave is represented by 15 increments, and for most problems 10 increments are sufficient. The user specifies the number of increments used to represent a trailing wave with the SFR2 input parameter NSTRAIL. 
An algorithm was written in FORTRAN using equations $9,11,12,13$, and 14 to simulate vertical unsaturated flow. This algorithm keeps track of the location, water content, velocity and flux of all waves in the unsaturated zone through time and the interaction of waves overtaking one another. Additionally, changes in the thickness of the unsaturated zone are considered with respect to waves reaching the water table and contributing to ground-water storage.

Boundary conditions used to represent infiltration from the land surface are formulated as an infiltration rate such that the specified flux at the surface is converted to water content in order to apply the characteristic solutions for unsaturated flow. A relation between water content and infiltration using equations 2 and 11 is:

$$
\begin{array}{cc}
\theta=\left(\frac{q_{\text {in }}}{K_{s}}\right)^{1 / \varepsilon}\left(S_{y}\right)+\theta_{r} \quad 0<q_{i n} \leq K_{s}, \\
\theta=\theta_{s} & K_{s}<q_{i n},
\end{array}
$$

where $\theta$ is the water content of a wave generated from infiltration, and $q_{i n}$ is the vertical flux or infiltration rate (length per time). The water content is set to the saturated water content when the infiltration rate exceeds the saturated vertical hydraulic conductivity.

In gravity-dominated flow, the flux in the unsaturated zone is equal to the unsaturated vertical hydraulic conductivity and cannot increase above the value of the saturated hydraulic conductivity. Consequently, seepage across the streambed in SFR2 is limited by the underlying vertical hydraulic conductivity in the unsaturated zone. This differs from SFR1, in which seepage is only limited by streambed conductance and the head difference between the stream and aquifer, or when the stream is hydraulically disconnected from the water table, by the head difference between the stream and the bottom of the streambed.

As with SFR1, numerical oscillations in SFR2 can occur when the streambed area is large relative to the corresponding model cell plan-view area. For these conditions, recharge from streambed seepage may be greater than storage and outflow from the model cell. To minimize oscillations, seepage in SFR2 is limited to the vertical hydraulic conductivity times the area of the model cell. When selecting the dimensions of model cells corresponding to stream reaches, oscillations are minimized when the plan-view area of a model cell is greater than the streambed area. This problem also may be alleviated by allowing seepage from a stream reach to be distributed to more than one MODFLOW cell. However, this capability is not presently available in SFR2.

\section{Surface-Water Flow and Infiltration}

Streamflow routing in SFR2 is done in the same manner as in SFR1 (Prudic and others, 2004). Streamflow is routed based on the continuity equation assuming steady, uniform flow such that the volumetric inflow is equal to the outflow minus all sources and sinks to the channel.

In SFR2 (as in SFR1), flows are routed through a network of channels where flow is always in the same direction along channels, and where seepage (ground-water recharge or discharge) is constant for each MODFLOW time step. Ground-water recharge resulting from streambed seepage and flow through the unsaturated zone may be variable within a MODFLOW time step, because the time steps used in calculating flow through the unsaturated zone may be shorter than those used in the saturated zone. Thus, all water reaching the water table from the unsaturated zone is totaled over the MODFLOW time step.

When the stream is separated from the water table by an unsaturated zone, the infiltration rate from streams is calculated using Darcy's Law and assuming uniform flow between a given section of stream and a corresponding volume of aquifer. The seepage out of the stream when the flux does not exceed the vertical hydraulic conductivity of the unsaturated zone is computed using:

$$
q=\frac{K}{m}\left(h_{s}-h_{b}\right)
$$

where $q$ is the infiltration rate; $K$ is the saturated hydraulic conductivity of streambed sediments; $h_{s}$ is the hydraulic head in stream determined from top of streambed sediments; $h_{b}$ is the hydraulic head at the bottom of the streambed; and $m$ is the thickness of streambed sediment as defined by the user.

The volume of water that seeps from a stream is calculated by multiplying the infiltration rate by the wetted area of the stream. The wetted area of the stream may be held constant or determined on the basis of the stream crosssectional dimensions, discharge, and stage. The relation between stage and discharge is calculated using Mannings equation. The option to simulate unsaturated flow between streams and aquifers may be used for a stream of constant wetted area and width or for an eight-point cross-section (fig. 3). The unsaturated zone may be discretized if a variable cross-section is specified ( $C A L C=2$ ). The unsaturated zone beneath a stream reach is discretized into I SUZN (as specified in the SFR2 input file) compartments. Water is routed independently within each of the unsaturated compartments (fig. 3). The option to simulate unsaturated flow beneath streams is not available when using $\mid$ CALC $=0,3$, or 4 . 


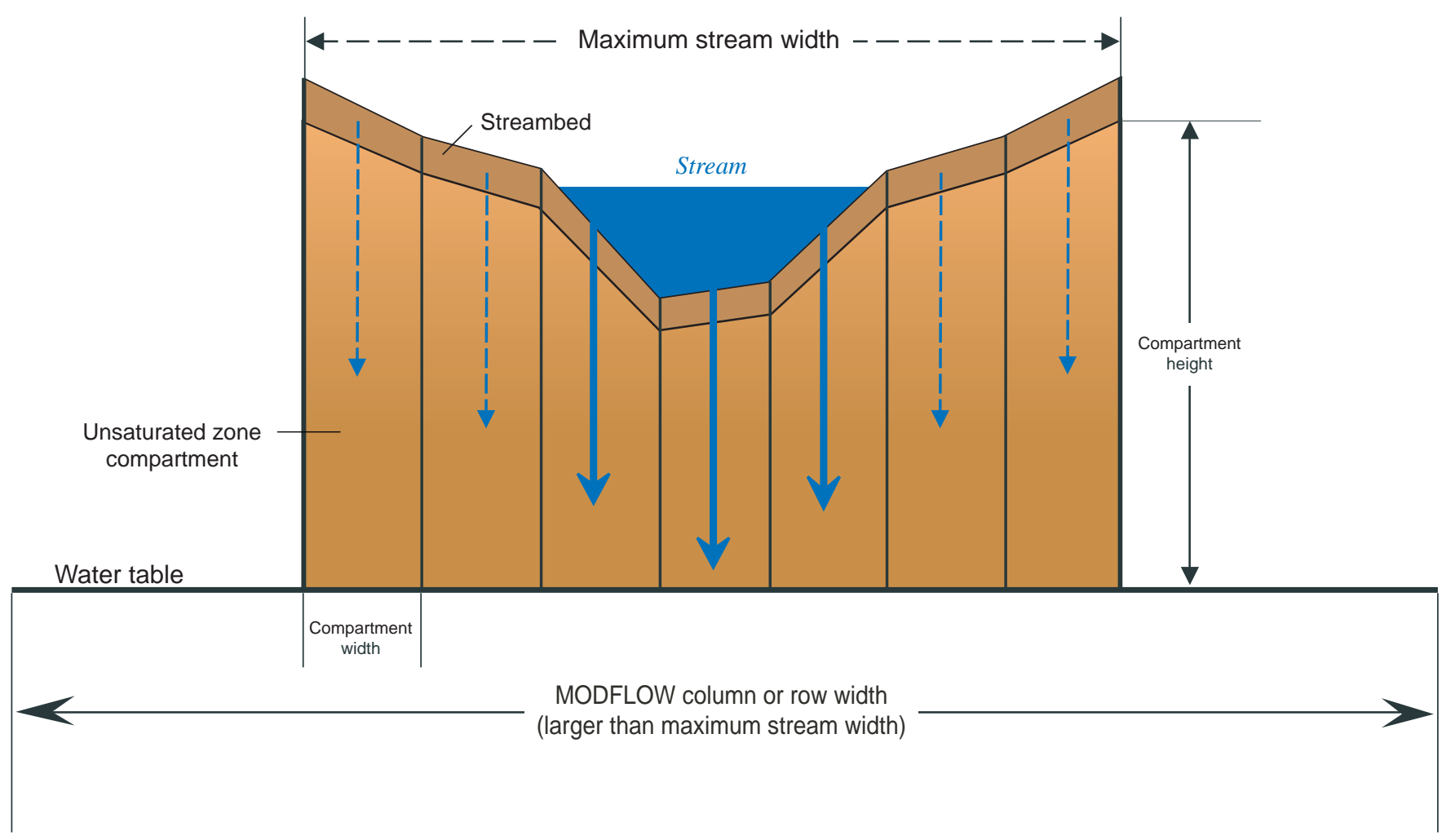

Figure 3. Discretization of unsaturated zone beneath a stream in a single MODFLOW cell.

The unsaturated zone is discretized into seven compartments defined by eight points in this example. Dashed lines represent stream depth and infiltration when stream is at maximum width.

\section{Coupling Unsaturated-Zone Flow in SFR2 to MODFLOW}

Water draining from the unsaturated zone is added to the ground-water flow equations in SFR2 when the water table is below the streambed. This approach differs from SFR1 in which seepage from the streambed instantly recharges the water table. Water leaving the unsaturated zone is subtracted from the right hand-side vector:

$$
A X=B-Q_{S F R 2},
$$

where $A$ is a matrix containing the coefficients of the conductance equations ( $\mathrm{HCOF}$ array) that are solved by MODFLOW-2000; $\mathrm{X}$ is a one-dimensional vector containing the ground-water heads that are solved by MODFLOW-2000; $B$ is a one-dimensional vector containing all known terms in the conductance equations that are not multiplied by unknown head values (RHS array); and $Q_{S F R 2}$ is the volumetric rate (volume per time) of recharge computed in a given model cell from SFR2. The layer, row, and column for each stream reach and underlying unsaturated zone are specified in the model input (Appendix 1). If the cell corresponding to the stream reach is inactive, the program will continue to route water in the unsaturated zone until it reaches the water table of the uppermost active cell. However, the hydraulic properties of the unsaturated zone $\left(K_{s}, S_{y}, \theta_{s}, \varepsilon\right)$ will remain constant even if the unsaturated zone spans more than one cell in the vertical direction.

The quantity of water that recharges an active model cell from the unsaturated zone is dependent on the degree of fluctuation of the water table. If the water table is rising into an unsaturated zone that is near saturation, then the water table rise will be exaggerated because there is little empty pore space available to be filled by the rising water table. Alternately, if the water table is falling due to ground-water discharge or pumping at some other location, then it will take longer for a wetting front from the unsaturated zone to reach the water table because the water content is at residual in the interval over which the water table declined.

Recharge resulting from a rising water table over a time step is calculated by first routing waves through the unsaturated zone using the base of the unsaturated zone as the water-table elevation at the end of the previous time step. Flow across the base is accumulated for each time step. The volume of water in the unsaturated zone through which the water table rose over a time step is added to the volume that flowed past the base. This sum is divided by the time step to obtain a volumetric recharge rate. Once the flow equation has been solved for the time step, a new base of the unsaturated zone is computed in each active cell. 
Recharge resulting from a declining water table over a time step is computed in a similar manner, except that the interval over which the water table declined during an iteration is set to the residual water content and waves are routed through the base of the unsaturated zone computed from the previous iteration. The volume of water that flowed across the base of the unsaturated zone is divided by the time step to obtain a volumetric recharge rate.

A water balance for the entire unsaturated zone is tracked independently of the ground-water balance equations within MODFLOW. The mass balance for the unsaturated zone accounts for all water between the streambed and the water table. Water passing across the water table is accounted for in the ground-water budget. When the water table rises above the bottom of the streambed in a model cell, then the unsaturated zone mass balance ceases to be calculated for that cell, and the unsaturated zone storage and change in storage for that cell are zero.

\section{Steady-State Simulations with SFR2}

A user may indicate that a stress period is steady state by using the character variable Ss/ $\mathrm{r}$ within the Discretization file (Harbaugh and others, 2000, p. 45). Steady-state simulations with SFR2 assume the infiltration rate through the streambed is equal to the ground-water recharge rate. SFR2 will use the unsaturated flow conditions at the end of a steadystate stress period as initial conditions for subsequent transient stress periods. Steady-state water content profiles may be printed to a file for specified locations using the Gage Package (Appendix 1).

\section{Assumptions and Limitations}

The kinematic-wave approximation does not account for the increased flux at the onset of wetting due to negative pressure gradients. Infiltration into initially dry material can be rapid due to large negative pressure gradients. However, gravity potential gradients dominate after the wetting front has advanced sufficiently far away from the surface, and infiltration slows to a value equivalent to the unsaturated hydraulic conductivity (Childs and Bybordi, 1969; Mein and Larson, 1973). Negative pressure gradients may also play a role in the flux of water during lateral and vertical redistribution in the unsaturated zone. Because negative pressure gradients are ignored, SFR2 likely under predicts the advancement of the wetting front at early times but over predicts during drying or redistribution.

The present form of the model does not simulate unsaturated flow through multiple layers of varying hydraulic properties. The model can simulate unsaturated flow through inactive cells to deeper active model cells. However, the hydraulic properties of an unsaturated column between the streambed and the uppermost active cell remain equal to their initial values during the simulation.
If the vertical hydraulic conductivity for the unsaturated zone is specified within the Layer Property Flow (LPF) Package input file by setting SFROPT $=2$ or 4 , then the vertical hydraulic conductivity specified for the uppermost active cell beneath a stream reach will be used for the unsaturated zone for the entire simulation. If the user is representing confining beds using the vertical hydraulic conductivity defined in the LPF input file, then it is recommended that the user specify separate hydraulic conductivity values for the unsaturated zone within the SFR2 input file by setting I SFROPT $=3$ or 5 .

SFR2 can simulate streambed seepage in partially penetrating streams; however, due to the Dupuit approximation for simulating unconfined ground-water flow, errors may occur in the model. Anderson (2004) showed that when effective or calibrated streambed conductance is used to restrict seepage, errors in forecasted simulation results will be minimized. Seepage in partially penetrating streams also may be biased in regional models where a model cell area is much larger than the corresponding stream reach area. In this case, treating the streambed conductance as a calibration parameter improves model predictability.

\section{Results and Discussion}

\section{Model Comparisons}

Results from the kinematic-wave approximation in SFR2 were compared with results from the USGS Variably Saturated Two-Dimensional Flow and Transport (VS2DT) Model (Healy, 1990) for two different problems. VS2DT solves Richards' equation numerically in terms of pressure potential. Although VS2DT can simulate two-dimensional unsaturated flow, the kinematic-wave approximation is limited to onedimensional vertical flow. Thus, the two test simulations were limited only to vertical flow. The stream was represented by boundary conditions in both models and streamflow was not explicitly simulated.

The first test simulation consisted of simulating a 100-m tall column of materials having hydraulic properties typical of a sandy clay loam. The same hydraulic properties that relate unsaturated hydraulic conductivity to water content ( $K$ and $\theta$ ) and the capillary potential to water content ( $\psi$ and $\theta$ ) were used in the simulation with SFR2 and VS2DT. Table 1 lists the input variables used for the first test simulation. The simulations consisted of a variable-flux boundary at the top of the column and a zero-pressure head boundary at the bottom. 


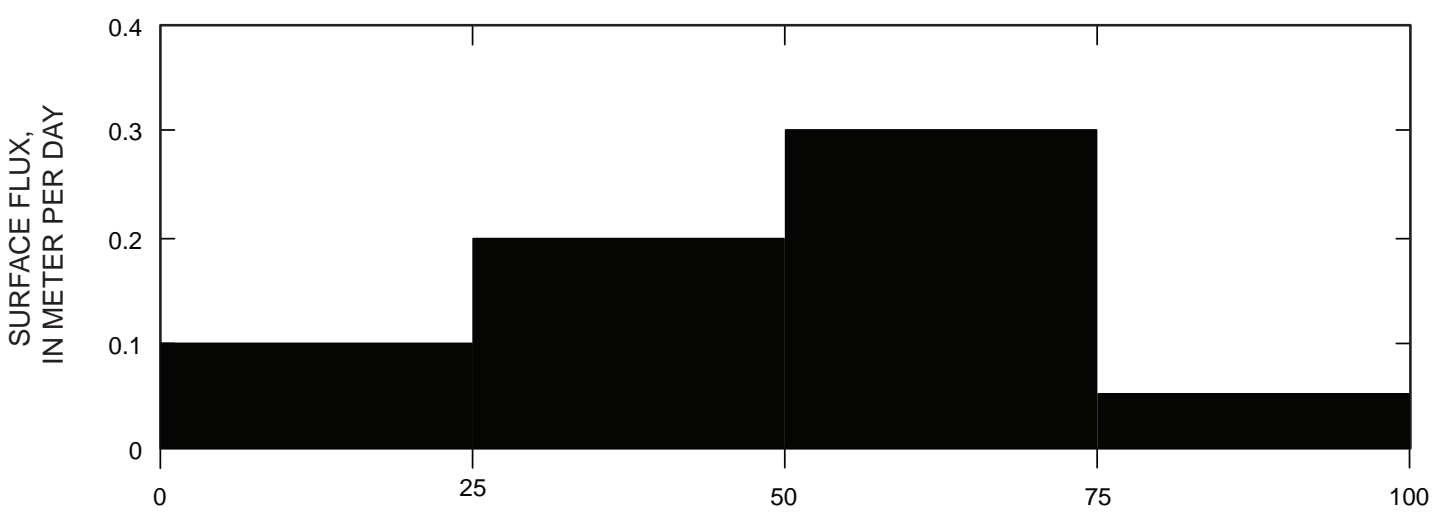

TIME, IN DAYS

A. Flux-boundary condition assigned in simulation.

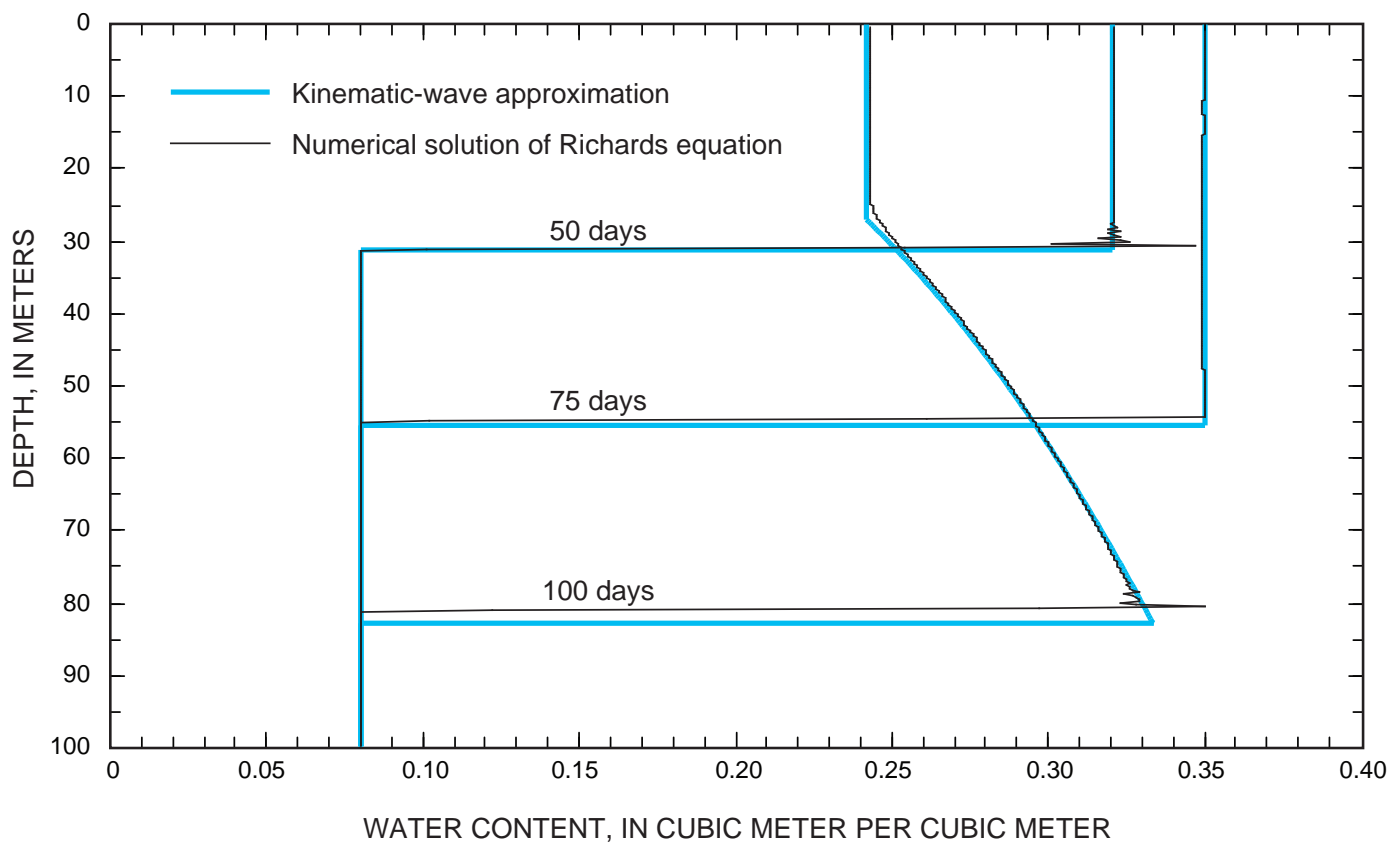

B. Distribution of vertical water content after 50,75 , and 100 days.

Figure 4. Comparison of results from the kinematic-wave approximation used in the Streamflow-Routing (SFR2) Package with the Variably Saturated Two-Dimensional Flow and Transport (VS2DT) Model (Healy, 1990).

Table 1. Hydraulic properties assigned in first test simulation assuming a column filled with sandy clay loam.

\begin{tabular}{ccccc}
\hline $\begin{array}{c}\text { Saturated vertical } \\
\text { hydraulic conductivity } \\
\text { (meter per second) }\end{array}$ & $\begin{array}{c}\text { Saturated water } \\
\text { content } \\
\text { (cubic meter } \\
\text { per meter) }\end{array}$ & $\begin{array}{c}\text { Specific yield } \\
\text { (cubic meter } \\
\text { per meter) }\end{array}$ & $\begin{array}{c}\text { Brooks-Corey } \\
\text { exponent } \\
\text { (dimensionless) }\end{array}$ & $\begin{array}{c}\text { Air entry } \\
\text { pressure } \\
\text { (meter) }\end{array}$ \\
\hline $3.4 \times 10^{-6}$ & 0.35 & 0.27 & 3.5 & -0.1 \\
\hline
\end{tabular}


The initial water content was set equal to the difference between saturated water content and specific yield throughout the model. Figure 4 shows a comparison of the water content profile after 50, 75, and 100 days of simulation. The advancement of the wetting front in the simulation with SFR2 is nearly the same as that with VS2DT (showing minimal difference at 50 and 75 days), whereas, during a drying period (75 to 100 days), the advancement of the wetting front is slightly greater in the simulation with SFR2 than that with VS2DT (see difference at 100 days). This difference suggests that negative pressure gradients resulting from infiltration into dry materials are attenuated within the first 50 days of infiltration and that during the last 25 days, capillary potentials slightly retard the advancement of the wetting front.
The second test simulation was designed to assess the ability of SFR2 to simulate streambed infiltration into an unsaturated zone with variable stream depths. In this simulation, the saturated hydraulic conductivity of the streambed is less than that of the unsaturated zone. Table 2 lists the input variables used for the simulation. Results of fluxes calculated by SFR2 and VS2DT for four different stream depths are listed in table 3 and are in reasonably good agreement. The corresponding advancement of the wetting front after 11.6, 23.2, and 34.7 days of infiltration shows good agreement between the two models (fig. 5).

Table 2. Input variables for second test simulation assuming vertical seepage through unsaturated zone that is restricted by a semipervious streambed.

[na, not applicable]

\begin{tabular}{lccccc}
\hline & $\begin{array}{c}\text { Saturated vertical } \\
\text { hydraulic conductivity } \\
\text { (meter per second) }\end{array}$ & $\begin{array}{c}\text { Saturated water } \\
\text { content } \\
\text { (cubic meter } \\
\text { per meter) }\end{array}$ & $\begin{array}{c}\text { Specific yield } \\
\text { (cubic meter } \\
\text { per meter) }\end{array}$ & $\begin{array}{c}\text { Brooks-Corey } \\
\text { exponent } \\
\text { (dimensionless) }\end{array}$ & $\begin{array}{c}\text { Air entry } \\
\text { pressure } \\
\text { (meter) }\end{array}$ \\
\hline Streambed & $1 \times 10^{-7}$ & na & na & na & na \\
Unsaturated zone & $1 \times 10^{-6}$ & 0.30 & 0.2 & 3.6 & -0.20 \\
\hline
\end{tabular}

Table 3. Comparison of calculated fluxes through a semipervious streambed resulting from four different stream stages from kinematic-wave approximation in the Streamflow-Routing (SFR2) Package with those from the Variably-Saturated TwoDimensional Flow and Transport (VS2DT) Model (Healy 1990). Fluxes correspond to the simulation time immediately following a change in the stream depth.

\begin{tabular}{lllll}
\hline Stream depth (meter) & 0.70 & 2.46 & 1.59 & 1.04 \\
Flux (meter per second; SFR2) & $9.54 \times 10^{-7}$ & $1.83 \times 10^{-6}$ & $1.40 \times 10^{-6}$ & $1.12 \times 10^{-6}$ \\
Flux (meter per second; VS2DT) & $9.44 \times 10^{-7}$ & $1.78 \times 10^{-6}$ & $1.37 \times 10^{-6}$ & $1.11 \times 10^{-6}$ \\
\hline
\end{tabular}




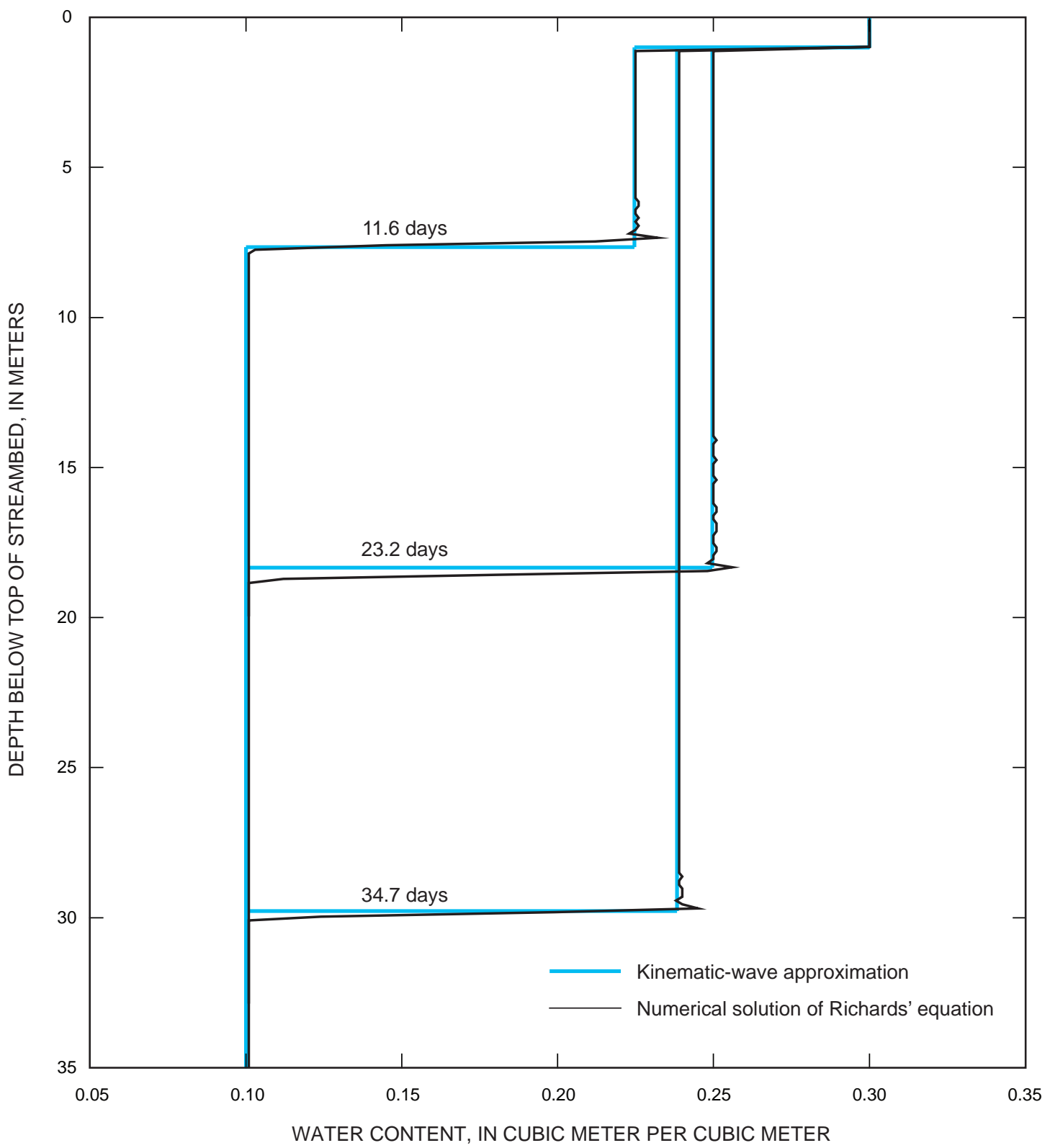

Figure 5. Comparison of results from the kinematic-wave approximation in the Streamflow-Routing (SFR2) Package with the Variably Saturated Two-Dimensional Flow and Transport (VS2DT; Healy, 1990) Model for seepage through a one-dimensional column filled with a silt loam.

Variations in water content below the streambed (thickness of 1 meter) are the result of different calculated flux rates across the streambed caused by varying stream depth (from Niswonger and Prudic, 2004, fig. 4). 


\section{Hypothetical Test Simulation}

A hypothetical aquifer was modeled assuming that an unsaturated zone separated the water table from a streambed (fig. 6). The hypothetical aquifer was divided into 7 cells in the y-direction (along columns), each 90-m long; 200 cells in the X-direction (along rows), each 100-m long; and one layer in the Z-direction, 140-110-m thick (fig. 6A). A stream was placed along the middle row in the $\mathrm{X}$-direction and had a maximum width at peak flow of $14 \mathrm{~m}$ and a depth of $6 \mathrm{~m}$ and was represented by an eight-point cross-section. A total of 200 stream reaches (corresponding to the 200 aquifer cells in the $\mathrm{X}$-direction) connected the individual cells.

The initial water table was set at $104 \mathrm{~m}$, resulting in an initial unsaturated zone that was $36 \mathrm{~m}$ and $6 \mathrm{~m}$, respectively, below the streambed at the upstream and downstream ends of the model. No-flow boundaries were assigned along all sides of the model, except the downstream side where a generalhead boundary was used. The unsaturated zone for each cell with a stream was divided into 7 vertical sections beneath the stream (fig. 6B). Unsaturated flow was not considered in any other cells.

Aquifer flow properties were considered homogeneous throughout the model, with a saturated horizontal hydraulic conductivity of $8 \times 10^{-4} \mathrm{~m} / \mathrm{s}$, a saturated vertical hydraulic conductivity of $6 \times 10^{-6} \mathrm{~m} / \mathrm{s}$, and a specific yield of 0.20 . The streambed and unsaturated zone hydraulic properties are listed in table 4. Streamflow into the first reach was specified using monthly-averaged streamflows from the Cosumnes River in California. The input data files and selected output files are listed in Appendix 2.

Streambed thickness was varied between 0.5 and $1.5 \mathrm{~m}$ and the resulting effects on seepage, recharge, stream depth and water table beneath a selected model cell midway along the stream (stream reach 100) were analyzed. Because the streambed had a lower hydraulic conductivity than the unsaturated zone, seepage, recharge, and the water table elevation decreased with increased streambed thickness (fig. 7). Seepage was more sensitive to streambed thickness for greater stream depths (fig. 7C).

This simulation suggests that seepage is sensitive to stream depth when the streambed hydraulic conductivity is lower than that of the materials in the unsaturated zone. However, stream depth becomes less important and the wetted area of the stream controls seepage when the streambed hydraulic conductivity is higher than that of the unsaturated zone.

The example was limited to unsaturated flow beneath a disconnected stream whereby seepage occurred only from the stream into the streambed. SFR2 can also be used to simulate streams where an unsaturated zone routinely appears and disappears beneath a stream (Niswonger and Prudic, 2004), or to simulate ground-water discharge to streams as demonstrated with SFR1 (Prudic and others, 2004).

Table 4. Unsaturated zone input variables used in example problem.

[Abbreviations: $\mathrm{m}$, meter; $\mathrm{m} / \mathrm{s}$, meter per second; $\mathrm{m}^{3} / \mathrm{m}^{3}$, cubic meter per cubic meter; na, not applicable]

\begin{tabular}{lcc}
\hline \multicolumn{1}{c}{ Model input parameter } & $\begin{array}{c}\text { Semipervious } \\
\text { streambed }\end{array}$ & $\begin{array}{c}\text { Unsaturated } \\
\text { zone }\end{array}$ \\
\hline Saturated vertical hydraulic conductivity, $\mathrm{K}_{\mathrm{sv}}(\mathrm{m} / \mathrm{s})$ & $5 \times 10^{-7}$ & $6 \times 10^{-6}$ \\
Saturated water content, $\theta_{\mathrm{s}}\left(\mathrm{m}^{3} / \mathrm{m}^{3}\right)$ & na & .30 \\
Specific yield, $\mathrm{S}_{\mathrm{y}}\left(\mathrm{m}^{3} / \mathrm{m}^{3}\right)$ & na & .20 \\
Brooks-Corey exponent, $\varepsilon$ & na & 3.5 \\
\hline
\end{tabular}




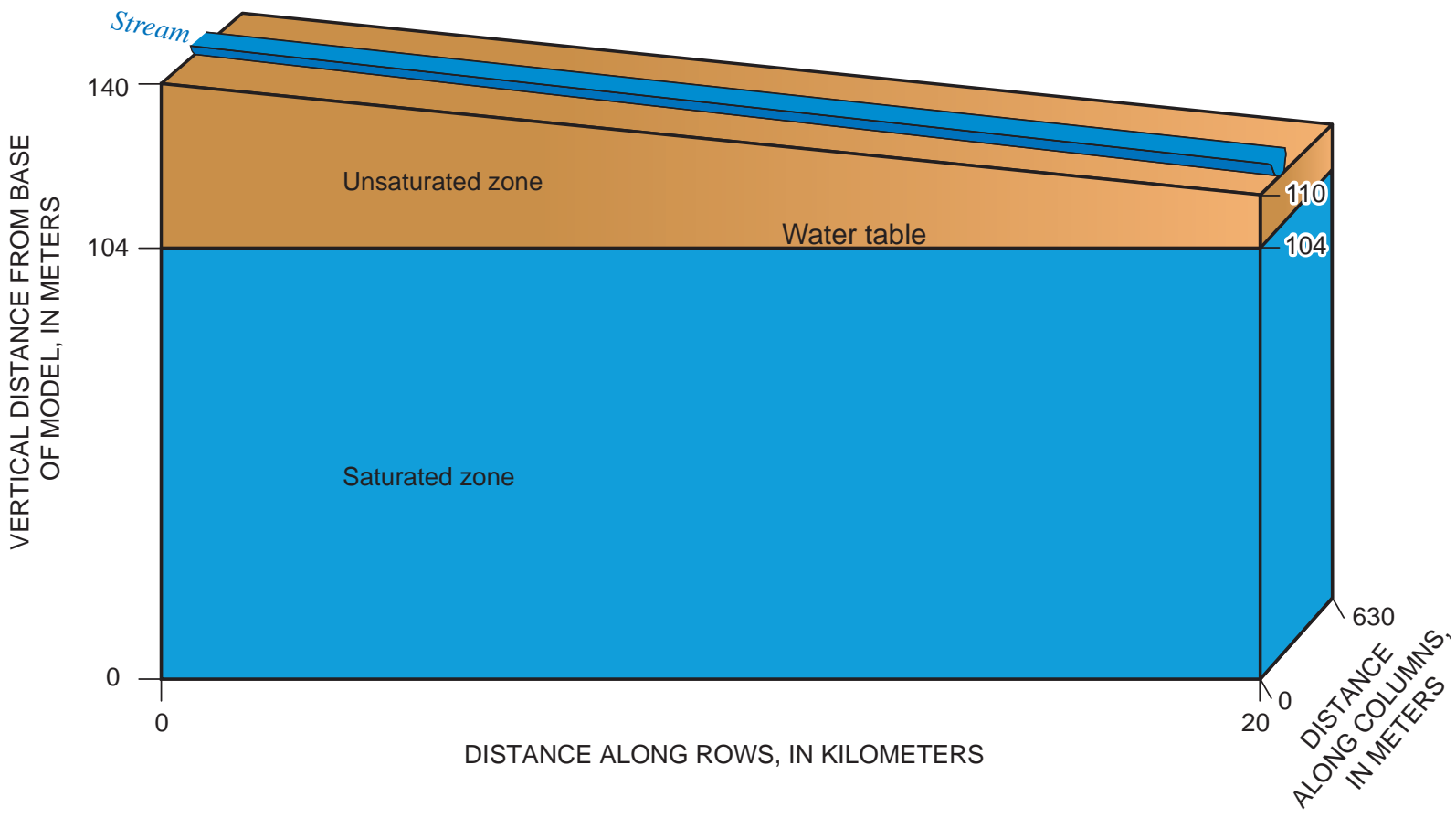

A. Physical boundaries of modeled area.

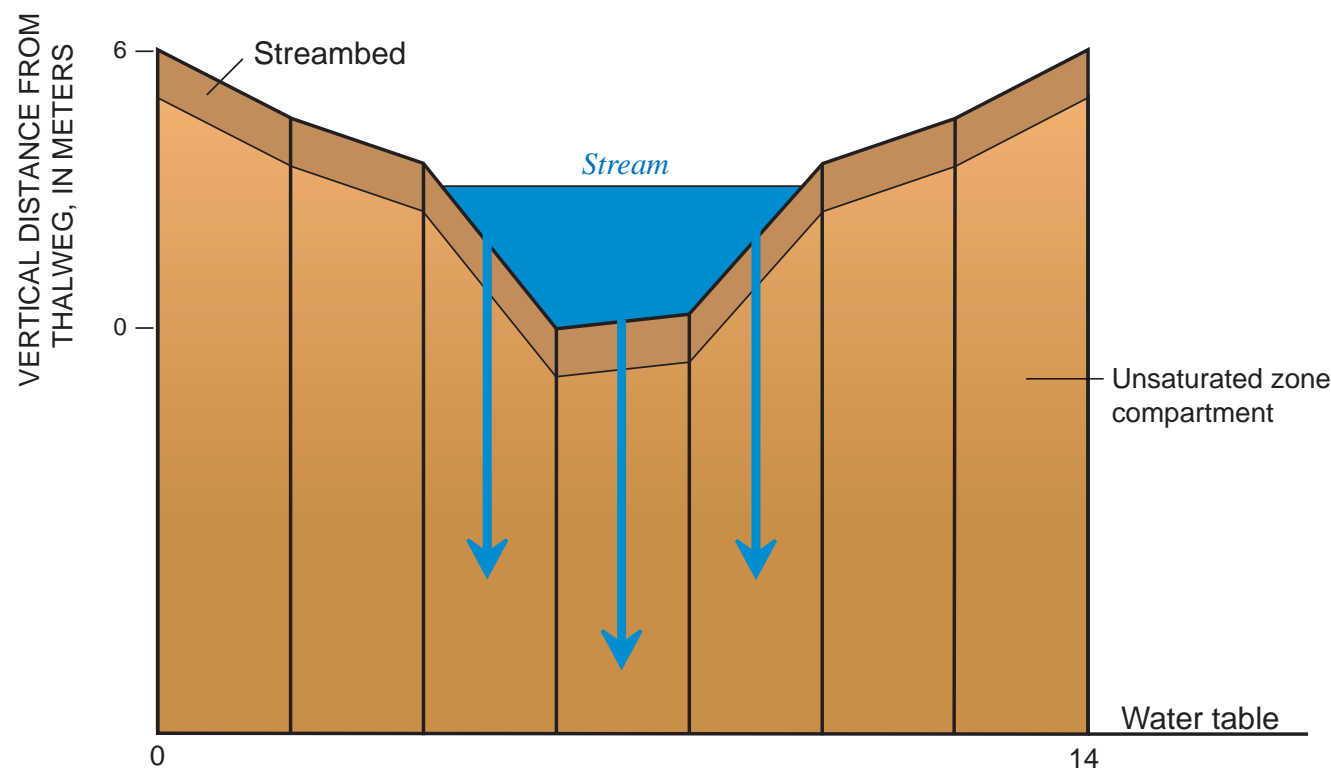

HORIZONTAL DISTANCE FROM LEFT EDGE OF STREAM, IN METERS

B. Division of unsaturated zone into seven compartments beneath stream channel (modified from Niswonger and Prudic, 2004).

Figure 6. Conceptualization of hypothetical test simulation. 


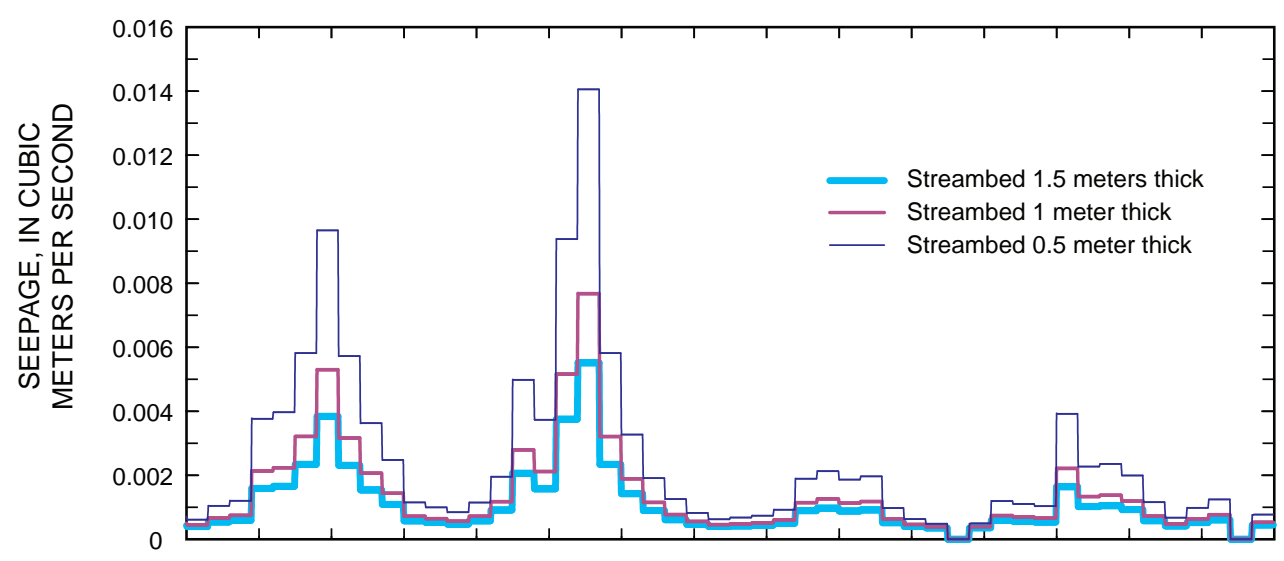

$\boldsymbol{A}$. Seepage rate across streambed.

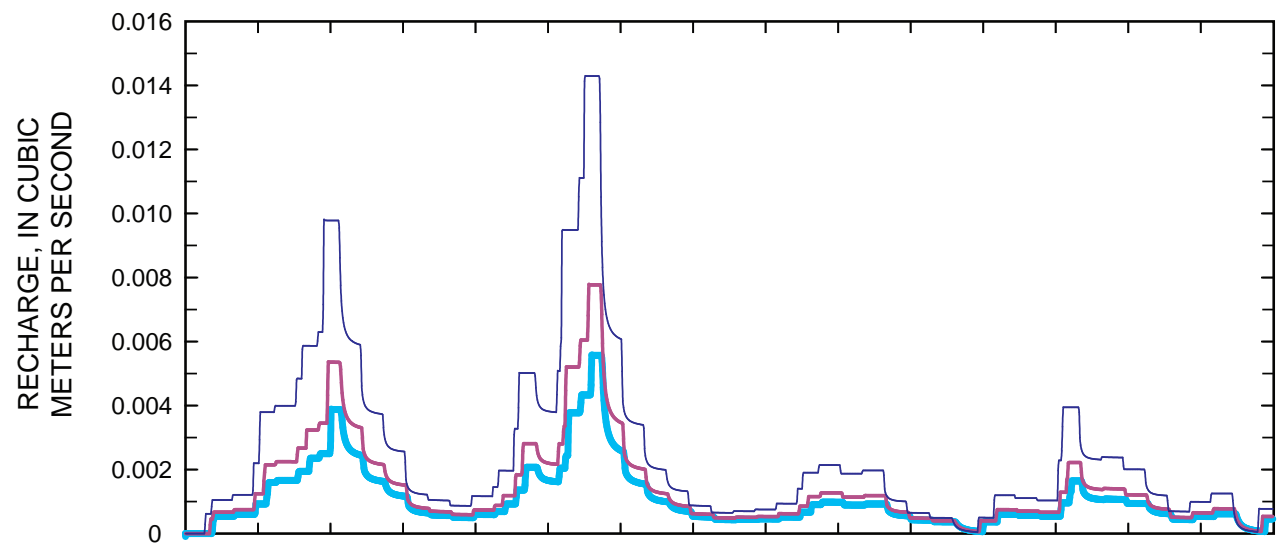

B. Recharge rate at water table.

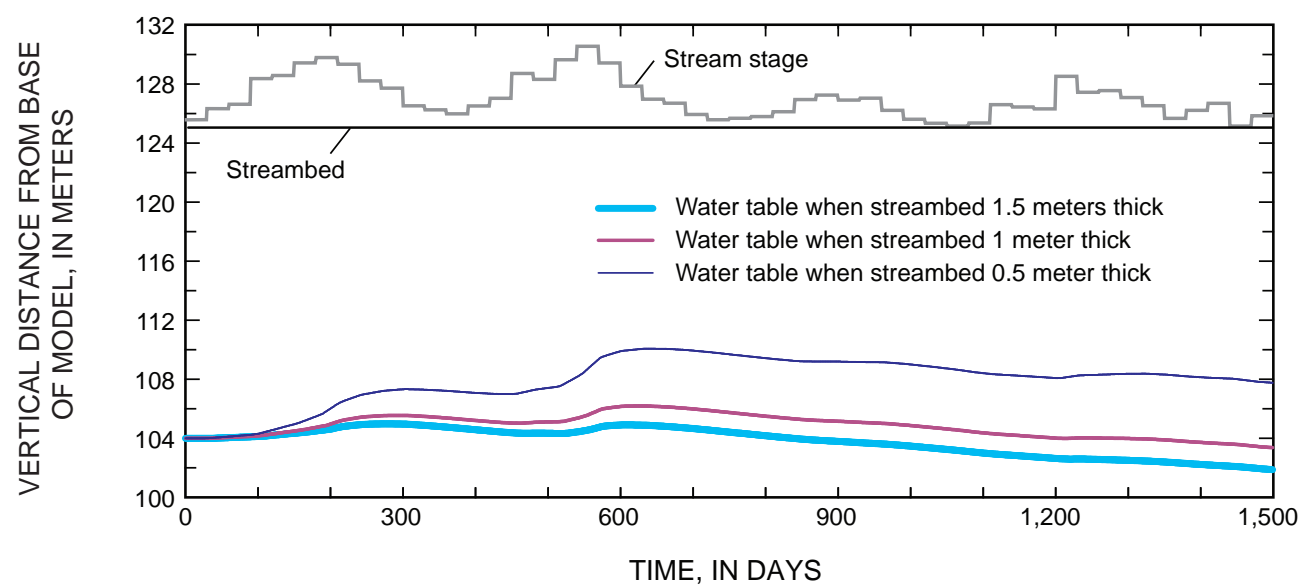

C. Water table for a stream reach midway along the stream.

Figure 7. Effects of variations in thickness of a semipervious streambed (from Niswonger and Prudic, 2004). 


\section{Implementation of SFR2 with MODFLOW-2000}

SFR2 consists of twenty subroutines that are used for the Ground-Water Flow (GWF1) Process of MODFLOW-2000 (Harbaugh and others, 2000), three subroutines are used to read and write parameters and non-parameters, and one subroutine checks for incompatibilities with the Sensitivity Process in MODFLOW-2000. The unsaturated-flow computations were included within the individual modules of SFR2. Each subroutine or module incorporated in the main listing of MODFLOW-2000 is identified first by the GWF1 Process, followed by SFR2 (version 2 of the StreamflowRouting Package), and then followed by the division of procedures used in MODFLOW-2000. Specifically, subroutine functions include: (1) memory allocation; (2) reading input data and initialization of variables at the beginning of the simulation; (3) setting values for the first stress period; (4) reading input data and initializing variables at the beginning of each stress period; (5) formulating characteristic and finite-difference equations; and (6) computing mass balance. These procedures occur within the following modules, GWF1SFR2ALP, GWF1SFR2RPP, GWF1SFR2RPS, GWF1SFR2AD, GWF1SFR2FM, and GWF1SFR2BD, respectively.

Three additional modules, GWF1SFR2UHC, GWF1SFR2UZOT and GWF1SFR2SSET were added to the main program. The module GWF1SFR2UHC was added to define the saturated vertical hydraulic conductivity in the unsaturated zone, either as a variable that is read into SFR2 or obtained from the LPF Package. When the vertical hydraulic conductivity for the unsaturated zone beneath a stream reach is specified within the LPF Package, the hydraulic conductivity of the uppermost active cell at the beginning of the simulation will be used throughout the entire simulation. The module GWF1SFR2UZOT was added for the printing of an overall mass balance of the unsaturated zone beneath streams. The subroutine GWF1SFR2SSET was added to initialize wave characteristics after a steady-state simulation.

In addition to the modules from the main program, several new modules were added to SFR2 for routing kinematic waves through the unsaturated zone. These modules are named ROUTWAVESIT, ROUTWAVEST, UZFLOW, LEADWAVE, TRAILWAVE, CALC_UNSAT_ INFIL, UNSAT_MASS_BAL, and CHANNELAREA. Additionally, three GAGE Package modules (GWF1GAG5DF, GWF1GAG5I, and GWF1GAG5SO) were modified to print time series data of unsaturated zone infiltration, storage, and ground-water recharge, and to print time series of watercontent profiles in the unsaturated zone.
Additionally, the MAIN program of MODFLOW-2000 has been modified to designate "SFR" in position 44 in CUNIT. Whenever "SFR" is used at the beginning of a line in the NAME file, the program will use the specified unit number and file name to obtain information for SFR2 and will execute MODFLOW-2000 using SFR2.

Data input from SFR1 can be read into SFR2 without modification. Output from SFR2 can be printed: (1) to the main listing file; (2) to a separate listing file when requested in the SFR2 input; and (or) (3) to separate files for each specified stream reach that provides a time series of selected information using the Gage Package. Two new options were added to the Gage Package (Appendix 1) for printing time series data of the unsaturated zone beneath a selected reach. Option 6 will print time, stage, ground-water head, streambed seepage, change in unsaturated storage and recharge to ground water. Option 7 will print time and the unsaturated water content profiles for the selected stream reach.

SFR2 has been programmed to apply leakage from a stream reach to a designated underlying cell. If the water level in the underlying cell becomes less than the bottom elevation of the cell, the cell is inactivated. When this happens, SFR2 will begin searching vertically below the designated cell to find the uppermost active cell. If it finds an active cell in the vertical column, recharge at the water table is applied to that cell, however, the unsaturated zone hydraulic properties remain unchanged. If all cells in the vertical column beneath a stream reach are inactive, no interaction with ground water is allowed and flow in the stream reach is passed to the next reach.

\section{Summary}

The U.S. Geological Survey modular ground-water model (MODFLOW-2000) has been used to model surface- and ground-water interaction over a wide range of spatial scales. Because of increased interest in the connection of surface water and ground water, the capability to simulate unsaturated flow beneath streams has been added to the StreamflowRouting (SFR2) Package of MODFLOW-2000. Unsaturated flow beneath streams is simulated using a kinematic-wave approximation and assumes that downward flow beneath streams is a result of gravity. SFR2 allows for the simulation of flow and storage in the unsaturated zone, and for the simulation of a time delay for recharge, while still maintaining the applicability of MODFLOW-2000 to basin-scale problems. 
Unsaturated flow is simulated independently of saturated flow within each model cell that corresponds to a stream reach in which the water table is below the bottom of the streambed. The relation between the unsaturated hydraulic conductivity and water content in the unsaturated zone is defined on the basis of the Brooks-Corey function. Variables used to simulate unsaturated flow include saturated and initial water contents; saturated vertical hydraulic conductivity; and the BrooksCorey exponent. The values of variables can be different for each stream reach.

In the simulation of unsaturated flow beneath streams, seepage flux (flow per unit area) across the streambed is limited to the vertical saturated hydraulic conductivity. This differs from the first version of the Streamflow-Routing (SFR1) Package in which the seepage losses are limited by the conductance term of the streambed and the head difference across the streambed. Additionally, when an unsaturated zone is simulated beneath a stream, recharge is not added to ground water unless water in the unsaturated zone drains to the water table. This approach also differs from SFR1, which assumes that water instantly recharges ground water.

The representative width of the stream may be held as a constant or determined on the basis of the stream cross section, discharge, and depth. When the water table rises, the quantity of water stored in the unsaturated zone above the residual water content is added to recharge. Thus, the water table can rise rapidly when the unsaturated zone is at or near saturation. A water budget for the unsaturated zone is calculated independently of the ground-water budget in MODFLOW-2000.
Two test simulations were used to compare results from the kinematic-wave approximation in SFR2 with the U.S. Geological Survey's Variably Saturated Two-Dimensional Flow and Transport (VS2DT) Model. The first test simulation checked the capability of SFR2 to simulate the advancement of a wetting front following a period of redistribution (drying), and the second test simulation checked the accuracy of representing a semipervious streambed. The simulations using SFR2 for both cases were in good agreement with the magnitude and downward progression of the wetting front with respect to the results from VS2DT. A third simulation assumed a stream was separated from ground water by an unsaturated zone. The simulation tested effects of different stream depths and streambed thicknesses on the timing of recharge to the aquifer. Results indicate that stream depth affects seepage loss when the hydraulic conductivity of the streambed is less than that in the unsaturated zone. However, stream depth becomes less important and the wetted area of the stream controls seepage loss when the streambed hydraulic conductivity is higher than that of the unsaturated zone.

The kinematic-wave approximation to unsaturated flow in SFR2 ignores the effects of negative potential gradients. Ignoring negative potential gradients during the onset of streamflow under predicts initial seepage across the streambed. Ignoring negative potential gradients after flow ceases over predicts the advancement of the wetting front. Seepage across a streambed also can exhibit a horizontal component of flow not accounted for in SFR2. For streambeds in which significant lateral flow occurs, SFR2 may over predict the advancement of the wetting front. Lastly, the model can simulate unsaturated flow through layers of cells but the hydraulic properties assigned to the unsaturated zone remain constant during the simulation. 


\section{References Cited}

Anderson, I.A., 2004, Modeling ground-water-surface-water interaction using the Dupuit approximation: Advances in Water Resources, v. 28, no. 4, p. 315-327.

Brooks, R.H., and Corey, A.T., 1966, Properties of porous media affecting fluid flow: American Society of Civil Engineers, Journal of Irrigation and Drainage, v. 101, p. 85-92.

Charbeneau, R.J., 1984, Kinematic models for soil moisture and solute transport: Water Resources Research, v. 20, no. 6, p. 699-706.

Childs, E.C., and Bybordi, M., 1969, The vertical movement of water in stratified porous material, 1. Infiltration: Water Resources Research, v. 5, no. 2, p. 446-459.

Danskin, W.R., and Hanson, R.T., 2002, Appendix 2: Documentation and description of changes made to the streamflow-routing package in the MODFLOW groundwater flow model, in Hanson, R.T., Martin, Peter, and Koczot, K.M., Simulation of ground-water/surface-water flow in the Santa Clara-Calleguas Basin, Ventura County, California: U.S. Geological Survey Water-Resources Investigations Report 02-4136, p. 187-193.

Harbaugh, A.W., Banta, E.R., Hill, M.C., and McDonald, M.G., 2000, MODFLOW-2000, the U.S. Geological Survey modular ground-water model-modularization concepts and the ground-water flow process: U.S. Geological Survey Open-File Report 00-92, 121 p.

Healy, R.W., 1990, Simulation of solute transport in variably saturated porous media with supplemental information on modification of the U.S. Geological Survey's computer program VS2D: U.S. Geological Survey Water-Resources Investigations Report 90-4025, 125 p.

Konikow, L.F., Goode, D.J., and Hornberger, G.Z., 1996, A three-dimensional method-of-characteristics solute-transport model (MOC3D): U.S. Geological Survey Water-Resources Investigations Report 96-4267, 87 p.
McDonald, M.G., and Harbaugh, A.W., 1988, A modular three-dimensional finite-difference ground-water flow model: U.S. Geological Survey Techniques of WaterResources Investigations, book 6, chap. A1, 586 p.

Mein, R.G., and Larson, C.L., 1973, Modeling infiltration during a steady rain: Water Resources Research, v. 9, no. 2, p. 384-394.

Meinzer, O.E., 1923, Outline of ground-water hydrology, with definitions: U.S. Geological Survey Water-Supply Paper 494, 71 p.

Merritt, M.L., and Konikow, L.F., 2000, Documentation of a computer program to simulate lake-aquifer interaction using the MODFLOW ground-water flow model and the MOC3D solute-transport model: U.S. Geological Survey WaterResources Investigations Report 00-4167, 146 p.

Niswonger, R.G., and Prudic, D.E., 2004, Modeling variably saturated flow using kinematic waves in MODFLOW, in Hogan, J.F., Phillips, F.M., and Scanlon, B.R., eds., Groundwater Recharge in a Desert Environment: The Southwestern United States: American Geophysical Union, Washington, D.C., Water Science and Application Series, v. 9, p. 101-112.

Prudic, D.E., 1989, Documentation of a computer program to simulate stream-aquifer relations using a modular, finitedifference, ground-water flow model: U.S. Geological Survey Open-File Report 88-729, 113 p.

Prudic, D.E., Konikow, L.F., and Banta, E.R., 2004, A new streamflow-routing (SFR1) package to simulate streamaquifer interaction with MODFLOW-2000: U.S. Geological Survey Open-File Report 2004-1042, p. 95.

Smith, R.E., 1983, Approximate sediment water movement by kinematic characteristics: Soil Science Society of America Journal, v. 47, p. 3-8.

Smith, R.E., and Hebbert, R.H.B., 1983, Mathematical simulation of interdependent surface and subsurface hydrologic processes: Water Resources Research, v. 19, no. 4 , p. $987-1001$. 


\section{Appendix 1: Data Input Instructions for the Streamflow-Routing (SFR2) Package with Unsaturated Flow Beneath Streams.}

\section{MODFLOW Name File}

The Streamflow-Routing Package is activated automatically by including a record in the MODFLOW name file using the file type (Ftype) "SFR" to indicate that relevant calculations are to be made in the model and to specify the related input data file. The user can optionally specify that stream gages and monitoring stations are to be represented at one or more locations along a stream channel by including a record in the MODFLOW name file using the file type (Ftype) "GAGE" that specifies the relevant input data file giving locations of gages. The modifications in SFR2 do not require any changes to the data input for SFR1. SFR2 is compatible with MODFLOW-2000 (Harbaugh and others, 2000), but not with earlier versions of MODFLOW.

\section{Input Data Instructions}

The modification of SFR2 to simulate unsaturated flow relies on the specific yield values as specified in the Layer Property Flow (LPF) Package, the Hydrogeologic-Unit Flow (HUF) Package, or the Block-Centered Flow (BCF) Package. When the option to use vertical hydraulic conductivity in the LPF Package is specified, the layer(s) that contain cells where unsaturated flow will be simulated must be specified as convertible. That is, the variable LAYTYP specified in LPF (or variable LTHUF in HUF) must not be equal to zero, otherwise the model will print an error and stop execution.

Additional variables that must be specified to define hydraulic properties of the unsaturated zone are all included within the SFR2 input file. All values are entered in as free format. Data input for SFR1 works without modification if unsaturated flow is not simulated. Parameters can be used to define streambed hydraulic conductivity only when data input follows the SFR1 input structure (Prudic and others, 2004); parameters cannot be specified when simulating unsaturated flow beneath streams. The calculation of sensitivities for, or estimation of, parameters using the Sensitivity Process is supported by neither SFR1 nor SFR2. Additionally, the Ground-Water Transport Process is only available using the original SFR1 input structure and is not available when simulating unsaturated flow beneath streams.

\section{For Each Simulation:}

\section{Data: [\#Text]}

Text A character variable (up to 199 characters) that is printed when the file is read. The "\#" character must be in column 1, and, accordingly, the variable starts in column 2. Any characters can be included in Text.

Note 1: Item 0 can be repeated multiple times.

$\begin{array}{ll}\text { 1. Data: } & \text { NSTRM NSS NSFRPAR NPARSEG CONST DLEAK ISTCBI ISTCB2 }\{\text { ISFROPT }\{\text { NSTRAIL } \\ & \{\text { ISUZN }\} \text { NSFRSETS }\{\text { IRTFLG }\{\text { NUMTIM }\} \text { WEIGHT }\{\text { FLWTOL }\end{array}$

NSTRM An integer value that can be specified to be positive or negative. The absolute value of NSTRM is equal to the number of stream reaches (finite-difference cells) that are active during the simulation and the number of lines of data to be included in Item 2, described below. When NSTRM is specified to be a negative integer, it is also used as a flag for changing the format of the data input, for simulating unsaturated flow beneath streams, and (or) for simulating transient streamflow routing (for MODFLOW-2005 simulations only), depending on the values specified for variables ISFROPT and IRTFLG, as described below. When NSTRM is negative, NSFRPAR must be set to zero, which means that parameters cannot be specified.

NSS An integer value equal to the number of stream segments (consisting of one or more reaches) that are used to define the complete stream network. The value of NSS represents the number of segments that must be defined through a combination of parameters and variables in Item 4 or variables in Item 6.

NSFRPAR An integer value equal to the number of stream parameters (associated with one or more segments) to be defined. This variable must be zero when NSTRM is negative. 
NPARSEG An integer value equal to (or exceeding) the number of stream-segment definitions associated with all parameters. This number can be more than the total number of segments (NSS) in the stream network because the same segment can be defined in multiple parameters, and because parameters can be time-varying. NPARSEG must equal or exceed the sum of NLST $\times \mathrm{N}$ for all parameters, where $\mathrm{N}$ is the greater of 1 and NUMINST; that is, NPARSEG must equal or exceed the total number of repetitions of item $4 \mathrm{~b}$. This variable must be zero when NSTRM is negative.

CONST A real value (or conversion factor) used in calculating stream depth for stream reach. If stream depth is not calculated using Manning's equation for any stream segment (that is, ICALC does not equal 1 or 2), then a value of zero can be entered. If Manning's equation is used, a constant of 1.486 is used for flow units of cubic feet per second, and a constant of 1.0 is used for units of cubic meters per second. The constant must be multiplied by 86,400 when using time units of days in the simulation. An explanation of time units used in MODFLOW is given by Harbaugh and others (2000, p. 10).

DLEAK A real value equal to the tolerance level of stream depth used in computing leakage between each stream reach and active model cell. Value is in units of length. Usually a value of 0.0001 is sufficient when units of feet or meters are used in model.

ISTCB1 An integer value used as a flag for writing stream-aquifer leakage values. If ISTCB1 > 0, it is the unit number to which unformatted leakage between each stream reach and corresponding model cell will be saved to a file whenever the cell-by-cell budget has been specified in Output Control (see Harbaugh and others, 2000, pages 52-55). If ISTCB1 = 0, leakage values will not be printed or saved. If ISTCB1 < 0 , all information on inflows and outflows from each reach; on stream depth, width, and streambed conductance; and on head difference and gradient across the streambed will be printed in the main listing file whenever a cell-by-cell budget has been specified in Output Control.

ISTCB2 An integer value used as a flag for writing to a separate formatted file all information on inflows and outflows from each reach; on stream depth, width, and streambed conductance; and on head difference and gradient across the streambed. If ISTCB2 > 0, then ISTCB2 also represents the unit number to which all information for each stream reach will be saved to a separate file when a cell-by-cell budget has been specified in Output Control. If ISTCB2 $<0$, it is the unit number to which unformatted streamflow out of each reach will be saved to a file whenever the cell-by-cell budget has been specified in Output Control.

\section{If NSTRM less than 0:}

An integer value that defines the format of the input data and whether or not unsaturated flow is simulated beneath streams. Values of ISEROPT are defined as follows:

0 No vertical unsaturated flow beneath streams. Streambed elevations, stream slope, streambed thickness, and streambed hydraulic conductivity are read for each stress period using variables defined in Items $6 \mathrm{~b}$ and $6 \mathrm{c}$; the optional variables in Item 2 are not used.

1 No vertical unsaturated flow beneath streams. Streambed elevation, stream slope, streambed thickness, and streambed hydraulic conductivity are read for each reach only once at the beginning of the simulation using optional variables defined in Item 2 ; Items $6 \mathrm{~b}$ and $6 \mathrm{c}$ are used to define stream width and depth for ICALC $=$ 0 and stream width for ICALC $=1$.

2 Streambed and unsaturated-zone properties are read for each reach only once at the beginning of the simulation using optional variables defined in Item 2; Items $6 \mathrm{~b}$ and $6 \mathrm{c}$ are used to define stream width and depth for ICALC $=0$ and stream width for ICALC $=1$. When using the LPF Package, saturated vertical hydraulic conductivity for the unsaturated zone is the same as the vertical hydraulic conductivity of the corresponding layer in LPF and input variable $\mathrm{UHC}$ is not read.

3 Same as 2 except saturated vertical hydraulic conductivity for the unsaturated zone (input variable UHC) is read for each reach.

4 Streambed and unsaturated-zone properties are read for the beginning and end of each stream segment using variables defined in Items $6 \mathrm{~b}$ and $6 \mathrm{c}$; the optional variables in Item 2 are not used. Streambed properties can vary each stress period. When using the LPF Package, saturated vertical hydraulic conductivity for the unsaturated zone is the same as the vertical hydraulic conductivity of the corresponding layer in LPF and input variable UHC1 is not read. 
5 Same as 4 except saturated vertical hydraulic conductivity for the unsaturated zone (input variable UHC1) is read for each segment at the beginning of the first stress period only.

Note 2: If BCF or HUF are used and unsaturated flow is active then ISFROPT must equal 3 or 5 . If ISFROPT>1, the specific yield must be specified in the flow package for each SFR reach for which ICALC $=1$ or 2 . This will require that at least one transient simulation period be included in the simulation and that any cells connected to such SFR reaches be unconfined or convertible.

When ISFROPT is greater than 1, (that is, unsaturated flow beneath streams is being simulated) read the following variables (otherwise, skip these variables):

NSTRAIL An integer value that is the number of trailing wave increments used to represent a trailing wave. Trailing waves are used to represent a decrease in the surface infiltration rate. The value can be increased to improve mass balance in the unsaturated zone. Values between 10 and 20 work well and result in unsaturated-zone mass balance errors beneath streams ranging between 0.001 and 0.01 percent. Please see Smith (1983) for further details.

ISUZN An integer value that is the maximum number of vertical cells used to define the unsaturated zone beneath a stream reach. If ICALC is 1 for all segments then ISUZN should be set to 1 .

NSFRSETS An integer value that is the maximum number of different sets of trailing waves used to allocate arrays. Arrays are allocated by multiplying NSTRAIL by NSERSETS. A value of 30 is sufficient for problems where the stream depth varies often. NSFRSETS does not affect model run time.

\section{If NSTRM less than 0 (for MODFLOW-2005 simulations only):}

IRTFLG An integer value that indicates whether transient streamflow routing is active. IRTFLG must be specified if NSTRM < 0. If IRTFLG > 0, streamflow will be routed using the kinematic-wave equation (see USGS Techniques and Methods 6-D1, p. 68-69); otherwise, IRTFLG should be specified as 0. Transient streamflow routing is only available for MODFLOW-2005; IRTFLG can be left blank for MODFLOW-2000 simulations.

If IRTFLG greater than 0 (for MODFLOW-2005 simulations only):

NUMTIM An integer value equal to the number of sub time steps used to route streamflow. The time step that will be used to route streamflow will be equal to the MODFLOW time step divided by NUMTIM.

WEIGHT

A real number equal to the time weighting factor used to calculate the change in channel storage. WEIGHT has a value between 0.5 and 1. Please refer to equation 83 in USGS Techniques and Methods 6-D1 for further details.

FLWTOL A real number equal to the streamflow tolerance for convergence of the kinematic wave equation used for transient streamflow routing. A value of 0.00003 cubic meters per second has been used successfully in test simulations (and would need to be converted to whatever units are being used in the particular simulation).

Note 3: The first two variables (NSTRM and NSS) are used for dimensioning arrays, and the absolute value of NSTRM must be equal to the actual number of stream reaches defined in Item 2 and NSS must be equal to the number of segments that define the complete stream network, respectively.

Note 4: SFR2 differs from the Stream (STR1) Package (Prudic, 1989) in that it solves for stream depth at the midpoint of each reach instead of at the beginning of the reach. SFR2 does this by use of Newton's iterative method. As a consequence, the user must specify variable DLEAK, which is a closure tolerance used for stopping the iterative process. A value of $1.0 \times 10^{-6}$ meters has been used successfully in test simulations (and would need to be converted to whatever units are being used in the particular simulation). 


\section{One record for each stream reach:}
2. Data:
$\mathrm{KRCH}$ IRCH JRCH ISEG
$\{$ THTS $\} \quad\{$ THTI $\} \quad\{$ EPS $\} \quad\{\mathrm{UHC}\}$
STRTOP $\} \quad\{$ SLOPE $\} \quad\{$ STRTHICK $\} \quad\{$ STRHC1 $\}$
$\mathrm{KRCH} \quad$ An integer value equal to the layer number of the cell containing the stream reach.
IRCH
An integer value equal to the row number of the cell containing the stream reach.
$\mathrm{JRCH}$
ISEG
An integer value equal to the column number of the cell containing the stream reach.
An integer value equal to the number of stream segment in which this reach is located. Stream segments contain one or more reaches and are assumed to have uniform or linearly varying characteristics unless NSTRM $<0$ and ISFROPT $=1,2$, or 3 (in which case streambed information is specified individually for each reach).

IREACH

An integer value equal to the sequential number in a stream segment of this reach (where a reach corresponds to a single cell in the model). Numbering of reaches in a segment begins with 1 for the farthest upstream reach and continues in downstream order to the last reach of the segment.

RCHLEN A real number equal to the length of channel of the stream reach within this model cell. The length of a stream reach can exceed the model cell dimensions because of the meandering nature of many streams. The length is used to calculate the streambed conductance for this reach. Also, the sum of the lengths of all stream reaches within a segment is used to calculate the average slope of the channel for the segment and subsequently other values, such as the elevation of the streambed and stream stage. A real number equal to the top elevation of the streambed. This variable is read when ISFROPT is 1,2 , or 3 . A real number equal to the stream slope across the reach. This variable is read when ISFROPT is 1,2 , or 3 . A real number equal to the thickness of the streambed. This variable is read when ISFROPT is 1,2 , or 3 . A real number equal to the hydraulic conductivity of the streambed. This variable is read when ISFROPT is 1,2 , or 3 .

THTS

A real number equal to the saturated volumetric water content in the unsaturated zone. This variable is read when ISFROPT is 2 or 3.

THTI

A real number equal to the initial volumetric water content. THTI must be less than or equal to THTS and greater than or equal to THTS minus the specific yield defined in either LPF, BCF, or HUF. This variable is read when ISFROPT is 2 or 3.

EPS

A real number equal to the Brooks-Corey exponent used in the relation between water content and hydraulic conductivity within the unsaturated zone (Brooks and Corey, 1966). This variable is read when ISFROPT is 2 or 3.

$\mathrm{UHC}$

A real number equal to the vertical saturated hydraulic conductivity of the unsaturated zone. This variable is necessary when using BCF or HUF, whereas it is optional when using LPF. This variable is read when ISFROPT is 3 .

Note 5: Reach information is read in sequential order from upstream to downstream, first by segments, and then sequentially by reaches. If segments are not numbered sequentially in downstream order, then the inflow to a segment during the current MODFLOW iteration will be the outflow from an upstream segment calculated during the previous iteration. Lagging the inflow by one iteration does not change the solution for flows into and out of a segment after MODFLOW converges; however, this approach may require an additional iteration for the model to converge. Reaches must be listed and read sequentially because the order determines the connections of inflows and outflows within a stream segment.

Note 6: The stream network is assumed to remain fixed geometrically over the duration of a simulation. The active part of the stream network, however, can be made to vary over time by making selected stream segments inactive for selected stress periods. This would be implemented by setting the streambed hydraulic conductivity, segment inflow, overland runoff, and direct precipitation to zero for the inactive segments in Items 4 or 6 for the specific stress periods when they are known to be inactive or dry. 
Note 7: If the model cell corresponding to a stream reach is inactive, the program will search for the uppermost active cell in the vertical column to apply the stream leakage. If there are no active cells or if the cell is a constant head, no interaction is allowed and flow in the reach is passed to the next reach.

Note 8: When STRTOP, SLOPE, STRTHICK, and STRHC1 are specified for each reach, then HCOND1, THICKM1, ELEVUP, HCOND2, THICKM2, and ELEVDN are not read using Items $6 \mathrm{~b}$ or $6 \mathrm{c}$.

Note 9: The residual water content for each cell is not specified by the user because it is calculated based on the specified saturated water content minus the specific yield of the active model cell corresponding to the stream reach. The calculation is performed internally to assure continuity between unsaturated and saturated zone storage.

Note 10: Although unsaturated flow variables THTS, THTI, EPS, and UHC will not be used for reaches that are designated as ICALC $=0,3$, and 4 in Items $4 \mathrm{~b}$ or $6 \mathrm{a}$, values for these variables must be included for all reaches when ISFROPT $=2$ or 3 . Dummy values for these variables may be used for reaches that are designated as ICALC $=0,3$, and 4 .

When NSFRPAR $=0$, (including when NSTRM is negative), skip Items 3 and 4 and enter all stream segment data using Items 5 and 6.

When NSFRPAR > 0, Items 3 and 4 are repeated NSFRPAR times:

3. Data: PARNAM PARTYP Parval NLST [INSTANCES NUMINST]

PARNAM A set of characters used to name a parameter to be defined. This name can consist of 1 to 10 characters and is not case sensitive. That is, any combination of the same characters with different cases will be equivalent.

PARTYP Type of parameter to be defined. For the SFR2 Package, the only allowed parameter type is SFR, which defines values of the streambed hydraulic conductivity.

Parval A real number that is a parameter value that may be overridden by a value in the Sensitivity Process input file when ISENALL in that file is less than zero.

NLST An integer value that is the number of stream segments associated with this parameter (this value also indicates how many times Item 4 is repeated in the next block of input data).

INSTANCES An optional keyword that designates a parameter as time varying. The keyword is case-insensitive; that is, it may be entered in any combination of upper- and lower-case letters. If INSTANCES is present, it must be followed by a value for NUMINST. If INSTANCES is absent, PARNAM is non-time-varying and NUMINST should not be present.

NUMINST An integer value that is the number of instances that are included in the definition of a time-varying parameter, where each instance is a sequence of Item 4 (Parts $4 \mathrm{~b}$ through $4 \mathrm{~g}$ ) defining reaches and associated properties. If the keyword INSTANCES is present, NUMINST must be present and must be at least 1 . If the keyword INSTANCES is absent, NUMINST should not be present.

When PARNAM is not time-varying, Part $4 \mathrm{a}$ is not read, and Parts $4 \mathrm{~b}$ through $\mathbf{4 g}$ are read sequentially for each of NLST stream segments; and

When PARNAM is time-varying, NUMINST instances are read. For each instance, Part $4 \mathrm{a}$ is read, and then Parts $4 \mathrm{~b}$ through $\mathbf{4 g}$ are read sequentially for each of NLST stream segments (see notes 11 and 12): 
4a. Data: $\quad\{$ INSTNAM $\}$

INSTNAM The name of an instance associated with the parameter PARNAM specified in the corresponding Item 3 (INS TNAM is read only if PARNAM is time-varying). The name can consist of 1 to 10 characters and is not case sensitive. That is, any combination of the same characters with different case will be equivalent. Names entered for INSTNAM must be unique for any given parameter, but names may be reused for instances associated with different parameters.
4b. Data:
NSEG
ICALC OUT
ROUGHCH
SEG IUPSEG
ROUGHBK $\}$
$\{$ IPRIOR $\}$
\{NSTRPTS $\}$ FLOW RUNOFF ETSW PPTSW

NSEG

An integer value of the stream segment for which information is given to identify inflow, outflow, and computation of stream depth.

ICALC

OUTSEG

An integer value used to indicate method used to calculate stream depth in this segment.

- If ICALC $\leq 0$, stream depth in each reach is specified at the beginning of a stress period and remains unchanged unless flow at the midpoint of a reach is zero, then depth is set to zero in that reach.

- If ICALC > 0, stream depth is calculated and updated each iteration of the MODFLOW solver within a time step.

- If ICALC $=1$, stream depth is calculated using Manning's equation and assuming a wide rectangular channel.

- If ICALC $=2$, stream depth is calculated using Manning's equation and assuming an eight-point channel cross section for each segment (which allows for the computation of a wetted perimeter and for changing hydraulic conductance of the streambed in relation to changes in flow).

- If ICALC $=3$, stream depth and width are calculated using a power function relating each to streamflow (Q) using equations 8 and 9 where DEPTH $(y)=\operatorname{CDPTH} \times \mathrm{Q}^{\mathrm{FDPTH}}$ and WIDTH $(w)=\operatorname{AWDTH} \times \mathrm{Q}^{\mathrm{BWDTH}}$.

- If ICALC $=4$, stream depth and width are calculated using a table relating streamflow to depth and width (the table is defined in Part 4f).

An integer value of the downstream stream segment that receives tributary inflow from the last downstream reach of this segment. If this segment (identified by NSEG) does not feed (or discharge into) another downstream (tributary) segment, then enter a value of " 0 " for this variable (Segment 7 in figure 3 is an example for which OUTSEG =0). If the segment ends within the modeled grid and OUTSEG $=0$, outflow from the segment is not routed anywhere and is no longer part of the stream network. One may wish to use this if all flow in the stream gets diverted into a lined canal or into a pipe. If the flow out of this segment discharges into a lake, set OUTSEG equal to the negative value of the lake identification number (where the minus sign is used as a flag to tell the model that flow enters a lake rather than a tributary stream segment).

An integer value of the upstream segment from which water is diverted (or withdrawn) to supply inflow to this stream segment if this segment originates as a diversion from an upstream segment. If the source of a stream segment is discharge from a lake, set IUPSEG equal to the negative value of the lake identification number (where the minus sign is used as a flag to tell the model that streamflow into this segment is derived from a lake rather than a stream segment). If this stream segment (identified by NSEG) does not receive inflow as a diversion from an upstream segment, then set IUP SEG $=0$.

IPRIOR An integer value that only is specified if IUPSEG > 0 (do not specify a value in this field if IUP SEG $=0$ or IUPSEG < 0). IPRIOR defines the prioritization system for diversion, such as when insufficient water is available to meet all diversion stipulations, and is used in conjunction with the value of FLOW (specified below).

- When IPRIOR $=0$, then if the specified diversion flow (FLOW) is greater than the flow available in the stream segment from which the diversion is made, the diversion is reduced to the amount available, which will leave no flow available for tributary flow into a downstream tributary of segment IUP SEG. 
- When IPRIOR = -1, then if the specified diversion flow (FLOW) is greater than the flow available in the stream segment from which the diversion is made, no water is diverted from the stream. This approach assumes that once flow in the stream is sufficiently low, diversions from the stream cease, and is the "priority" algorithm that originally was programmed into the STR1 Package (Prudic, 1989).

- When IPRIOR = -2, then the amount of the diversion is computed as a fraction of the available flow in segment IUP SEG; in this case, $0.0 \leq$ FLOW $\leq 1.0$.

- When IPRIOR $=-3$, then a diversion is made only if the streamflow leaving segment IUP SEG exceeds the value of FLOW. If this occurs, then the quantity of water diverted is the excess flow and the quantity that flows from the last reach of segment IUP SEG into its downstream tributary (OUTSEG) is equal to FLOW. This represents a flood-control type of diversion, as described by Danskin and Hanson (2002).

An integer value specified only when ICALC $=4$. It is used to dimension a table relating streamflow with stream depth and width as specified in Items 4e and 6e. NSTRPTS must be at least 2 but not more than 50 . If the table exceeds $3 \times 50$ (for streamflow, stream depth, and width) values, then MAXP TS in the allocation subroutine GWF1SFR1ALP will need to be increased from $3 \times 50$ to $3 \times$ (the desired maximum value).

A real number that is the streamflow (in units of volume per time) entering or leaving the upstream end of a stream segment (that is, into the first reach).

- If the stream is a headwater stream, FLOW defines the total inflow to the first reach of the segment. The value can be any number $\geq 0$.

- If the stream is a tributary stream, FLOW defines additional specified inflow to or withdrawal from the first reach of the segment (that is, in addition to the discharge from the upstream segment of which this is a tributary). This additional flow does not interact with the ground-water system. For example, a positive number might be used to represent direct outflow into a stream from a sewage treatment plant, whereas a negative number might be used to represent pumpage directly from a stream into an intake pipe for a municipal water treatment plant. (Also see additional explanatory notes below.)

- If the stream is a diversionary stream, and the diversion is from another stream segment, FLOW defines the streamflow diverted from the last reach of stream segment IUPSEG into the first reach of this segment. The diversion is computed or adjusted according to the value of IPRIOR.

- If the stream is a diversionary stream, and the diversion is from a lake, FLOW defines a fixed rate of discharge diverted from the lake into the first reach of this stream segment (unless the lake goes dry) and flow from the lake is not dependent on the value of ICALC. However, if FLOW $=0$, then the lake outflow into the first reach of this segment will be calculated on the basis of lake stage relative to the top of the streambed for the first reach using one of the methods defined by ICALC.

RUNOFF A real number that is the volumetric rate of the diffuse overland runoff that enters the stream segment (in units of volume per time). The specified rate is apportioned to each reach of the segment in direct relation to the fraction of the total length of the stream channel in the segment that is present in each reach.

ETSW

PPTSW

ROUGHCH

ROUGHBK
A real number that is the volumetric rate per unit area of water removed by evapotranspiration directly from the stream channel (in units of length per time). ETSW is defined as a positive value.

A real number that is the volumetric rate per unit area of water added by precipitation directly on the stream channel (in units of length per time).

A real number that is Manning's roughness coefficient for the channel in all reaches in this segment. This variable is only specified if ICALC $=1$ or 2 .

A real number that is Manning's roughness coefficient for the overbank areas in all reaches in this segment. This variable is only specified if ICALC $=2$. 
CDPTH A real number that is the coefficient used in the equation:

$\mathrm{DEPTH}=\mathrm{CDPTH} \times \mathrm{Q}^{\mathrm{FDPTH}}$ that relates stream depth in all reaches in this segment to streamflow. This variable is only specified if ICALC $=3$.

FDPTH A real number that is the coefficient used in the equation:

$\mathrm{DEPTH}=\mathrm{CDPTH} \times \mathrm{Q}^{\mathrm{FDPTH}}$ that relates stream depth in all reaches in this segment to streamflow. This variable is only specified if ICALC $=3$.

AWDTH A real number that is the coefficient used in the equation:

WIDTH $=$ AWDTH $\times Q^{\text {BWDTH }}$ that relates stream width in all reaches in this segment to streamflow. This variable is only specified if ICALC $=3$.

BWDTH A real number that is the coefficient used in the equation:

$\mathrm{WIDTH}=\mathrm{AWDTH} \times \mathrm{Q}^{\mathrm{BWDTH}}$ that relates stream width in all reaches in this segment to streamflow. This variable is only specified if ICALC $=3$.

4c. Data: Hclfact THICKM1 ELEVUP \{WIDTH1\} \{DEPTH1\}

Hclfact A real number that is a factor used to calculate hydraulic conductivity of the streambed at the upstream end of this segment from the parameter value (in units of length per time).

THICKM1 A real number that is the thickness of streambed material at the upstream end of this segment (in units of length).

ELEVUP A real number that is the elevation of the top of the streambed at the upstream end of this segment (in units of length).

WIDTH1 A real number that is the average width of the stream channel at the upstream end of this segment (in units of length). This variable is only specified if ICALC $\leq 1$.

DEPTH1 A real number that is the average depth of water in the channel at the upstream end of this segment (units of length). This variable is only specified if ICALC $=0$, in which case the stream stage in a reach is assumed to equal the elevation of the top of the streambed plus the depth of water.

4d. Data: Hc2fact THICKM2 ELEVDN \{WIDTH2\} \{DEPTH2\}

Hc2 fact A real number that is the factor used to calculate hydraulic conductivity of the streambed at the downstream end of this segment from the parameter value (units of length per time).

THICKM2 A real number that is the thickness of streambed material at the downstream end of this segment (units of length).

ELEVDN A real number that is the elevation of the top of the streambed at the downstream end of this segment (units of length).

WIDTH2 A real number that is the average width of the stream channel at the downstream end of this segment (units of length). This variable is only specified if ICALC $\leq 1$.

DEPTH2 A real number that is the average depth of water in the channel at the downstream end of this segment (units of length). This variable is only specified if ICALC $=0$, in which case the stream stage in a reach is assumed to equal the elevation of the top of the streambed plus the depth of water. 
If ICALC $=\mathbf{2}:$

4e. Data: $\mathrm{XCPT} 1 \mathrm{XCPT} 2 \ldots \mathrm{XCPT} 8$

$\mathrm{XCPT} i \quad$ A real number that is the distance relative to the left bank of the stream channel (when looking downstream) for the eight points (XCPT1 through XCPT8) used to describe the geometry of this segment of the stream channel. By definition, location XCPT1 represents the left edge of the channel cross section, and its value should be set equal to 0.0 ; values $\mathrm{XCPT} 2$ through $\mathrm{XCPT} 8$ should be equal to or greater than the previous distance.

$\mathrm{ZCPT} i \quad$ A real number that is the height relative to the top of the lowest elevation of the streambed (thalweg). One value (ZCPT1 through ZCPT8) is needed for each of the eight horizontal distances defined by XCPT $i$. The location of the thalweg (set equal to 0.0 ) can be any location from XCPT2 through XCPT 7 .

\section{If ICALC = 4:}
4f. Data: FLOWTAB (1) FLOWTAB (2) ... FLOWTAB (NSTRPTS)
Data: DPTHTAB (1) DPTHTAB (2) ... DPTHTAB (NSTRPTS)
Data: WDTHTAB (1) WDTHTAB (2) ... WDTHTAB (NSTRPTS)

FLOWTAB A real number that is the streamflow (units of volume per time) related to a given depth and width. One value is needed for each streamflow that has a corresponding value of depth and width up to the total number of values used to define the table-FLOWTAB (1) through FLOWTAB (NSTRPTS). NSTRPTS is defined in Part $4 \mathrm{~b}$.

DP THTAB A real number that is the average depth (units of length) corresponding to a given flow. The number and order of values, DP THTAB (1) through DP THTAB (NSTRPTS) must coincide with the streamflow values FLOWTAB (1) through FLOWTAB (NSTRPTS) •

WDTHTAB A real number that is the stream width (units of length) corresponding to a given flow. The number and order of values, WDTHTAB (1) through WDTHTAB (NSTRPTS), must coincide with the streamflow values FLOWTAB (1) through FLOWTAB (NSTRPTS).

\section{If Ground-Water Transport (GWT) Process is active (Ftype "GWT" exists), then read Part 4g NSOL times (where NSOL is the number of solutes being simulated, see note 17):}

4g. Data: $\quad$ CONCQ (NSOL) $\}$ CONCRUN (NSOL) CONCPPT (NSOL)

CONCQ A real number that is the solute concentration associated with "FLOW" (Part 4b-specified flow entering the upstream end of the stream segment). Only specify this variable for stream segments where IUP SEG $=0$.

CONCRUN A real number that is the solute concentration in the overland runoff entering the stream segment.

CONCPPT A real number that is the solute concentration in precipitation that directly falls onto the stream surface.

NSOL An integer value that is the number of solutes that are being simulated. The version of the Ground-Water Flow (GWT) Process for MODFLOW-2000 (MODFLOW-GWT) documented by Konikow and others (1996) is limited to simulating one solute, and until a new version is released, NSOL must be 1 .

Note 11: Item 4, Parts 4b through 4g must be completed sequentially for each of the NLST stream segments; that is, Parts $4 \mathrm{~b}$ through $4 \mathrm{~g}$ for one stream segment must be entered before Parts $4 \mathrm{~b}$ through $4 \mathrm{~g}$ of the next stream segment. However, the data for stream segments need not be entered sequentially by stream segment number. For example, data for stream segment 2 can be entered before data for stream segment 1 . 
Note 12: When the defined parameter (PARNAM) is not time-varying, Item 4, Part 4a is omitted, and each stream segment controlled by parameter PARNAM is defined by one sequence of Parts $4 \mathrm{~b}$ through $4 \mathrm{~g}$. When the defined parameter (PARNAM) is time-varying, Item 4, Parts 4a through $4 \mathrm{~g}$ must be completed for each of NUMINST instances. For each instance, Part 4a is defined followed by Parts $4 \mathrm{~b}$ through $4 \mathrm{~g}$ for each of the NLST stream segments associated with that instance. For example, NUMINST $=2$, NLST $=3$, ICALC $=1$ and the GWT Process is inactive, the sequence of records for Item 4 would be: $4 \mathrm{a}, 4 \mathrm{~b}, 4 \mathrm{c}$, 4d, 4b, 4c, 4d, 4b, 4c, 4d, 4a, 4b, 4c, 4d, 4b, 4c, 4d, 4b, 4c, and 4d.

Note 13: Record 4b will contain 8 to 13 variables; depending on the values of ICALC and IUPSEG. ICALC determines how stream depth is to be calculated; when ICALC is 1 or 2, depth is calculated using Manning's equation, which, in turn, requires a channel roughness coefficient $($ ICALC $=1$ ) or a channel and bank roughness coefficient (ICALC $=2)$. Similarly, Parts $4 \mathrm{c}$ and $4 \mathrm{~d}$ will include 3 to 5 values.

Note 14: A stream segment that receives inflow from upstream segments is allowed to have as many as ten upstream segments feeding it, as defined by the respective values of OUTSEG in Part $4 \mathrm{~b}$.

Note 15: Stream properties and stresses defined in Parts $4 \mathrm{~b}$ are assumed constant and uniform within a single stream segment. Additionally, hydraulic conductivity, streambed thickness, elevation of top of streambed, stream width, and stream depth may vary smoothly and linearly within a single stream segment. For these variables, data values at the upstream end of the segment are described in Part 4c and data values at the downstream end of the segment are described in Part 4d. Values of these variables for individual reaches of a segment are estimated using linear interpolation. To make any variable the same throughout the segment, simply specify equal values in Parts $4 \mathrm{c}$ and $4 \mathrm{~d}$. The two elevations in Parts $4 \mathrm{c}$ and $4 \mathrm{~d}$ are used in conjunction with the total length of the stream segment (calculated from RCHLEN given for each reach in Item 2) to compute the slope of the stream and the elevations for any intermediate reaches. The streambed thickness is subtracted from the top of streambed elevations to calculate the elevations of the bottom of the streambed (used in calculations of leakage).

Note 16: If Part 4e is included (for ICALC = 2), it is assumed that the cross-sectional geometry defined by these data is the same over the entire length of the segment. Similarly, if Part $4 \mathrm{f}$ is included (for ICALC $=4$ ), it is assumed the tabulated relation between streamflow and stream depth and width is the same over the entire length of the segment.

Note 17: If the Lake (LAK3) Package (Merritt and Konikow, 2000) is also implemented, then flow out of the lake into a stream segment is dependent on the option used to compute stream depth (ICALC $=1,2,3$, or 4). Constant discharge from a lake can be simulated no matter what value of ICALC is assigned to the stream segment emanating from the lake by assigning a positive value to FLOW in Part 4b.

Note 18: If a diversionary flow is large enough to warrant representation in the model, but is discharged into a pipeline, lined canal, or other structure or system that does not interact with the aquifer and the flow might exceed the available streamflow, then there is an alternative means to represent it. Instead of specifying a negative value of FLOW, we suggest representing the withdrawal by a single-reach diversionary stream segment, which would be located in the same model cell as the reach from the upstream segment (IUPSEG) from which the diversion is made; specifying the segment's streambed hydraulic conductivity equal to 0 will preclude interaction with the aquifer and setting OUTSEG $=0$ will remove the flow from the system. The diversion will then be subject to the constraints associated with the value of IPRIOR.

Note 19: The version of MODFLOW-GWT documented by Konikow and others (1996) is limited to simulating one solute, and until a new multi-species version is released, NSOL automatically defaults to a value of 1 . 


\section{For Each Stress Period:}

5. Data: ITMP IRDFLG IPTFLG $\{\mathrm{NP}\}$

ITMP An integer value for reusing or reading stream segment data that can change each stress period. If ITMP $=0$ then all stream segment data are defined by Item 4 (NSFRPAR > 0; number of stream parameters is greater than 0). If ITMP > 0, then stream segment data are not defined in Item 4 and must be defined in Item 6 below for a number of segments equal to the value of ITMP. If ITMP $<0$, then stream segment data not defined in Item 4 will be reused from the last stress period (Item 6 is not read for the current stress period). ITMP must be defined $\geq 0$ for the first stress period of a simulation.

IRDFLG An integer value for printing input data specified for this stress period. If IRDFLG $=0$, input data for this stress period will be printed. If IRDFLG > 0 , then input data for this stress period will not be printed.

IPTFLG An integer value for printing streamflow-routing results during this stress period. If IPTFLG $=0$, or whenever the variable ICBCFL or "Save Budget" is specified in Output Control, the results for specified time steps during this stress period will be printed. If IPTFLG $>0$, then the results during this stress period will not be printed.

NP

An integer value of the number of parameters used in the current stress period. The parameters being used are subsequently listed in Item 7 below. NP and Item 7 below are not read when NSFRPAR $=0$.

Note 20: In each stress period, the sum of ITMP plus the sum of all NLST values in Item 3 associated with the NP parameters listed in Item 7 must equal or be less than (some stream segments may not be active during a stress period) the total number of stream segments in the stream network (NSS of Item 1). Stream segments defined by Items 3, 4, and 7 cannot be repeated using ITMP and Item 6.

If ITMP > 0:

6a. Data:

NSEG ICALC OUTSEG IUPSEG \{IPRIOR\} \{NSTRPTS\} FLOW RUNOFF ETSW PPTSW $\{$ ROUGHCH $\} \quad\{$ ROUGHBK $\} \quad\{\mathrm{CDPTH}\} \quad\{\mathrm{FDPTH}\} \quad\{\mathrm{AWDTH}\} \quad\{\mathrm{BWDTH}\}$

An integer value of the stream segment for which information is given to identify inflow, outflow, and computation of stream depth.

ICALC An integer value used to indicate method used to calculate stream depth in this segment.

- If ICALC $\leq 0$, stream depth in each reach is specified at the beginning of a stress period and remains unchanged unless flow at the midpoint of a reach is zero, then depth is set to zero in that reach. Unsaturated flow is not allowed.

- If ICALC > 0, stream depth is calculated and updated each iteration of the MODFLOW solver within a time step.

- If ICALC $=1$, stream depth is calculated using Manning's equation and assuming a wide rectangular channel. Unsaturated flow is simulated when ISEROPT $>1$ and the value of ICALC must remain 1 for the specified segment during the simulation.

- If ICALC = 2, stream depth is calculated using Manning's equation and assuming an eight-point channel cross section for each segment (which allows for the computation of a wetted perimeter and for changing hydraulic conductance of the streambed in relation to changes in flow). Unsaturated flow is simulated when ISFROPT $>1$ and the value of ICALC must remain 2 for the specified segment during the simulation.

- If ICALC $=3$, stream depth and width are calculated using a power function relating each to streamflow (Q) using equations 8 and 9 where $\operatorname{DEPTH}(y)=\mathrm{CDPTH} \times \mathrm{Q}^{\mathrm{FDPTH}}$ and $\operatorname{WIDTH}(w)=\operatorname{AWDTH} \times \mathrm{Q}^{\mathrm{BWDTH}}$. Unsaturated flow is not allowed.

- If ICALC $=4$, stream depth and width are calculated using a table relating streamflow to depth and width (the table is defined in Part 4f). Unsaturated flow is not allowed. 
OUTSEG An integer value of the downstream stream segment that receives tributary inflow from the last downstream reach of this segment. If this segment (identified by NSEG) does not feed (or discharge into) another downstream (tributary) segment, then enter a value of " 0 " for this variable (Segment 7 in figure 3 is an example for which OUTSEG $=0$ ). If the segment ends within the modeled grid and OUTSEG $=0$, outflow from the segment is not routed anywhere and is no longer part of the stream network. One may wish to use this if all flow in the stream gets diverted into a lined canal or into a pipe. If the flow out of this segment discharges into a lake, set OUTSEG equal to the negative value of the lake identification number (where the minus sign is used as a flag to tell the model that flow enters a lake rather than a tributary stream segment).

IUP SEG An integer value of the upstream segment from which water is diverted (or withdrawn) to supply inflow to this stream segment if this segment originates as a diversion from an upstream segment. If the source of a stream segment is discharge from a lake, set IUPSEG equal to the negative value of the lake identification number (where the minus sign is used as a flag to tell the model that streamflow into this segment is derived from a lake rather than a stream segment). If this stream segment (identified by NSEG) does not receive inflow as a diversion from an upstream segment, then set IUP SEG $=0$.

IPRIOR An integer value that only is specified if IUPSEG > 0 (do not specify a value in this field if IUP SEG $=0$ or IUPSEG < 0). IPRIOR defines the prioritization system for diversion, such as when insufficient water is available to meet all diversion stipulations, and is used in conjunction with the value of FLOW (specified below).

- When IPRIOR $=0$, then if the specified diversion flow (FLOW) is greater than the flow available in the stream segment from which the diversion is made, the diversion is reduced to the amount available, which will leave no flow available for tributary flow into a downstream tributary of segment IUP SEG.

- When IPRIOR = -1, then if the specified diversion flow (FLOW) is greater than the flow available in the stream segment from which the diversion is made, no water is diverted from the stream. This approach assumes that once flow in the stream is sufficiently low, diversions from the stream cease, and is the "priority" algorithm that originally was programmed into the STR1 Package (Prudic, 1989).

- When IPRIOR = -2, then the amount of the diversion is computed as a fraction of the available flow in segment IUP SEG; in this case, $0.0 \leq \mathrm{FLOW} \leq 1.0$.

- When IPRIOR $=-3$, then a diversion is made only if the streamflow leaving segment IUP SEG exceeds the value of FLOW. If this occurs, then the quantity of water diverted is the excess flow and the quantity that flows from the last reach of segment IUP SEG into its downstream tributary (OUTSEG) is equal to FLOW. This represents a flood-control type of diversion, as described by Danskin and Hanson (2002).

NSTRPTS An integer value specified only when ICALC $=4$. It is used to dimension a table relating streamflow with stream depth and width as specified in Items 4e and 6e. NSTRPTS must be at least 2 but not more than 50 . If the table exceeds $3 \times 50$ (for streamflow, stream depth, and width) values, then MAXPTS in the allocation subroutine GWF1SFR1ALP will need to be increased from $3 \times 50$ to $3 \times$ (the desired maximum value).

A real number that is the streamflow (in units of volume per time) entering or leaving the upstream end of a stream segment (that is, into the first reach).

- If the stream is a headwater stream, FLOW defines the total inflow to the first reach of the segment. The value can be any number $\geq 0$.

- If the stream is a tributary stream, FLOW defines additional specified inflow to or withdrawal from the first reach of the segment (that is, in addition to the discharge from the upstream segment of which this is a tributary). This additional flow does not interact with the ground-water system. For example, a positive number might be used to represent direct outflow into a stream from a sewage treatment plant, whereas a negative number might be used to represent pumpage directly from a stream into an intake pipe for a municipal water treatment plant. (Also see additional explanatory notes below.)

- If the stream is a diversionary stream, and the diversion is from another stream segment, FLOW defines the streamflow diverted from the last reach of stream segment IUP SEG into the first reach of this segment. The diversion is computed or adjusted according to the value of IPRIOR.

- If the stream is a diversionary stream, and the diversion is from a lake, FLOW defines a fixed rate of discharge diverted from the lake into the first reach of this stream segment (unless the lake goes dry) and flow from the lake is not dependent on the value of ICALC. However, if FLOW $=0$, then the lake outflow into the first reach of this segment will be calculated on the basis of lake stage relative to the top of the streambed for the first reach using one of the methods defined by ICALC. 
RUNOFF A real number that is the volumetric rate of the diffuse overland runoff that enters the stream segment (in units of volume per time). The specified rate is apportioned to each reach of the segment in direct relation to the fraction of the total length of the stream channel in the segment that is present in each reach.

ETSW A real number that is the volumetric rate per unit area of water removed by evapotranspiration directly from the stream channel (in units of length per time). ETSW is defined as a positive value.

PPTSW A real number that is the volumetric rate per unit area of water added by precipitation directly on the stream channel (in units of length per time).

ROUGHCH A real number that is Manning's roughness coefficient for the channel in all reaches in this segment. This variable is only specified if ICALC $=1$ or 2 .

ROUGHBK A real number that is Manning's roughness coefficient for the overbank areas in all reaches in this segment. This variable is only specified if ICALC $=2$.

CDPTH A real number that is the coefficient used in the equation:

$\mathrm{DEPTH}=\mathrm{CDPTH} \times \mathrm{Q}^{\mathrm{FDPTH}}$ that relates stream depth in all reaches in this segment to streamflow. This variable is only specified if ICALC $=3$.

FDPTH A real number that is the coefficient used in the equation:

$\mathrm{DEPTH}=\mathrm{CDPTH} \times \mathrm{Q}^{\mathrm{FDPTH}}$ that relates stream depth in all reaches in this segment to streamflow. This variable is only specified if ICALC $=3$.

AWDTH A real number that is the coefficient used in the equation:

$\mathrm{WIDTH}=\mathrm{AWDTH} \times \mathrm{Q}^{\mathrm{BWDTH}}$ that relates stream width in all reaches in this segment to streamflow. This variable is only specified if ICALC $=3$.

BWDTH A real number that is the coefficient used in the equation:

WIDTH $=$ AWDTH $\times Q^{\text {BWDTH }}$ that relates stream width in all reaches in this segment to streamflow. This variable is only specified if ICALC $=3$.

6b. Data: $\{$ HCOND1 $\}$ TTHICKM1 $\}$ ELEVUP $\}$ \{WIDTH1 $\quad\{$ DEPTH1

$\{$ THTS1\} $\{$ THTI $\} \quad\{$ EPSI $\}$ UHHC1\}

HCOND1 Hydraulic conductivity of the streambed at the upstream end of this segment (units of length per time). This variable is read for each stress period when NSTRM is positive or when NSTRM is negative and ISEROPT is 0,4 , or 5 .

THICKM1 Thickness of streambed material at the upstream end of this segment (in units of length). This variable is read each stress period for all segments when NSTRM is positive or when NSTRM is negative and ISFROPT is 0 .

When ISFROPT is 4 or 5, the variable is read each stress period for a segment when ICALC is 0,3 , or 4 , and is read only the first stress period when ICALC is 1 or 2.

ELEVUP Elevation of the top of the streambed at the upstream end of this segment (in units of length). This variable is read each stress period for all segments when NSTRM is positive or when NSTRM is negative and ISFROPT is 0 . When ISFROPT is 4 or 5 , the variable is read each stress period for a segment when ICALC is 0,3 , or 4 , and is read only the first stress period when ICALC is 1 or 2 .

WIDTH1 Average width of the stream channel at the upstream end of this segment (in units of length). This variable is read each stress period for all segments identified with an ICALC of 0 and is not dependent on ISFROPT. When ICALC is 1, the variable is read each stress period when NSTRM is positive or when NSTRM is negative and ISFROP T is 0 or 1 , and is read only for the first stress period when ISFROPT is 2, 3, 4, or 5 .

DEPTH1 Average depth of water in the channel at the upstream end of this segment (units of length). This variable is read only when ICALC is 0 and is not dependent on the value of NSTRM or ISFROPT. The stream stage in a reach is assumed to equal the elevation of the top of the streambed plus the depth of water.

THTS1 Saturated volumetric water content in the unsaturated zone beneath the upstream end of this segment. This variable is read for the first stress period when ICALC is 1 or 2 and ISFROPT is 4 or 5.

THTI1 Initial volumetric water content beneath the upstream end of this segment. THTI1 must be less than or equal to THTS and greater than or equal to the THTS minus the specific yield defined in either LPF, BCF, or HUF. This variable is read for the first stress period when ICALC is 1 or 2 and ISFROPT is 4 or 5. 
EPS1 Brooks-Corey exponent used in the relation between water content and hydraulic conductivity within the unsaturated zone beneath the upstream end of this segment. This variable is read for the first stress period when ICALC is 1 or 2 and ISFROPT is 4 or 5.

UHC1 Vertical saturated hydraulic conductivity of the unsaturated zone beneath the upstream end of this segment. This variable is necessary when using BCF or HUF, whereas it is optional when using LPF. This variable is read only for the first stress period when ICALC is 1 or 2 and ISFROP T is 5.

6c. Data: $\{$ HCOND2 $\} \quad\{$ THICKM2 $\} \quad\{$ ELEVDN $\} \quad\{$ WIDTH 2$\} \quad\{$ DEPTH 2$\}$

$\{$ THTS 2$\} \quad\{$ THTI2 $\} \quad\{$ EPS 2$\} \quad\{$ UHC2 $\}$

HCOND2 Hydraulic conductivity of the streambed at the downstream end of this segment (units of length per time). This variable is read for each stress period when NSTRM is positive or when NSTRM is negative and ISFROP T is 0,4 . or 5 .

THICKM2 Thickness of streambed material at the downstream end of this segment (in units of length). This variable is read each stress period for all segments when NSTRM is positive or when NSTRM is negative and ISFROPT is 0 . When ISFROPT is 4 or 5 , the variable is read each stress period for a segment when ICALC is 0,3 , or 4 , and is read only the first stress period when ICALC is 1 or 2 .

ELEVDN Elevation of the top of the streambed at the downstream end of this segment (in units of length). This variable is read each stress period for all segments when NSTRM is positive or when NSTRM is negative and ISFROPT is 0 . When ISFROPT is 4 or 5 , the variable is read each stress period for a segment when ICALC is 0,3 , or 4 , and is read only the first stress period when ICALC is 1 or 2.

WIDTH2 Average width of the stream channel at the downstream end of this segment (in units of length). This variable is read each stress period for all segments identified with an ICALC of 0 and is not dependent on ISFROPT. When ICALC is 1 , the variable is read each stress period when NSTRM is positive or when NSTRM is negative and ISFROPT is 0 or 1, and is read only for the first stress period when ISFROPT is 2, 3, 4, or 5.

DEPTH2 Average depth of water in the channel at the downstream end of this segment (units of length). This variable is read only when ICALC is 0 and is not dependent on the value of NSTRM or ISFROPT. The stream stage in a reach is assumed to equal the elevation of the top of the streambed plus the depth of water.

THTS2 Saturated volumetric water content in the unsaturated zone beneath the downstream end of this segment. This variable is read for the first stress period when ICALC is 1 or 2 and ISFROPT is 4 or 5.

THTI2 Initial volumetric water content beneath the downstream end of this segment. THTI2 must be less than or equal to THTS and greater than or equal to THTS minus the specific yield defined in either LPF, BCF. or HUF. This variable is read for the first stress period when ICALC is 1 or 2 and ISFROP T is 4 or 5.

EPS2 Brooks-Corey exponent used in the relation between water content and hydraulic conductivity within the unsaturated zone beneath the downstream end of this segment. This variable is read for the first stress period when ICALC is 1 or 2 and ISFROPT is 4 or 5 .

UHC2 Vertical saturated hydraulic conductivity of the unsaturated zone beneath the downstream end of this segment. This variable is necessary when using BCF or HUF, whereas it is optional when using LPF. This variable is read only for the first stress period when ICALC is 1 or 2 and ISFROP T is 5.

\section{If ICALC $=2$ :}

6d. Data: XCPT1 XCPT2 ... XCPT8

Data: $\quad \mathrm{ZCPT} 1 \mathrm{ZCPT} 2 \ldots \mathrm{ZCPT} 8$

See Item 4, Part 4e for variable definitions. These variables are read only for the first stress period if ISFROPT is 2, 3, 4, or 5 (that is, unsaturated flow is active) because the channel geometry cannot change during the simulation when unsaturated flow is active. 
If ICALC = 4:

6e. Data: FLOWTAB (1) FLOWTAB (2) ... FLOWTAB (NSTRPTS)

Data: DPTHTAB (1) DPTHTAB (2) ... DPTHTAB (NSTRPTS)

Data: WDTHTAB (1) WDThtAB (2) ... WDTHTAB (NSTRPTS)

See Item 4, Part 4f for variable definitions.

\section{If Ground-Water Transport (GWT) Process is active (Ftype "GWT" exists), then read Part 6f NSOL times (where NSOL is the number of solutes being simulated):}

\section{6f. Data: $\{$ CONCQ (NSOL) $\}$ CONCRUN (NSOL) CONCPPT (NSOL)}

See Item 4, Part 4g for variable definitions.

Note 21: Item 6 must be completed ITMP times. The data need not be defined in sequential order by stream segment number. All active segments in the stream network must be defined for each stress period through a combination of ITMP and Item 6 and NP and Item 7.

Note 22: If ITMP $\leq 0$, then Item 6 is excluded for this stress period. If I TMP $<0$, then values for Item 6 from the previous stress period are reused. If ITMP $=0$, then no Item 6 records are read, and all segments must be defined using parameters.

Note 23: If Item 6, Part $6 \mathrm{f}$ is included because solute transport is being simulated, then Part $6 \mathrm{f}$ should consist of one record (line) for each solute; each record must contain two or three values; and there must be as many records as the number of solutes being simulated (NSOL). The default value of NSOL is 1 and the presently documented version of MODFLOW-GWT is limited to simulating one solute.

Note 24: All the explanatory notes applicable to Item 4 (except those related to parameters) are also relevant to Item 6.

If $\mathrm{NP}>\mathbf{0}$, then:

7. Data: Pname [Iname]

Pname The name of a parameter that is being used in the current stress period. Repeat Item 7 NP times (see Item 5). Iname An instance name that is read only if Pname is a time-varying parameter. Multiple instances of the same time-varying parameter are not allowed in a stress period.

\section{Stream Gaging (Monitoring) Station File (GAGE)}

Cells of the model grid can be designated as "stream gaging station" locations. At each designated cell (or stream reach), the time, stage, streamflow out of that reach, the streambed seepage, unsaturated storage, change in unsaturated storage, and ground-water recharge will be written to a separate output file to facilitate model output evaluation and graphical post processing of the calculated data. Several options are available to print additional information. The input file for specifying gaging station locations is read if the file type (Ftype) "GAGE" is included in the MODFLOW name file. The output file will contain two header lines that provide relevant information (the text will be contained within quotes). 


\section{For Each Simulation, if Gage Package is Used:}

1. Data: NUMGAGE

NUMGAGE Number of gaging stations.

\section{For Each Gaging Station:}

\section{Data: GAGESEG GAGERCH UNIT OUTTYPE}

GAGESEG An integer value that is the stream segment number where gage is located.

GAGERCH An integer value that is the stream reach number where gage is located.

UNIT An integer value that is the unit number of output file for this gage.

OUTTYPE An integer value that is a flag for type of expanded listing desired in output file:

0 Use standard default listing of time, stage, outflow, and solute concentration.

$1 \quad$ Default values plus depth, width, and flow at midpoint.

2 Default values plus streambed conductance for the reach, head difference across streambed, and hydraulic gradient across streambed.

3 Default values plus solute load in stream (if GWT is active).

$4 \quad$ All of the above.

5 Used for diversions to provide a listing of time, stage, flow diverted, maximum assigned diversion rate, flow at end of upstream segment prior to diversion, solute concentration, and solute load.

Used for unsaturated flow routing to provide a listing of time, stage, ground-water head, streambed seepage, change in unsaturated storage, and recharge.

Used for unsaturated flow routing to provide a listing of time and the unsaturated water content profile beneath the stream. Two profiles are printed. The first is the volume average water content of ISUZN unsaturated cells beneath a stream reach. The second profile is the volume averaged water content beneath the low flow channel only. If ISUZN $=1$ then both water content profiles will be the same.

Note 1: A unique unit number must be specified for each stream gaging station and the MODFLOW name file (see Harbaugh and others, 2000, p. 42-44) must specify the file for each unit. The file type in the name file must be "DATA".

Note 2: If the LAK3 Package is also active, a gaging station may be placed on a lake. In this case, only two required variables and one optional variable are read. The first variable should be the negative value of the lake number and the second is the unit number for the output. The original description of the Gage Package (Merritt and Konikow, 2000, p. 57) did not include additional print options listed for OUTTYPE. For a gaging station on a lake, a minus sign on the unit number is a flag indicating that OUTTYPE for a lake will be read.

Note 3: Data Set 2 must include exactly NUMGAGE lines (records) of data. If NUMGAGE > 1, it is permissible to interleaf the Item 2 lines for stream gaging stations with lines for lake gages. Data lines (records) within Item 2 can be listed in any arbitrary order.

Note 4: Solute is not routed through the unsaturated zone. For this reason, solute routing between streams and ground water cannot be simulated when using the unsaturated flow option in SFR2.

Note 5: Unsaturated flow is not simulated beneath lakes. 


\section{Appendix 2: Selected Input Data and Printed Results for the Hypothetical Test Simulation.}

The hypothetical test simulation is designed to demonstrate the capability of version 2 of the Streamflow-Routing (SFR2) Package that includes unsaturated flow. The test simulation simulates recharge occurring from stream seepage in an alluvial basin that is separated from ground water by an unsaturated zone. The test simulation includes a sensitivity analysis of the streambed thickness on the timing and magnitude of recharge. A description of the basin-fill aquifer is presented in figure 6 . Variables used to route flow in streams and flow through the aquifer and results from these simulations are presented in the section titled "Hypothetical Test Simulation" and in table 4 and figure 7.

Selected sections of several key input and output data files are shown below-sometimes with annotations; gaps in the listings are indicated by an ellipsis. A complete set of the files is available for distribution over the Internet. Contents of some files are enclosed in a border and explanations are noted outside of the border; for other files, explanations are sometimes included as comments following a semi-colon on the line being explained. Information pertaining specifically to the SFR2 Package is highlighted by shading. 


\section{Listing of Selected Input Data Sets for the Hypothetical Test Simulation}

Following (enclosed in a border) are the contents of the MODFLOW name file for the hypothetical test simulation; explanations are noted outside of border:

File name: Testsfr2.nam

\begin{tabular}{|c|c|c|}
\hline LIST & 12 testsfr2.lst & $\rightarrow$ Output file for MODFLOW \\
\hline BAS 6 & 41 testsfr2.bs 6 & $\rightarrow$ Input file for Basic Package \\
\hline LPF & 42 testsfr2.lpf & $\rightarrow$ Input file for Layer Property Flow Package \\
\hline pcg & 43 testsfr2.pcg & $\rightarrow$ Input file for pcg solver Package \\
\hline OC & 44 testsfr2.oc & $\rightarrow$ Input file for Output Control option \\
\hline global & 11 testsfr2.glo & $\rightarrow$ Output file for global output \\
\hline DATA & 15 testsfr2.ghb & $\rightarrow$ Input file for general head boundary \\
\hline DATA & 83 testsfr2.gg1 & $\rightarrow$ Seepage and recharge for stream reach 20 \\
\hline DATA & 84 testsfr2.gg2 & $\rightarrow$ Water content profiles for reach 20 \\
\hline DATA & 88 testsfr2.gg6 & $\rightarrow$ Water content profiles for reach 60 \\
\hline DATA & 89 testsfr2.gg7 & $\rightarrow$ Seepage and recharge for stream reach 80 \\
\hline DATA & 90 testsfr2.gg8 & $\rightarrow$ Water content profiles for reach 80 \\
\hline$\uparrow$ & $\uparrow$ & \\
\hline 1 & 3 & \\
\hline \multicolumn{3}{|c|}{1 Ftype (that is, the type of file) } \\
\hline \multicolumn{3}{|c|}{2 Unit number } \\
\hline \multicolumn{3}{|c|}{3 File name (name chosen to reflect contents of file) } \\
\hline
\end{tabular}


Following (enclosed in a border) are the contents of the Basic Package input file for the hypothetical test simulation; explanations are noted outside of border:

File name: testsfr2.bs6

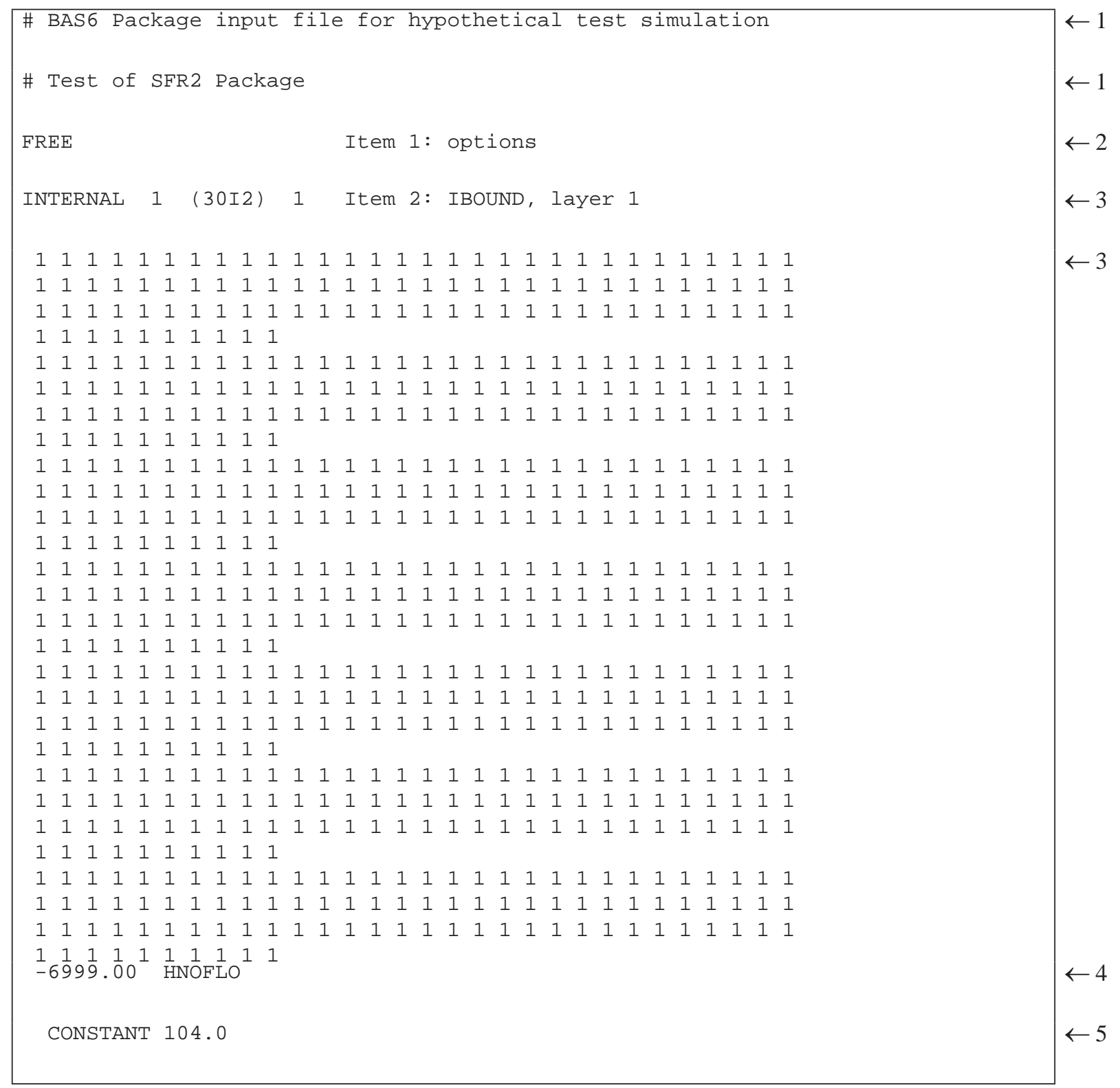

1 Two header lines of comments.

2 Options line.

3 IBOUND array.

4 Head value assigned to inactive cells.

5 Initial head information for transient simulation values are rounded to nearest tenth of meter. 
Following (enclosed in a border) are the contents of the Discretization Package input file for the hypothetical test simulation; explanations are noted outside of border:

File name: testsfr2.dis

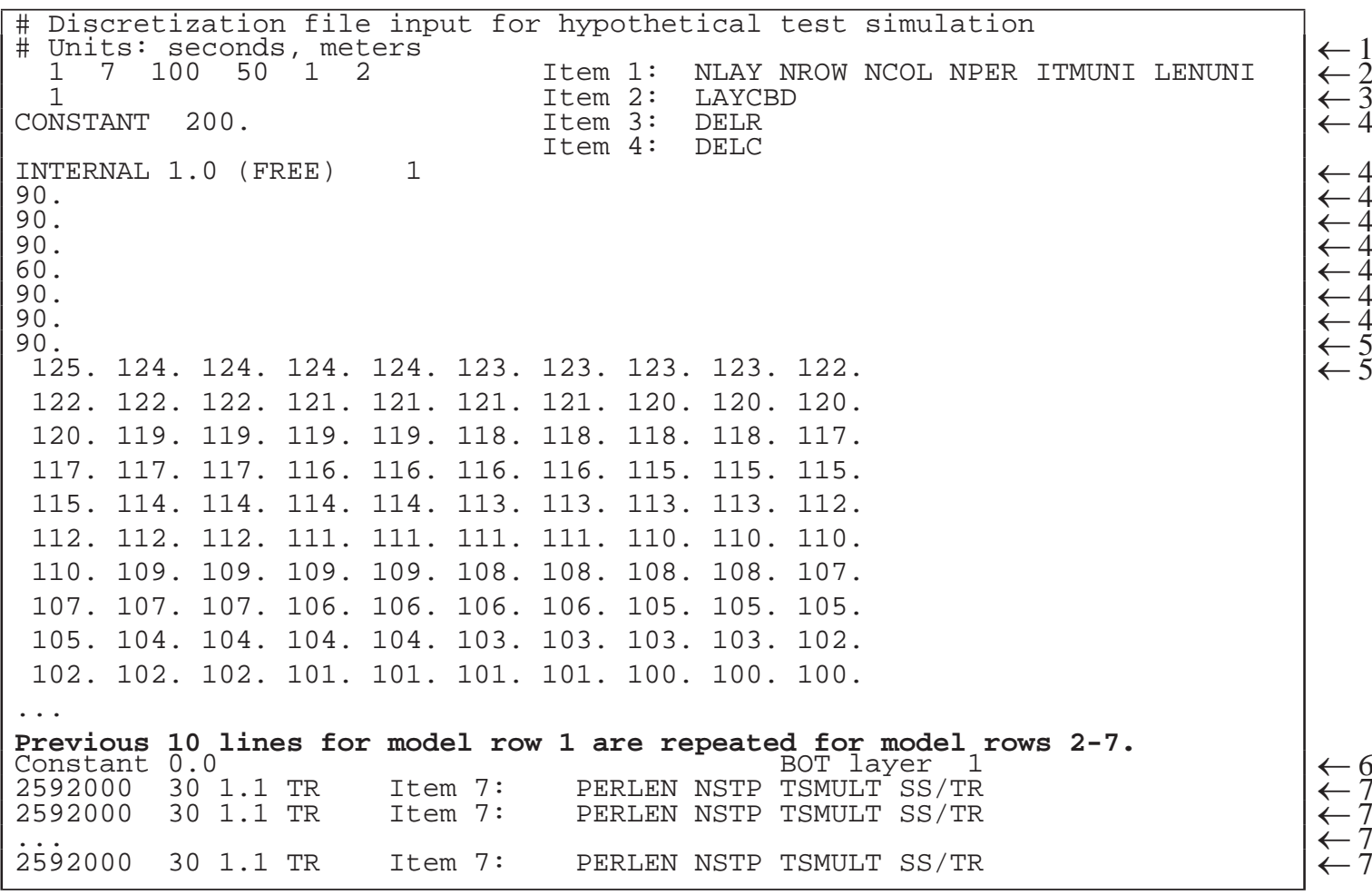

1 Grid characterization data.

2 Flags for quasi-3D simulation.

3 Row discretization data.

${ }^{4}$ Column discretization data.

5 Top elevations for layer 1 read from following data.

6 Bottom elevations for layer 1 read from following data.

7 Time step and stress period information. 
Following (enclosed in a border) are the contents of the Layer-Property Flow Package input file for the hypothetical test simulation; explanations are noted outside of border:

File name: testsfr2.lpf

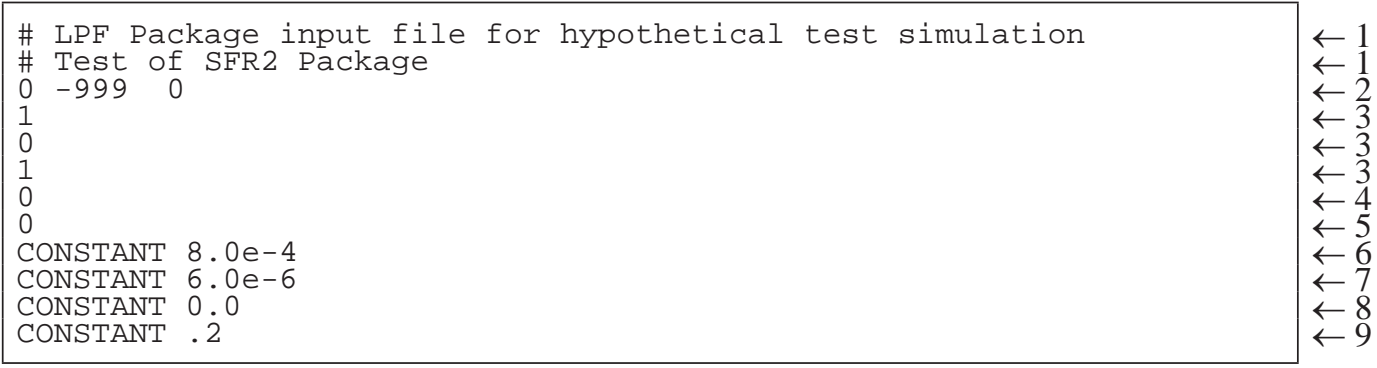

1 Comment lines.

2 Flag for cell-by-cell flow terms, head in cell for wet-dry simulations, and flag related to wet-dry simulations.

3 Layer type, method for computing transmissivity, horizontal anisotropy.

${ }^{4}$ Flag to determine vertical hydraulic conductivity.

5 Flag to determine if rewetting is active.

${ }^{6}$ Hydraulic conductivity data for layer 1 read from following data.

7 Vertical hydraulic conductivity.

8 Specific storage for layer 1.

9 Specific yield for layer 1.

Following (enclosed in a border) are the contents of the General-Head Boundary Package input file for the hypothetical test simulation; explanations are noted outside of border:

File name: testsfr2.ghb

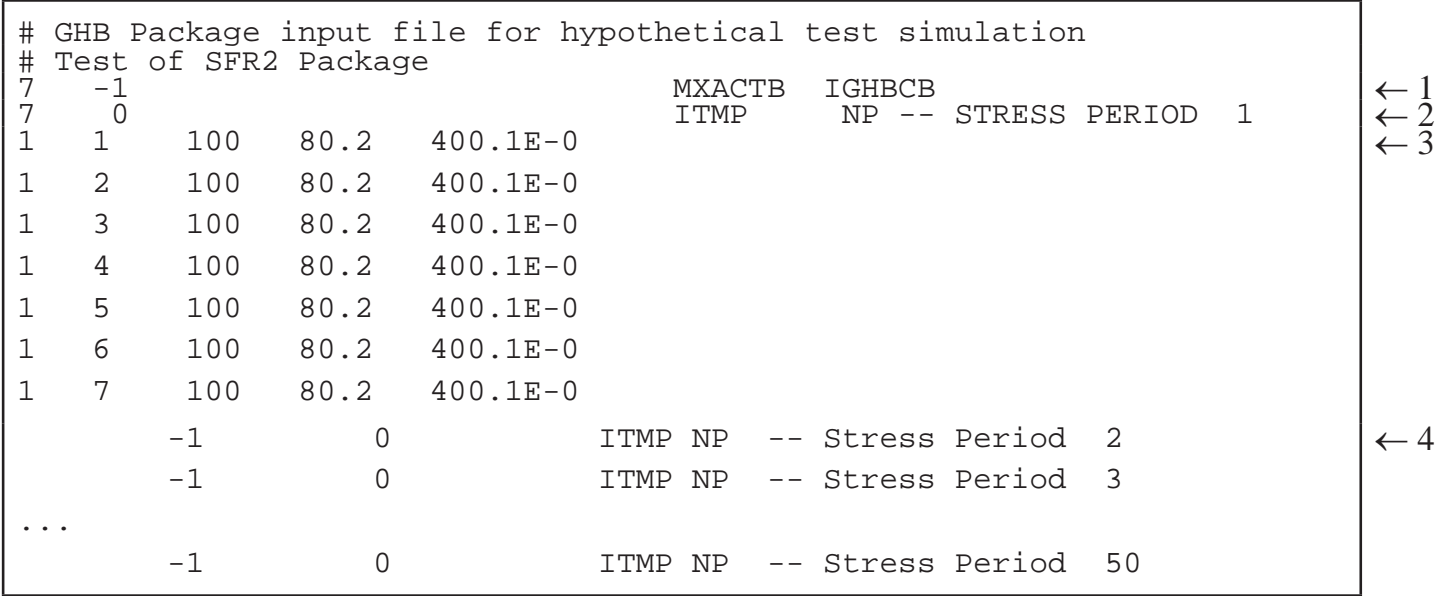

${ }_{1}$ Maximum number of general-head boundary cells and unit number for storing cell-by-cell flow terms.

2 Read flags for stress period 1.

3 General-head boundary cells for stress period 1.

${ }^{4}$ Read flags for stress period 2 (reusing information from stress period 1).

Following (enclosed in a border) are the contents of the Preconditioned Conjugate-Gradient Package input file for the hypothetical test simulation; explanations are noted outside of border:

File name: testsfr2.pcg

\begin{tabular}{|c|c|c|c|c|c|c|c|c|c|c|c|}
\hline $\begin{array}{r}300 \\
.00001\end{array}$ & $\begin{array}{ll}20 & 1 \\
.00001\end{array}$ & .9 & 2 & 0 & 1 & 0.96 & $\begin{array}{ll}\text { MXITER ITERI NPCOND } \\
\text { HCLOSE RCLOSE RELAX }\end{array}$ & NBPOL & IPRPCG & MUTPCG & DAMP \\
\hline
\end{tabular}

\footnotetext{
1 Maximum iterations, number of inner iterations, flag for matrix conditioning method.

2 Head change criterion, residual criterion for closure, relaxation parameter, upper bound on max eigenvalue NBPOL=2 when option is not used, printout interval for PCG, flag for printing convergence information, dampening factor.
} 
Following (enclosed in a border) are the contents of the Streamflow-Routing (SFR2) Package input file for the hypothetical test simulation; explanations are noted outside of border:

File name: Testsfr2.sfr

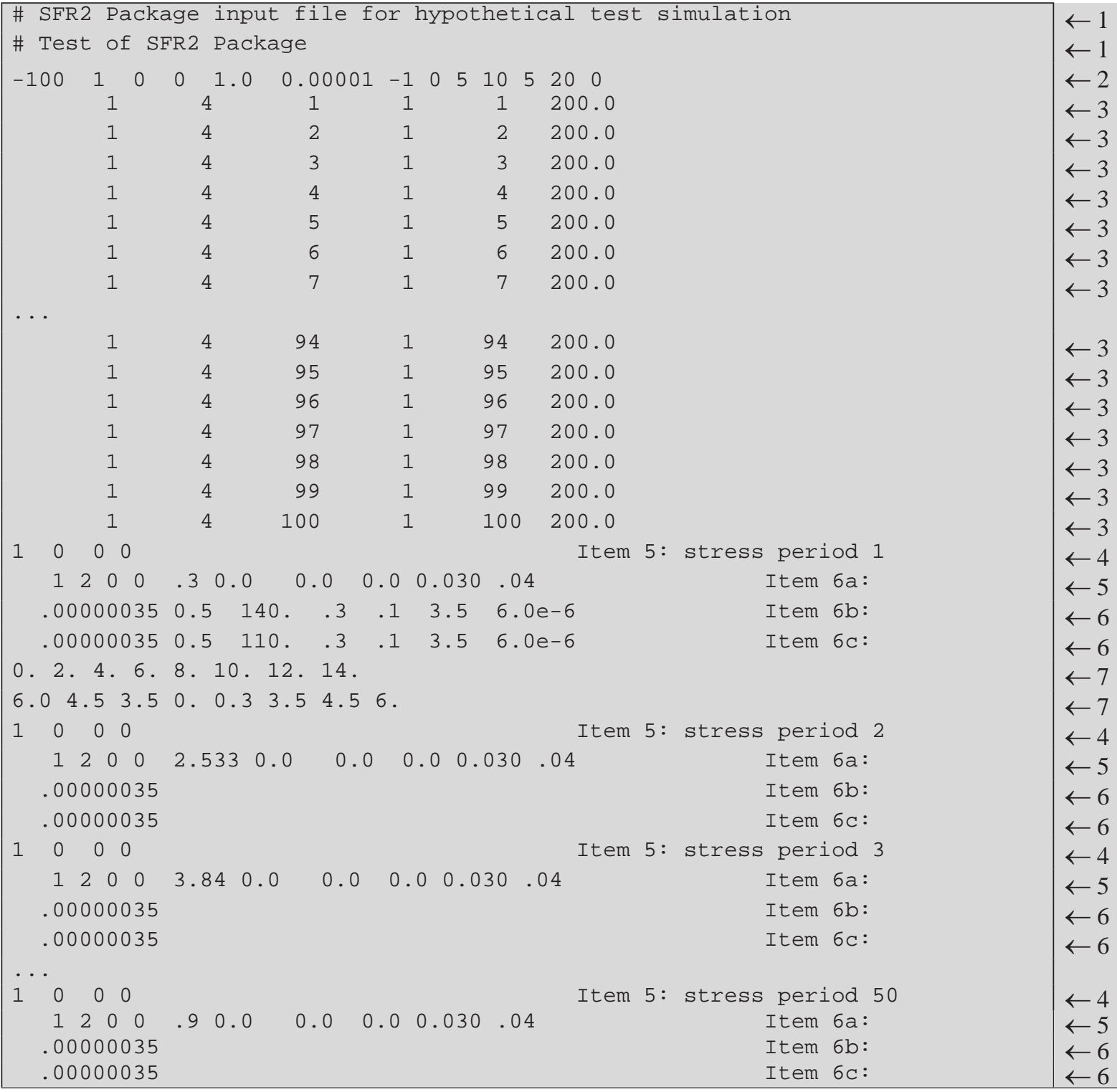

1 Optional text line for comments.

2 Basic stream network description (Input Item 1).

3 Stream reach descriptions, unsaturated flow variables(Input Item 2).

${ }^{4}$ Read and print flags for stress period (Input Item 5).

5 General stream segment data (Input item 6a).

6 Stream segment data for upstream and downstream ends (Input Items $6 \mathrm{~b} \& 6 \mathrm{c}$ ).

7 Stream segment data for 8-point cross section (Input Item 6d). 


\section{Documentation of the Streamflow-Routing (SFR2) Package-A Modification to SFR1}

Following (enclosed in a border) are the contents of the Output-Control input file for the hypothetical test simulation. Input was constructed in the optional style using words:

File name: testsfr2.oc

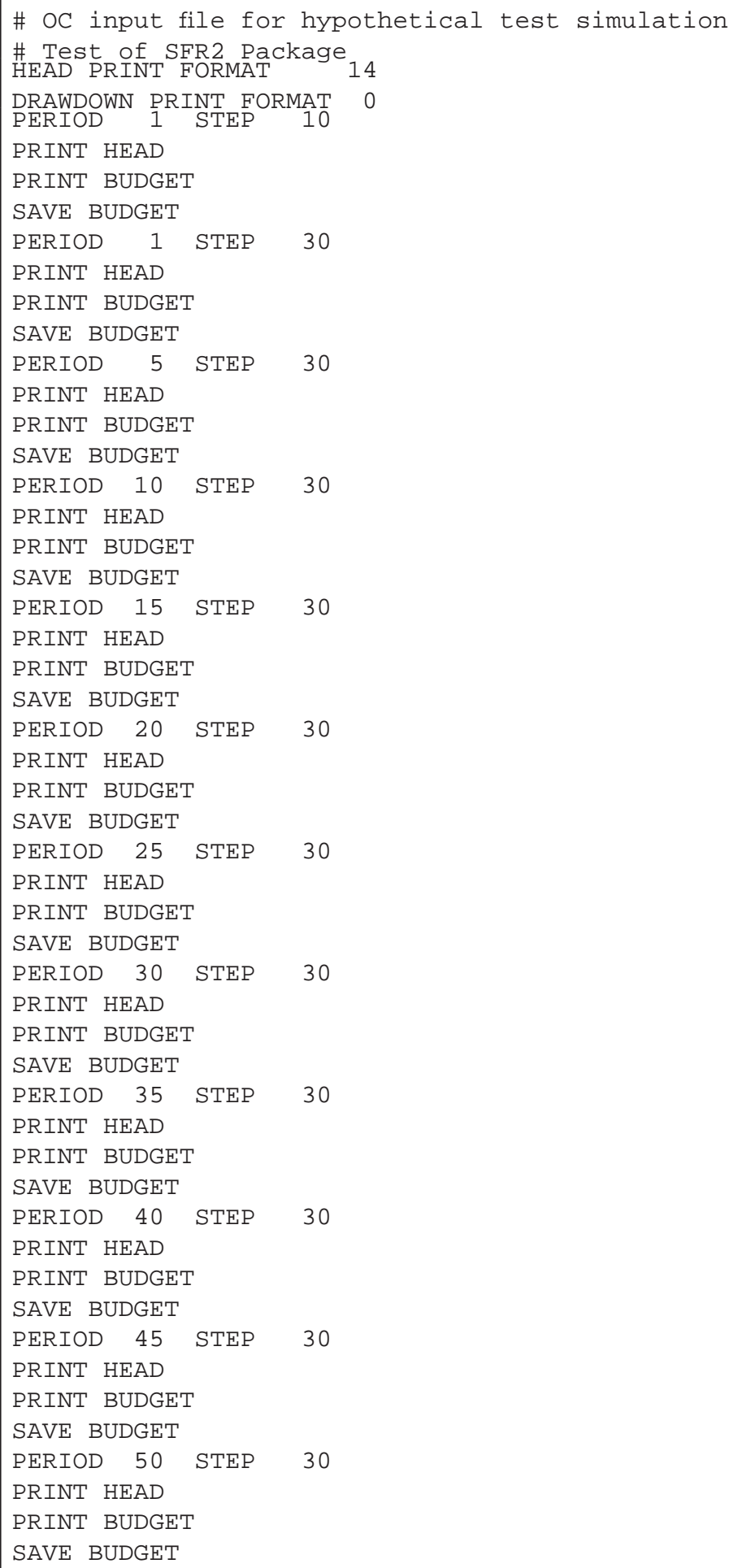


Following are the contents of the Gage package input file for the hypothetical test simulation; explanations are noted as comments at the end of each record (Unit numbers are linked to a file name through the Ftype "DATA" in the MODFLOW name file):

File name: testsfr2.gag

\begin{tabular}{|llllllll}
\hline 8 & \multicolumn{7}{c|}{ NUMGAgE (number of gaging stations) } \\
1 & 20 & 83 & 6 & Stream Segment \& Reach \#; Output file for Gage 1; Output option \\
1 & 20 & 84 & 7 & Stream Segment \& Reach \#; Output file for Gage 2; Output option \\
1 & 40 & 85 & 6 & Stream Segment \& Reach \#; Output file for Gage 3; Output option \\
1 & 40 & 86 & 7 & Stream Segment \& Reach \#; Output file for Gage 4; Output option \\
1 & 60 & 87 & 6 & Stream Segment \& Reach \#; Output file for Gage 5; Output option \\
1 & 60 & 88 & 7 & Stream Segment \& Reach \#; Output file for Gage 6; Output option \\
1 & 80 & 89 & 6 & Stream Segment \& Reach \#; Output file for Gage 7; Output option \\
1 & 80 & 90 & 7 & Stream Segment \& Reach \#; Output file for Gage 8; Output option
\end{tabular}




\section{Documentation of the Streamflow-Routing (SFR2) Package-A Modification to SFR1 \\ Listing of Selected Output Files for the Test Simulation}

Following are the contents of the main MODFLOW listing file of the hypothetical test simulation:

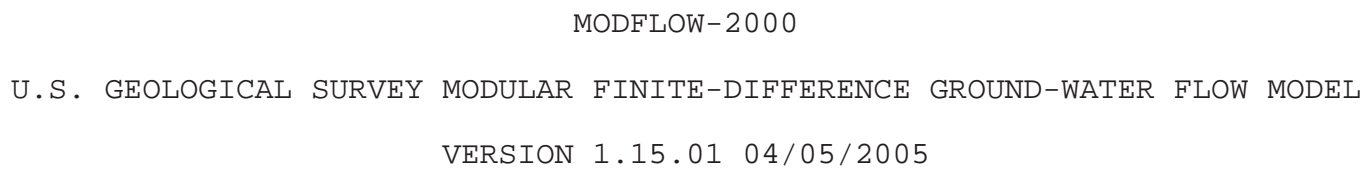




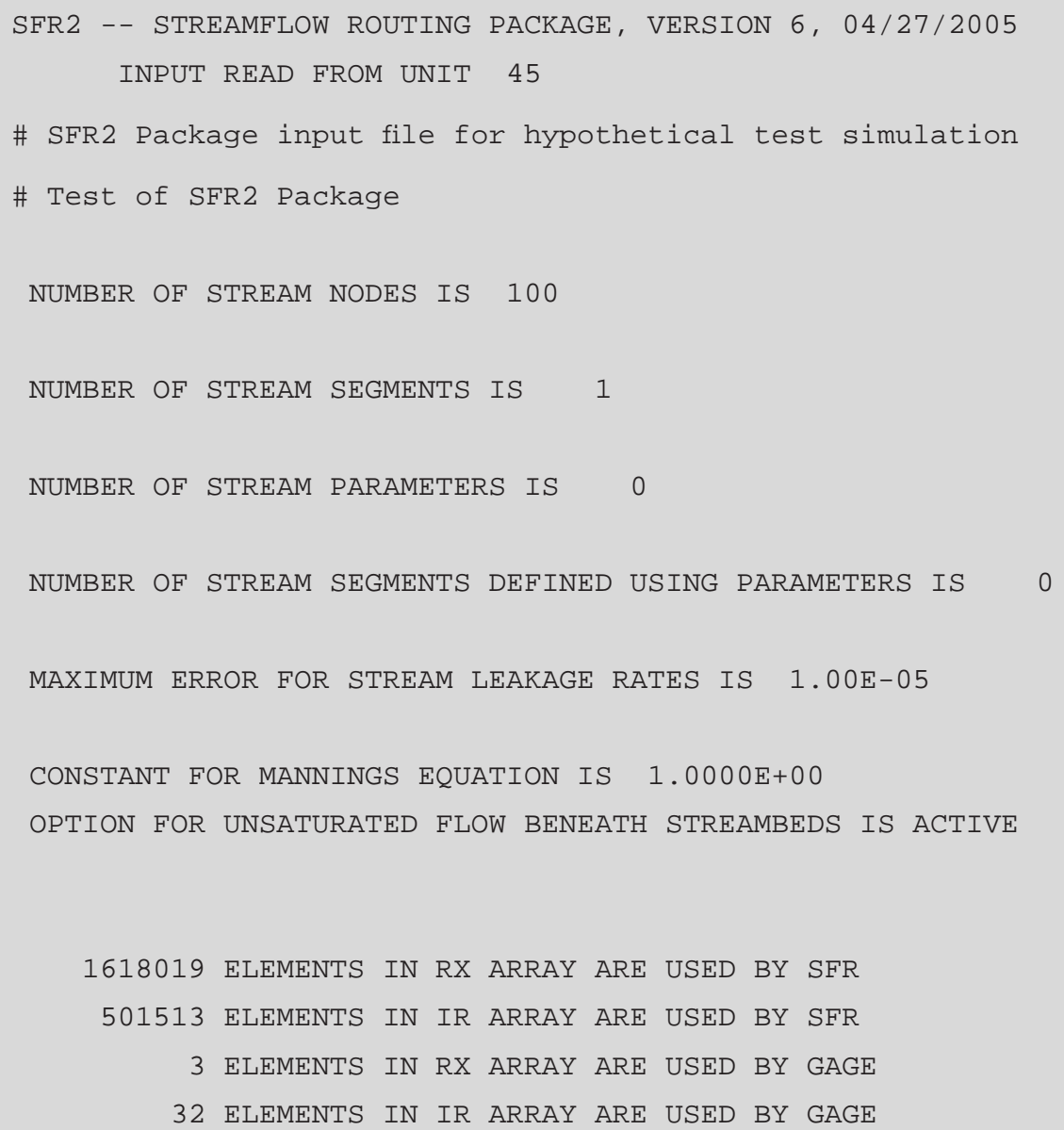




$\begin{array}{llllllllll}\text { BOUNDARY } & 6 & \text { LAYER } & 1 & \text { ROW } & 6 & \text { COL } & 100 & \text { RATE } & -0.300730 \\ \text { BOUNDARY } & 7 & \text { LAYER } & 1 & \text { ROW } & 7 & \text { COL } & 100 & \text { RATE } & -0.300835\end{array}$

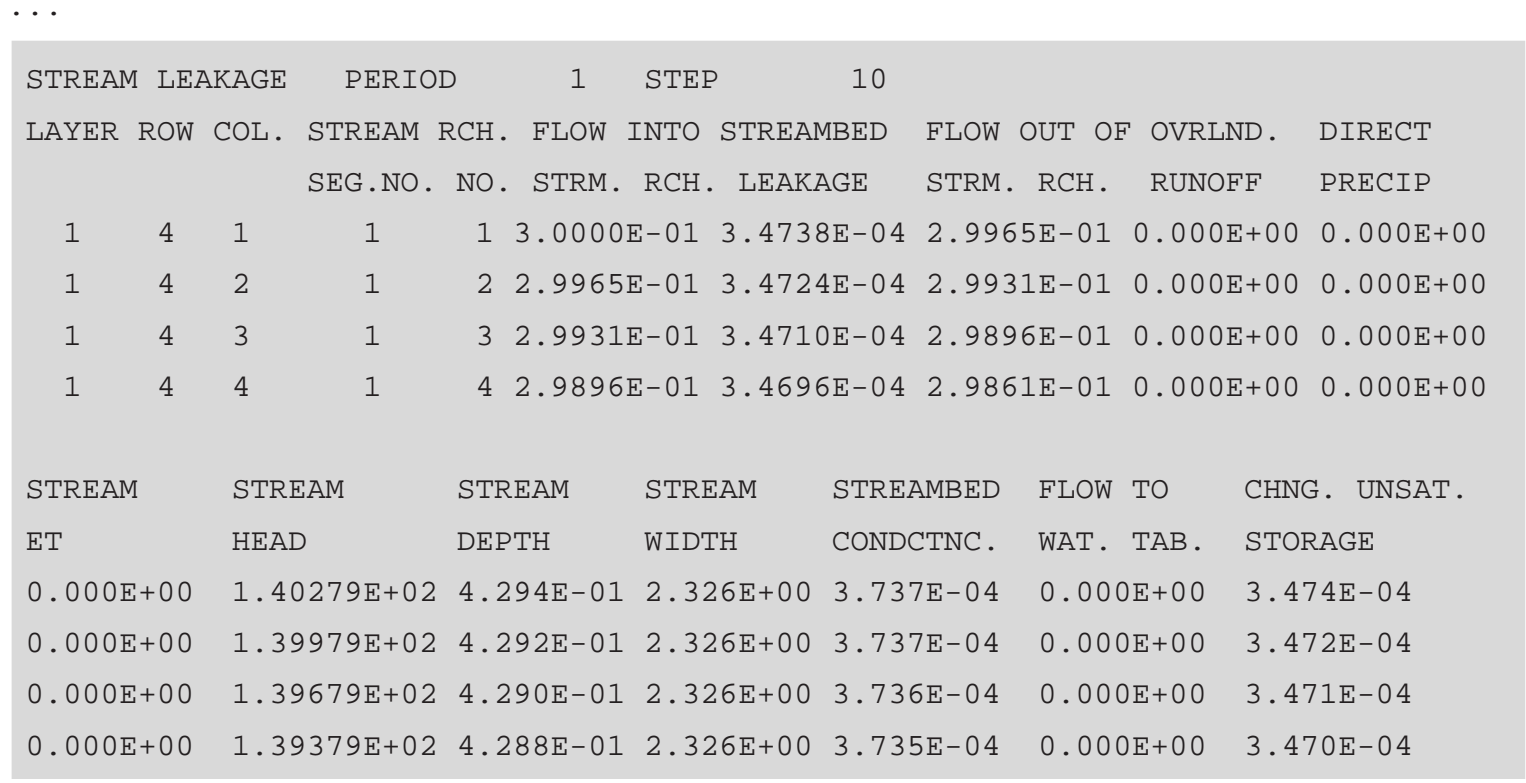

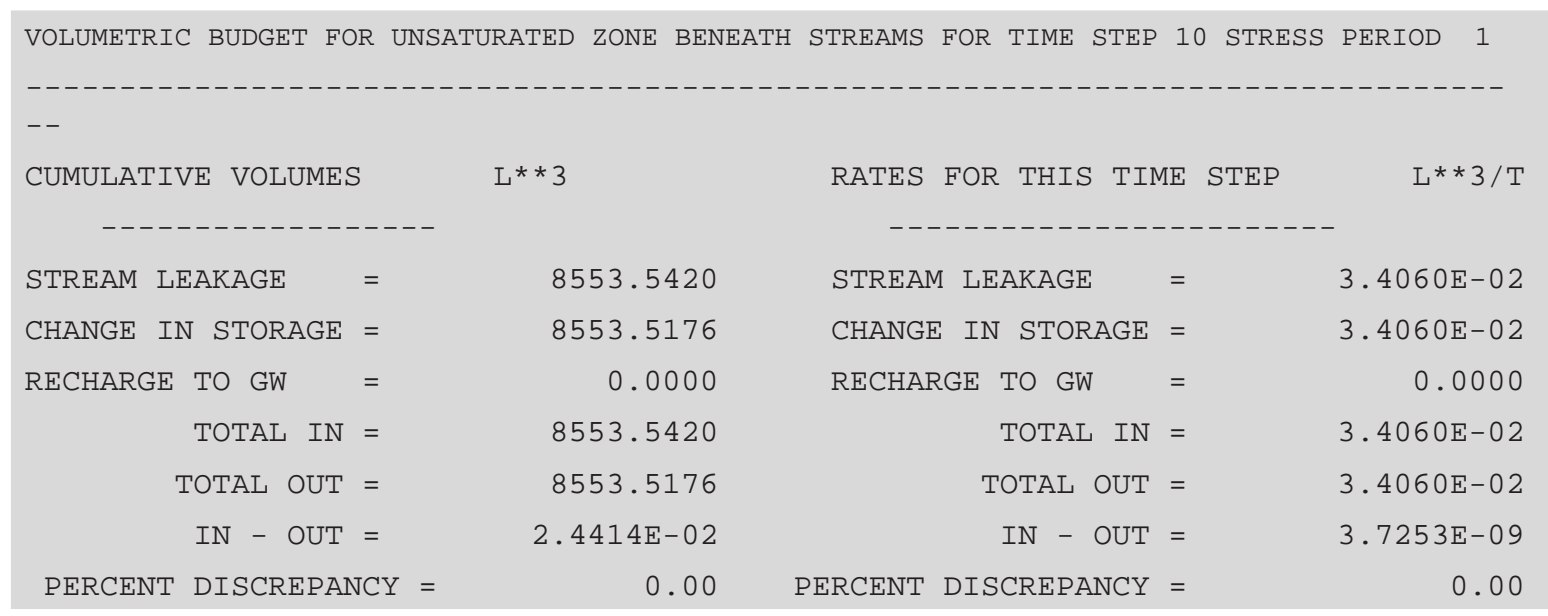
$\cdots$

HEAD IN LAYER 1 AT END OF TIME STEP 10 IN STRESS PERIOD 1

$\begin{array}{rrrrrrrrrr}1 & 2 & 3 & 4 & 5 & 6 & 7 & 8 & 9 & 10 \\ 11 & 12 & 13 & 14 & 15 & 16 & 17 & 18 & 19 & 20 \\ 21 & 22 & 23 & 24 & 25 & 26 & 27 & 28 & 29 & 30 \\ 31 & 32 & 33 & 34 & 35 & 36 & 37 & 38 & 39 & 40 \\ 41 & 42 & 43 & 44 & 45 & 46 & 47 & 48 & 49 & 50 \\ 51 & 52 & 53 & 54 & 55 & 56 & 57 & 58 & 59 & 60 \\ 61 & 62 & 63 & 64 & 65 & 66 & 67 & 68 & 69 & 70 \\ 71 & 72 & 73 & 74 & 75 & 76 & 77 & 78 & 79 & 80 \\ 81 & 82 & 83 & 84 & 85 & 86 & 87 & 88 & 89 & 90 \\ 91 & 92 & 93 & 94 & 95 & 96 & 97 & 98 & 99 & 100\end{array}$




\begin{tabular}{|c|c|c|c|c|c|c|c|c|c|c|}
\hline \multirow[t]{10}{*}{1} & 104.0 & 104.0 & 104.0 & 104.0 & 104.0 & 104.0 & 104.0 & 104.0 & 104.0 & 104.0 \\
\hline & 104.0 & 104.0 & 104.0 & 104.0 & 104.0 & 104.0 & 104.0 & 104.0 & 104.0 & 104.0 \\
\hline & 104.0 & 104.0 & 104.0 & 104.0 & 104.0 & 104.0 & 104.0 & 104.0 & 104.0 & 104.0 \\
\hline & 104.0 & 104.0 & 104.0 & 104.0 & 104.0 & 104.0 & 104.0 & 104.0 & 104.0 & 104.0 \\
\hline & 104.0 & 104.0 & 104.0 & 104.0 & 104.0 & 104.0 & 104.0 & 104.0 & 104.0 & 104.0 \\
\hline & 104.0 & 104.0 & 104.0 & 104.0 & 104.0 & 104.0 & 104.0 & 104.0 & 104.0 & 104.0 \\
\hline & 104.0 & 104.0 & 104.0 & 104.0 & 104.0 & 104.0 & 104.0 & 104.0 & 104.0 & 104.0 \\
\hline & 104.0 & 104.0 & 104.0 & 104.0 & 104.0 & 104.0 & 104.0 & 104.0 & 104.0 & 104.0 \\
\hline & 104.0 & 104.0 & 103.9 & 103.8 & 103.7 & 103.5 & 103.3 & 103.1 & 102.9 & 102.6 \\
\hline & 102.3 & 102.0 & 101.6 & 101.0 & 100.4 & 99.3 & 96.9 & 92.6 & 85.5 & 75.1 \\
\hline
\end{tabular}

$\cdots$

$\begin{array}{rrrrrrrrrr}104.0 & 104.0 & 104.0 & 104.0 & 104.0 & 104.0 & 104.0 & 104.0 & 104.0 & 104.0 \\ 104.0 & 104.0 & 104.0 & 104.0 & 104.0 & 104.0 & 104.0 & 104.0 & 104.0 & 104.0 \\ 104.0 & 104.0 & 104.0 & 104.0 & 104.0 & 104.0 & 104.0 & 104.0 & 104.0 & 104.0 \\ 104.0 & 104.0 & 104.0 & 104.0 & 104.0 & 104.0 & 104.0 & 104.0 & 104.0 & 104.0 \\ 104.0 & 104.0 & 104.0 & 104.0 & 104.0 & 104.0 & 104.0 & 104.0 & 104.0 & 104.0 \\ 104.0 & 104.0 & 104.0 & 104.0 & 104.0 & 104.0 & 104.0 & 104.0 & 104.0 & 104.0 \\ 104.0 & 104.0 & 104.0 & 104.0 & 104.0 & 104.0 & 104.0 & 104.0 & 104.0 & 104.0 \\ 104.0 & 104.0 & 104.0 & 104.0 & 104.0 & 104.0 & 104.0 & 104.0 & 104.0 & 104.0 \\ 104.0 & 104.0 & 103.9 & 103.8 & 103.7 & 103.5 & 103.3 & 103.1 & 102.9 & 102.6 \\ 102.3 & 102.0 & 101.6 & 101.0 & 100.4 & 99.3 & 96.9 & 92.6 & 85.5 & 75.1\end{array}$

1

VOLUMETRIC BUDGET FOR ENTIRE MODEL AT END OF TIME STEP 10 IN STRESS PERIOD 1

\begin{tabular}{|c|c|c|c|c|}
\hline CUMULATIVE VOLUMES & RATES & FOR THIS TIME STEP & $\mathrm{L} * \star 3 / \mathrm{T}$ & \\
\hline $\begin{array}{l}\text { IN }: \\
---\end{array}$ & & $\begin{array}{l}\text { IN : } \\
---\end{array}$ & & \\
\hline STORAGE $=$ & 1302278.8750 & STORAGE $=$ & $=$ & 2.0056 \\
\hline CONSTANT HEAD = & 0.0000 & CONSTANT HEAD $=$ & $=$ & 0.0000 \\
\hline HEAD DEP BOUNDS = & 0.0000 & HEAD DEP BOUNDS = & $=$ & 0.0000 \\
\hline STREAM LEAKAGE = & 0.0000 & STREAM LEAKAGE $=$ & $=$ & 0.0000 \\
\hline TOTAL IN $=$ & 1302278.8750 & TOTAL IN $=$ & $=$ & 2.0056 \\
\hline OUT: & & OUT: & & \\
\hline---- & & ---- & & \\
\hline STORAGE $=$ & 29.8633 & STORAGE $=$ & $=$ & $1.8395 \mathrm{E}-04$ \\
\hline CONSTANT HEAD = & 0.0000 & CONSTANT HEAD = & $=$ & 0.0000 \\
\hline HEAD DEP BOUNDS = & 1302252.2500 & HEAD DEP BOUNDS $=$ & $=$ & 2.0058 \\
\hline STREAM LEAKAGE = & 0.0000 & STREAM LEAKAGE = & $=$ & 0.0000 \\
\hline TOTAL OUT $=$ & 1302282.1250 & TOTAL OUT $=$ & $=$ & 2.0060 \\
\hline $\mathrm{IN}-\mathrm{OUT}=$ & -3.2500 & IN - OUT $=$ & $=$ & $-3.4690 \mathrm{E}-04$ \\
\hline ENT DISCREPANCY = & 0.00 & PERCENT DISCREPANCY & $=$ & -0.02 \\
\hline
\end{tabular}




\begin{tabular}{|c|c|c|c|c|c|c|c|}
\hline & TIME & E SUMM & $\begin{array}{l}\text { ARY AT END O } \\
\text { SECONDS }\end{array}$ & $\begin{array}{l}\text { F TIME STEP } \\
\text { MINUTES }\end{array}$ & $\begin{array}{l}10 \text { IN STRESS } \\
\text { HOURS }\end{array}$ & $\begin{array}{l}\text { S PERIOD } \\
\text { DAYS }\end{array}$ & 1 YEARS \\
\hline TIME & STEP L & LENGTH & 37155 & 619.25 & 10.321 & 0.43004 & $1.17738 \mathrm{E}-03$ \\
\hline STRESS & PERIOD & D TIME & $2.51132 \mathrm{E}+05$ & 4185.5 & 69.759 & 2.9066 & $7.95791 \mathrm{E}-03$ \\
\hline & TOTAL & L TIME & $2.51132 \mathrm{E}+05$ & 4185.5 & 69.759 & 2.9066 & $7.95791 \mathrm{E}-03$ \\
\hline
\end{tabular}

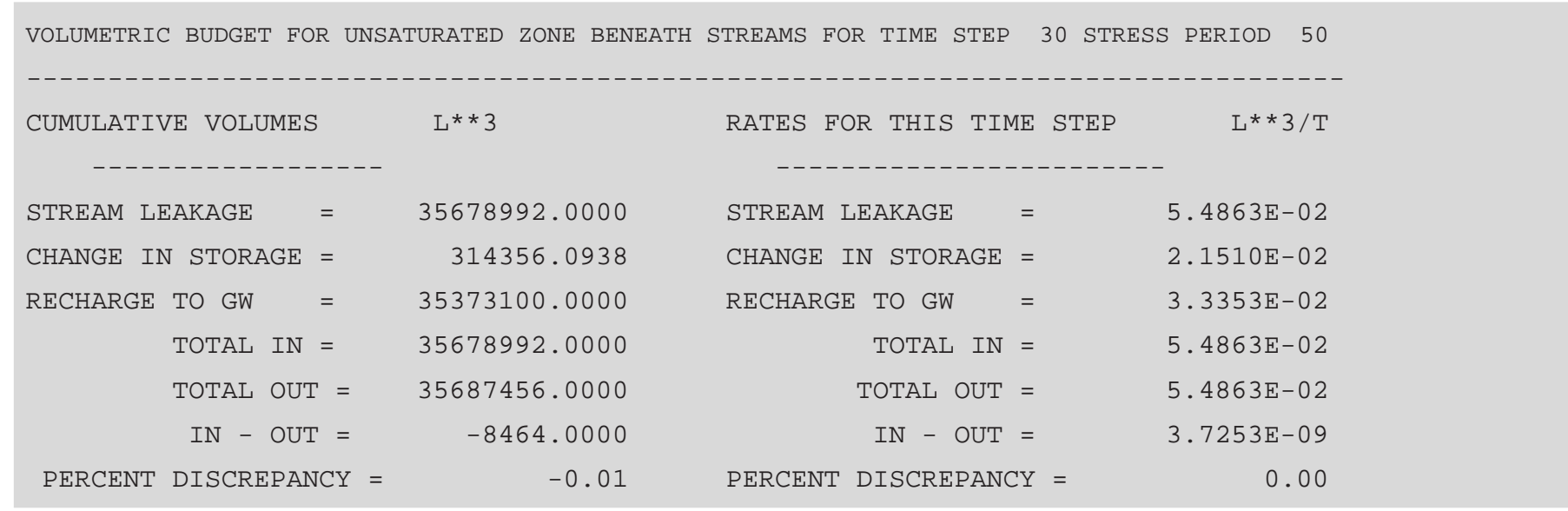

HEAD IN LAYER 1 AT END OF TIME STEP 30 IN STRESS PERIOD 50

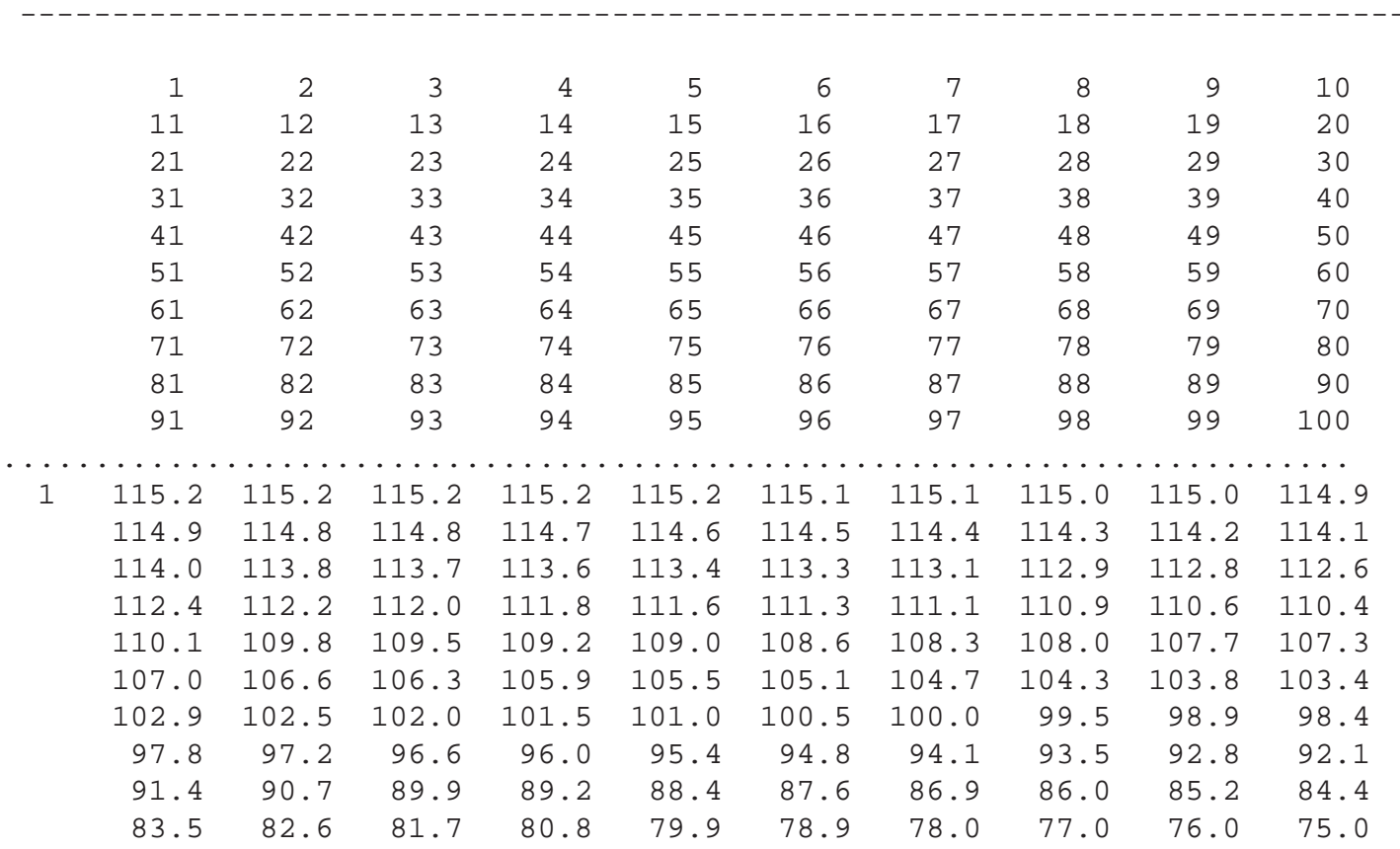




$\begin{array}{rrrrrrrrrrr}7 & 115.2 & 115.2 & 115.2 & 115.2 & 115.2 & 115.1 & 115.1 & 115.0 & 115.0 & 114.9 \\ 114.9 & 114.8 & 114.8 & 114.7 & 114.6 & 114.5 & 114.4 & 114.3 & 114.2 & 114.1 \\ 114.0 & 113.8 & 113.7 & 113.6 & 113.4 & 113.3 & 113.1 & 112.9 & 112.8 & 112.6 \\ 112.4 & 112.2 & 112.0 & 111.8 & 111.6 & 111.3 & 111.1 & 110.9 & 110.6 & 110.4 \\ 110.1 & 109.8 & 109.5 & 109.2 & 109.0 & 108.6 & 108.3 & 108.0 & 107.7 & 107.3 \\ 107.0 & 106.6 & 106.3 & 105.9 & 105.5 & 105.1 & 104.7 & 104.3 & 103.8 & 103.4 \\ 102.9 & 102.5 & 102.0 & 101.5 & 101.0 & 100.5 & 100.0 & 99.5 & 98.9 & 98.4 \\ 97.8 & 97.2 & 96.6 & 96.0 & 95.4 & 94.8 & 94.1 & 93.5 & 92.8 & 92.1 \\ 91.4 & 90.7 & 89.9 & 89.2 & 88.4 & 87.6 & 86.9 & 86.0 & 85.2 & 84.4 \\ 83.5 & 82.6 & 81.7 & 80.8 & 79.9 & 78.9 & 78.0 & 77.0 & 76.0 & 75.0\end{array}$

1

VOLUMETRIC BUDGET FOR ENTIRE MODEL AT END OF TIME STEP 30 IN STRESS PERIOD 50

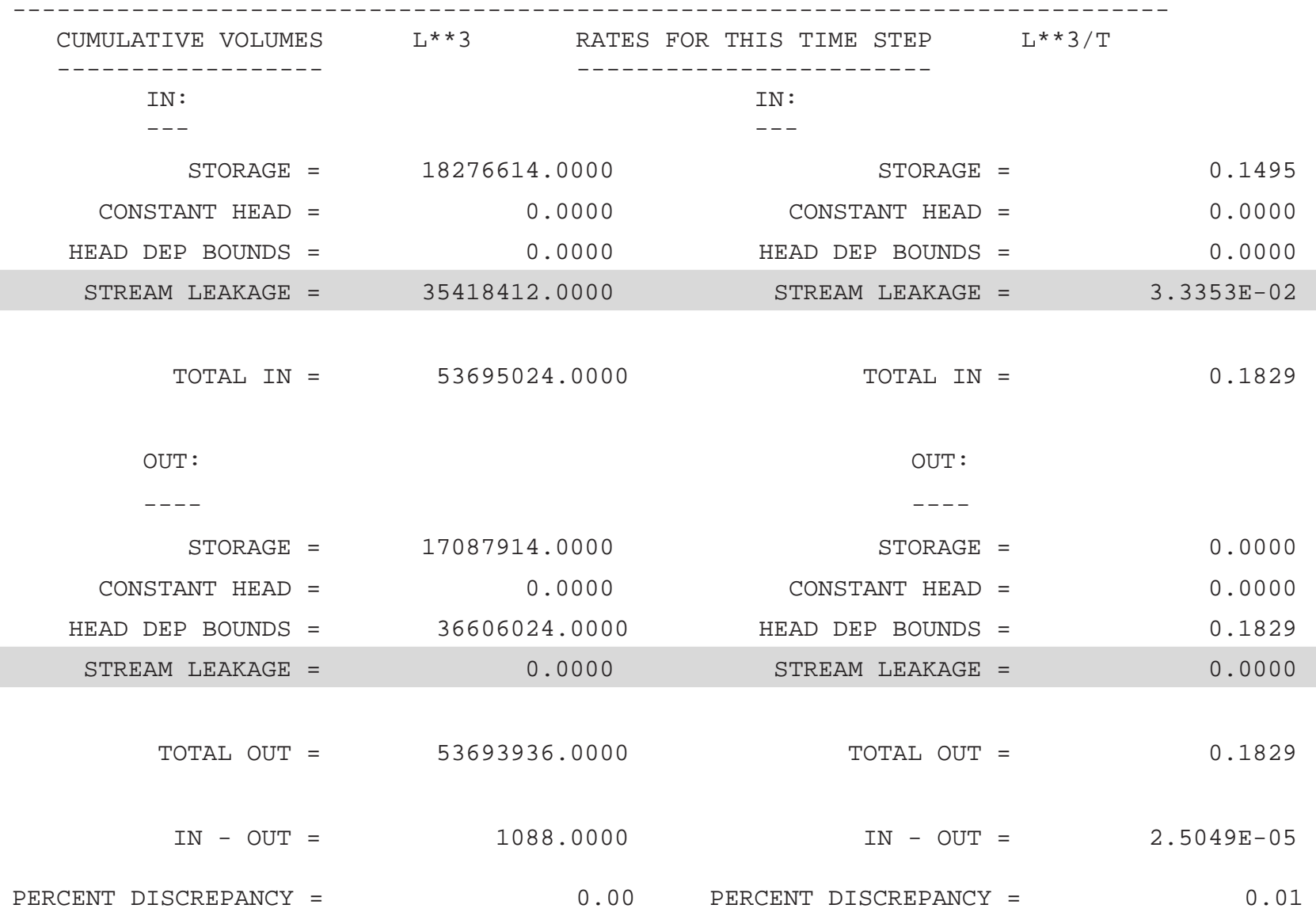

TIME SUMMARY AT END OF TIME STEP 30 IN STRESS PERIOD 50

SECONDS MINUTES HOURS DAYS YEARS

$\begin{array}{lllllll}\text { TIME STEP LENGTH } & 2.49961 \mathrm{E}+05 & 4166.0 & 69.434 & 2.8931 & 7.92080 \mathrm{E}-03\end{array}$

STRESS PERIOD TIME 2.59200E+06 43200. $320.00 \quad 30.000 \quad 8.21355 \mathrm{E}-02$ TOTAL TIME 1.29600E+08 $2.16000 \mathrm{E}+06 \quad 36000 . \quad 1500.0 \quad 4.1068$ 


\section{$48 \quad$ Report Title}

Following are the abridged contents of Gaging Station 5 output file for the hypothetical test simulation:

File name: testSFR2.gg5

\begin{tabular}{|c|c|c|c|c|c|c|c|}
\hline $\begin{array}{l}\text { "GAGE No. 5: } \\
\text { Time } \\
\text { Vol. UZ Stor." }\end{array}$ & $\begin{array}{c}K, I, J \text { Coord } . \\
\text { Stage }\end{array}$ & $\begin{array}{l}\text { 1, 4, } \\
\text { Depth }\end{array}$ & $\begin{array}{l}\text { STREAM } \\
\text { GW Head }\end{array}$ & $\begin{array}{l}\text { SEGMENT }= \\
\qquad \text { M-P Flow }\end{array}$ & $\begin{array}{l}\text { 1; } \quad \mathrm{REACH}= \\
\text { Leakage }\end{array}$ & $\begin{array}{c}60 \text { " " DATA: } \\
\text { GW Rech. }\end{array}$ & Chnge UZ Stor. \\
\hline $\begin{array}{l}1.5757 \mathrm{E}+04 \\
5.3462 \mathrm{E}+00\end{array}$ & $1.2257 \mathrm{E}+02$ & $4.1743 \mathrm{E}-01$ & $1.0400 \mathrm{E}+02$ & $2.7957 \mathrm{E}-01$ & $3.3929 \mathrm{E}-04$ & $0.0000 \mathrm{E}+00$ & $3.3928 E-04$ \\
\hline $\begin{array}{l}3.3091 \mathrm{E}+04 \\
1.1227 \mathrm{E}+01\end{array}$ & $1.2257 \mathrm{E}+02$ & $4.1743 \mathrm{E}-01$ & $1.0400 \mathrm{E}+02$ & $2.7957 \mathrm{E}-01$ & $3.3929 \mathrm{E}-04$ & $0.0000 \mathrm{E}+00$ & $3.3929 \mathrm{E}-04$ \\
\hline $1.7696 \mathrm{E}+01$ & $1.2257 \mathrm{E}+02$ & $4.1743 \mathrm{E}-01$ & $1.0400 \mathrm{E}+02$ & $2.7957 \mathrm{E}-01$ & $3.3929 \mathrm{E}-04$ & $0.0000 \mathrm{E}+00$ & $3.3929 \mathrm{E}-04$ \\
\hline $2.4812 \mathrm{E}+01$ & $1.2257 \mathrm{E}+02$ & $4.1743 \mathrm{E}-01$ & $1.0400 \mathrm{E}+02$ & $2.7957 \mathrm{E}-01$ & $3.3929 \mathrm{E}-04$ & $0.0000 \mathrm{E}+00$ & $3.3929 \mathrm{E}-04$ \\
\hline $3.2640 \mathrm{E}+01$ & $1.2257 \mathrm{E}+02$ & $4.1743 \mathrm{E}-01$ & $1.0400 \mathrm{E}+02$ & $2.7957 \mathrm{E}-01$ & $3.3929 \mathrm{E}-04$ & $0.0000 \mathrm{E}+00$ & $3.3929 \mathrm{E}-04$ \\
\hline 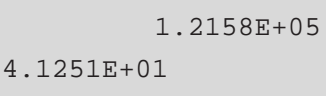 & $1.2257 \mathrm{E}+02$ & $4.1743 \mathrm{E}-01$ & $1.0400 \mathrm{E}+02$ & $2.7957 \mathrm{E}-01$ & $3.3929 E-04$ & $0.0000 \mathrm{E}+00$ & $3.3929 \mathrm{E}-04$ \\
\hline $\begin{array}{l}1.4949 \mathrm{E}+05 \\
5.0722 \mathrm{E}+01\end{array}$ & $1.2257 \mathrm{E}+02$ & $4.1743 \mathrm{E}-01$ & $1.0400 \mathrm{E}+02$ & $2.7957 \mathrm{E}-01$ & $3.3929 \mathrm{E}-04$ & $0.0000 \mathrm{E}+00$ & $3.3929 \mathrm{E}-04$ \\
\hline $\begin{array}{l}1.8020 \mathrm{E}+05 \\
6.1141 \mathrm{E}+01\end{array}$ & $1.2257 \mathrm{E}+02$ & $4.1743 \mathrm{E}-01$ & $1.0400 \mathrm{E}+02$ & $2.7957 \mathrm{E}-01$ & $3.3929 \mathrm{E}-04$ & $0.0000 \mathrm{E}+00$ & $3.3929 \mathrm{E}-04$ \\
\hline $7.2601 \mathrm{E}+01$ & $1.2257 \mathrm{E}+02$ & $4.1743 \mathrm{E}-01$ & $1.0400 \mathrm{E}+02$ & $2.7957 \mathrm{E}-01$ & $3.3929 \mathrm{E}-04$ & $0.0000 \mathrm{E}+00$ & $3.3929 \mathrm{E}-04$ \\
\hline $8.5208 \mathrm{E}+01$ & $1.2257 \mathrm{E}+02$ & $4.1743 \mathrm{E}-01$ & $1.0400 \mathrm{E}+02$ & $2.7957 \mathrm{E}-01$ & $3.3929 \mathrm{E}-04$ & $0.0000 \mathrm{E}+00$ & $3.3929 \mathrm{E}-04$ \\
\hline $\begin{array}{l}2.9200 \mathrm{E}+05 \\
9.9075 \mathrm{E}+01\end{array}$ & $1.2257 \mathrm{E}+02$ & $4.1743 \mathrm{E}-01$ & $1.0400 \mathrm{E}+02$ & $2.7957 \mathrm{E}-01$ & $3.3929 E-04$ & $0.0000 \mathrm{E}+00$ & $3.3929 \mathrm{E}-04$ \\
\hline $1.1433 \mathrm{E}+02$ & $1.2257 \mathrm{E}+02$ & $4.1743 \mathrm{E}-01$ & $1.0400 \mathrm{E}+02$ & $2.7957 \mathrm{E}-01$ & $3.3929 \mathrm{E}-04$ & $0.0000 \mathrm{E}+00$ & $3.3929 \mathrm{E}-04$ \\
\hline $1.3111 \mathrm{E}+02$ & $1.2257 \mathrm{E}+02$ & $4.1743 \mathrm{E}-01$ & $1.0400 \mathrm{E}+02$ & $2.7957 \mathrm{E}-01$ & $3.3929 \mathrm{E}-04$ & $0.0000 \mathrm{E}+00$ & $3.3929 \mathrm{E}-04$ \\
\hline $\begin{array}{l}4.4081 \mathrm{E}+05 \\
1.4957 \mathrm{E}+02\end{array}$ & $1.2257 \mathrm{E}+02$ & $4.1743 \mathrm{E}-01$ & $1.0400 \mathrm{E}+02$ & $2.7957 \mathrm{E}-01$ & $3.3929 \mathrm{E}-04$ & $0.0000 \mathrm{E}+00$ & $3.3929 \mathrm{E}-04$ \\
\hline $1.6987 \mathrm{E}+02$ & $1.2257 \mathrm{E}+02$ & $4.1743 \mathrm{E}-01$ & $1.0400 \mathrm{E}+02$ & $2.7957 \mathrm{E}-01$ & $3.3929 \mathrm{E}-04$ & $0.0000 \mathrm{E}+00$ & $3.3929 \mathrm{E}-04$ \\
\hline $1.9220 \mathrm{E}+02$ & $1.2257 \mathrm{E}+02$ & $4.1743 \mathrm{E}-01$ & $1.0400 \mathrm{E}+02$ & $2.7957 \mathrm{E}-01$ & $3.3929 \mathrm{E}-04$ & $0.0000 \mathrm{E}+00$ & $3.3929 \mathrm{E}-04$ \\
\hline $\begin{array}{r}6.3888 \mathrm{E}+05 \\
2.1677 \mathrm{E}+02\end{array}$ & $1.2257 \mathrm{E}+02$ & $4.1743 \mathrm{E}-01$ & $1.0400 \mathrm{E}+02$ & $2.7957 \mathrm{E}-01$ & $3.3929 \mathrm{E}-04$ & $0.0000 \mathrm{E}+00$ & $3.3929 \mathrm{E}-04$ \\
\hline $2.4379 \mathrm{E}+02$ & $1.2257 \mathrm{E}+02$ & $4.1743 \mathrm{E}-01$ & $1.0400 \mathrm{E}+02$ & $2.7957 \mathrm{E}-01$ & $3.3929 \mathrm{E}-04$ & $0.0000 \mathrm{E}+00$ & $3.3929 \mathrm{E}-04$ \\
\hline $2.7352 \mathrm{E}+02$ & $1.2257 \mathrm{E}+02$ & $4.1743 \mathrm{E}-01$ & $1.0400 \mathrm{E}+02$ & $2.7957 \mathrm{E}-01$ & $3.3929 \mathrm{E}-04$ & $0.0000 \mathrm{E}+00$ & $3.3929 \mathrm{E}-04$ \\
\hline $\begin{array}{r}9.0251 \mathrm{E}+05 \\
3.0621 \mathrm{E}+02\end{array}$ & $1.2257 \mathrm{E}+02$ & $4.1743 \mathrm{E}-01$ & $1.0400 \mathrm{E}+02$ & $2.7957 \mathrm{E}-01$ & $3.3929 \mathrm{E}-04$ & $0.0000 \mathrm{E}+00$ & $3.3929 \mathrm{E}-04$ \\
\hline $\begin{array}{l}1.0085 \mathrm{E}+06 \\
3.4218 \mathrm{E}+02\end{array}$ & $1.2257 \mathrm{E}+02$ & $4.1743 \mathrm{E}-01$ & $1.0400 \mathrm{E}+02$ & $2.7957 \mathrm{E}-01$ & $3.3929 \mathrm{E}-04$ & $0.0000 \mathrm{E}+00$ & $3.3929 \mathrm{E}-04$ \\
\hline $\begin{array}{l}1.1251 \mathrm{E}+06 \\
3.8175 \mathrm{E}+02\end{array}$ & $1.2257 \mathrm{E}+02$ & $4.1743 \mathrm{E}-01$ & $1.0400 \mathrm{E}+02$ & $2.7957 \mathrm{E}-01$ & $3.3929 \mathrm{E}-04$ & $0.0000 \mathrm{E}+00$ & $3.3929 \mathrm{E}-04$ \\
\hline
\end{tabular}

$\cdots$ 
Following are the abridged contents of Gaging Station 6 output file for the hypothetical test simulation:

File name: testSFR2.gg6

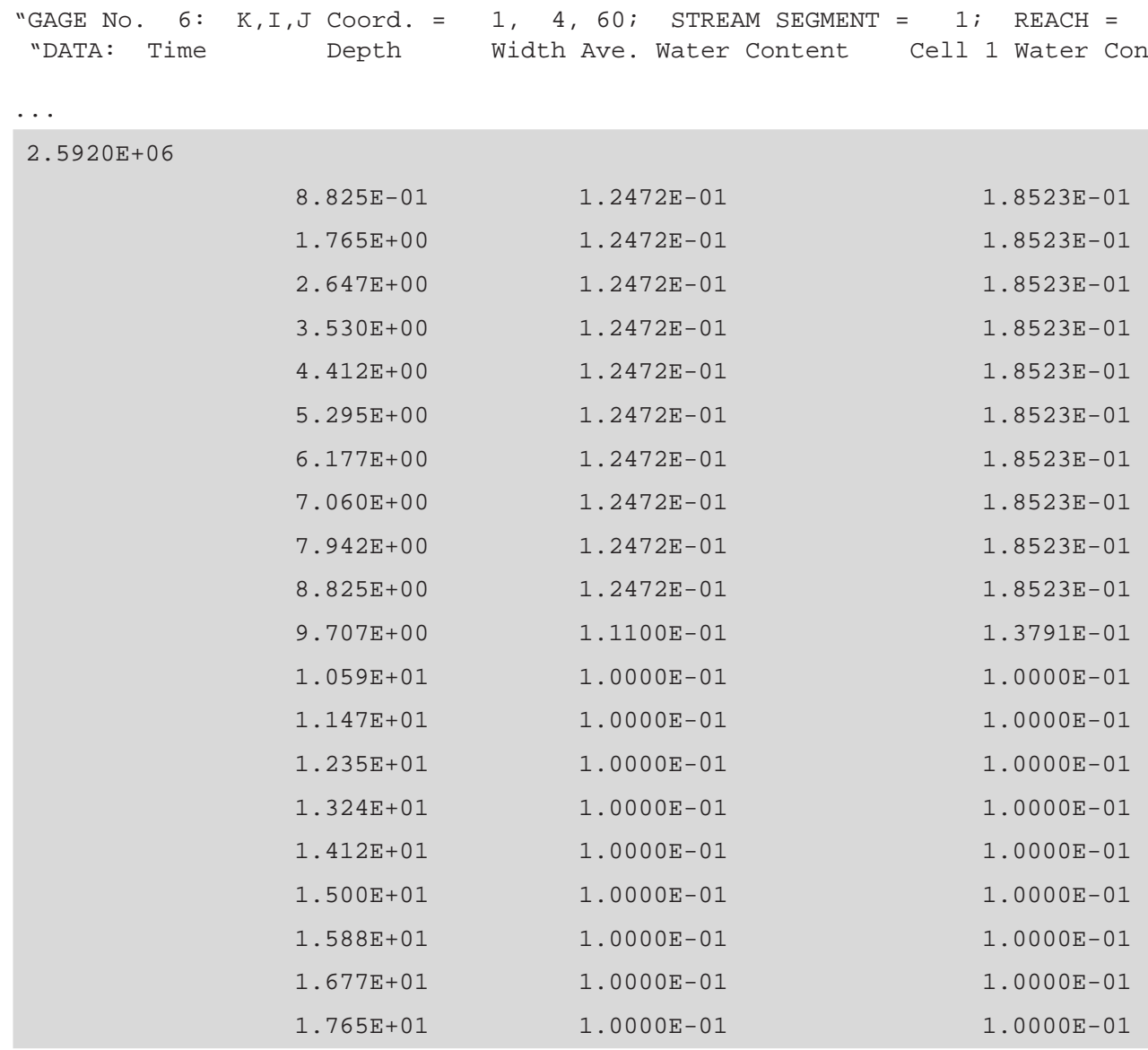

1. $2960 \mathrm{E}+08$

$\begin{array}{lll}9.132 \mathrm{E}-01 & 1.2907 \mathrm{E}-01 & 1.9768 \mathrm{E}-01 \\ 1.826 \mathrm{E}+00 & 1.2966 \mathrm{E}-01 & 1.9768 \mathrm{E}-01 \\ 2.739 \mathrm{E}+00 & 1.3019 \mathrm{E}-01 & 1.9768 \mathrm{E}-01 \\ 3.653 \mathrm{E}+00 & 1.3454 \mathrm{E}-01 & 1.9768 \mathrm{E}-01 \\ 4.566 \mathrm{E}+00 & 1.3523 \mathrm{E}-01 & 1.9768 \mathrm{E}-01 \\ 5.479 \mathrm{E}+00 & 1.3573 \mathrm{E}-01 & 1.9768 \mathrm{E}-01 \\ 6.392 \mathrm{E}+00 & 1.3779 \mathrm{E}-01 & 1.9768 \mathrm{E}-01 \\ 7.305 \mathrm{E}+00 & 1.4028 \mathrm{E}-01 & 1.9768 \mathrm{E}-01 \\ 8.218 \mathrm{E}+00 & 1.4028 \mathrm{E}-01 & 1.9768 \mathrm{E}-01 \\ 9.132 \mathrm{E}+00 & 1.4028 \mathrm{E}-01 & 1.9768 \mathrm{E}-01 \\ 1.004 \mathrm{E}+01 & 1.4028 \mathrm{E}-01 & 1.9768 \mathrm{E}-01 \\ 1.096 \mathrm{E}+01 & 1.4028 \mathrm{E}-01 & 1.9768 \mathrm{E}-01 \\ 1.187 \mathrm{E}+01 & 1.4028 \mathrm{E}-01 & 1.9768 \mathrm{E}-01 \\ 1.278 \mathrm{E}+01 & 1.4075 \mathrm{E}-01 & 1.9768 \mathrm{E}-01 \\ 1.370 \mathrm{E}+01 & 1.4134 \mathrm{E}-01 & 1.9768 \mathrm{E}-01 \\ 1.461 \mathrm{E}+01 & 1.4134 \mathrm{E}-01 & 1.9768 \mathrm{E}-01 \\ 1.552 \mathrm{E}+01 & 1.4134 \mathrm{E}-01 & 1.9768 \mathrm{E}-01 \\ 1.644 \mathrm{E}+01 & 1.4134 \mathrm{E}-01 & 1.9768 \mathrm{E}-01 \\ 1.735 \mathrm{E}+01 & 1.4134 \mathrm{E}-01 & 1.9768 \mathrm{E}-01 \\ 1.826 \mathrm{E}+01 & 1.4134 \mathrm{E}-01 & 1.9768 \mathrm{E}-01\end{array}$


This page left intentionally blank 
Manuscript approved for publication, August 29, 2005

Prepared by the USGS, Tacoma Publishing Service Center

USGS Publishing staff

Bill Gibbs

Linda Rogers

Angelia M. Thacker

For more information concerning the research in this report, contact the Director, Nevada Water Science Center

U.S. Geological Survey, 333 W. Nye Lane, Room 203

Carson City, NV 89706-0866

http://nevada.usgs.gov 
